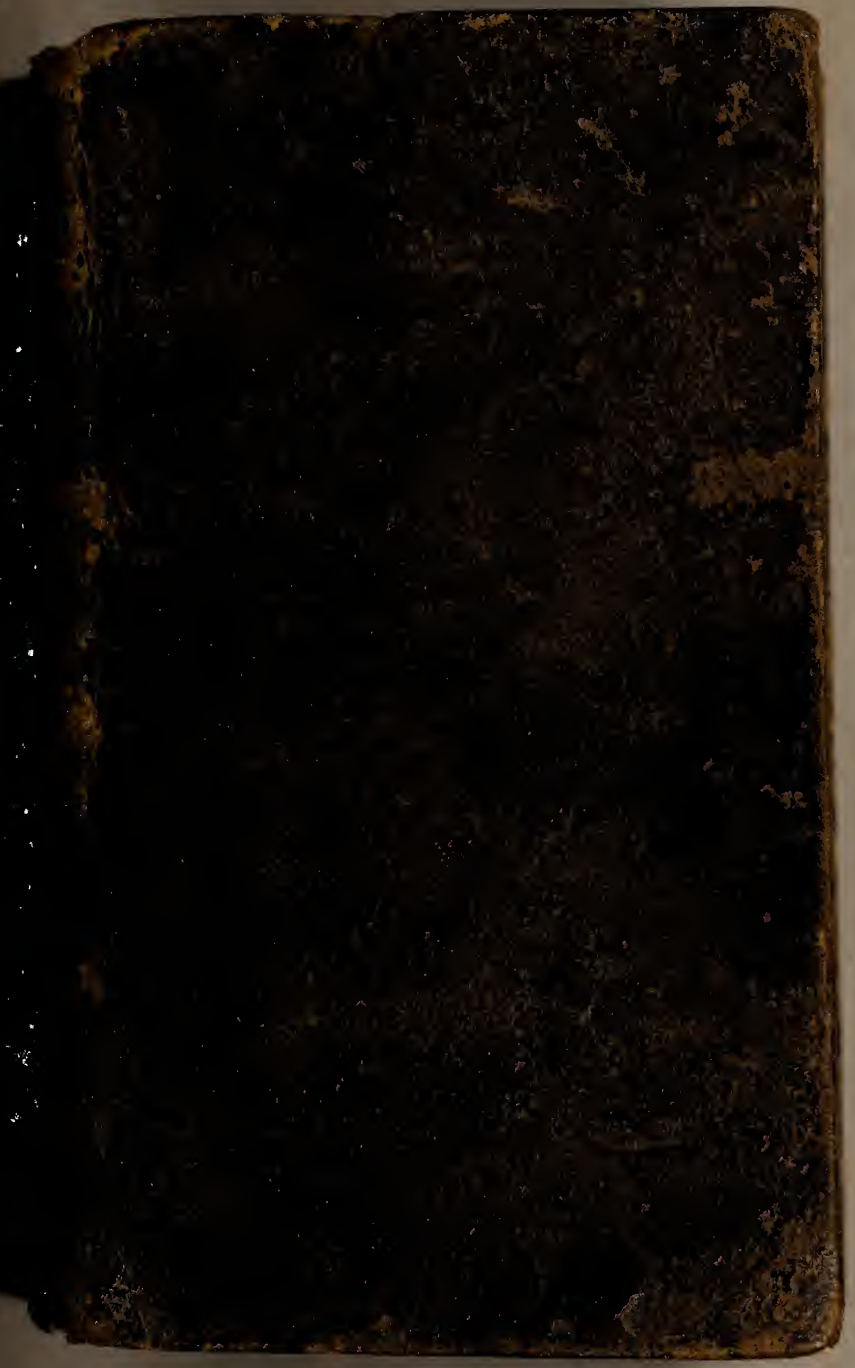


Chocolin Latedes vieillars istaud et ne fernente pas 210umarique el inc de Slecheposs Huilewx et 12énfla une p.25. Merc defiance
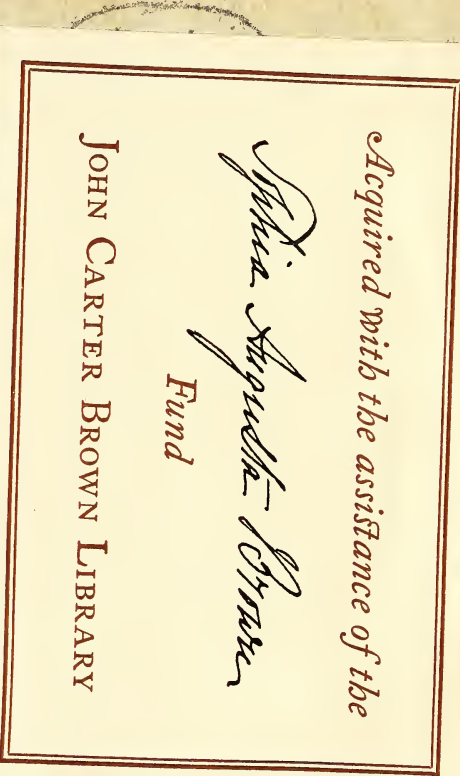

Lefueve bica Rafine of te the yewo Convicunent

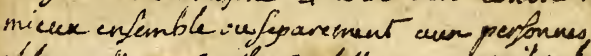

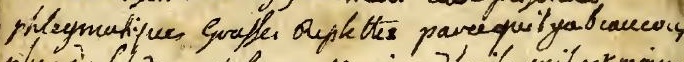

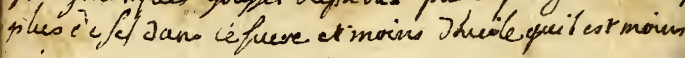
visquerear

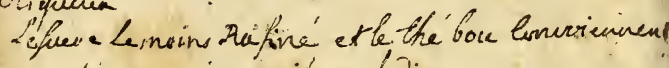
soce ctignee maigures vifs maladive

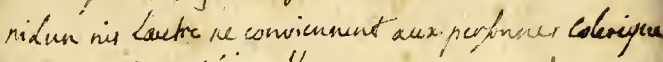
oncove swier sefó gue thy ow

Chocolat sicparis

DuCacao Rófi a propos antant de fueve 2 gros De vinille voite fout

fuw fix i 7 ences deace une on ce de chwoula ale mexique. Septleut amawes de Cacas une livne etdenifiere 2 onees cemelle

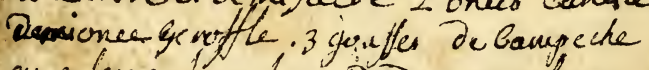
an a leurplace le poid d un quarteron anis, Dc lachist auteur quiléfaut pour

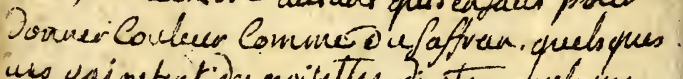

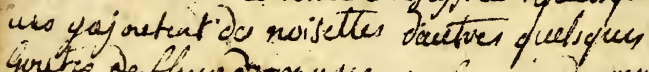

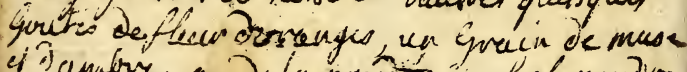

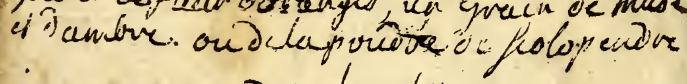
joun. accun. Decent 1754 



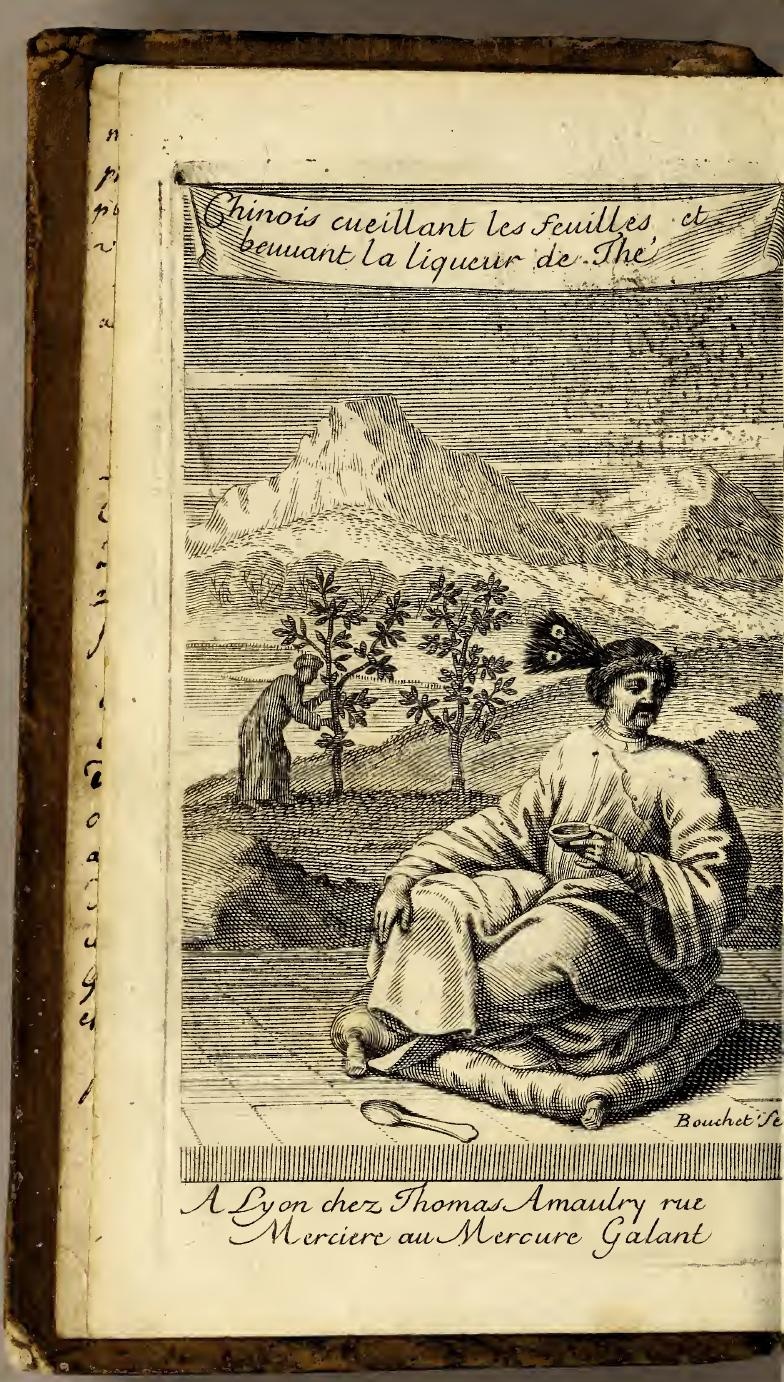




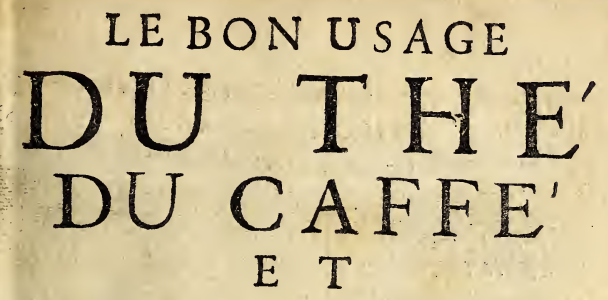

DU CHOCOLAT POUR LA PRESER VATION \& pour la guerifon des Maladies.

$\operatorname{Par} M^{r}$ DE BLEGNY, Confciller, Medecin Artifte ordinaire du Roy o de Monfeur, o prépofé par ordre de Sa Mijefié, à la Recherche of Verification des nowvelles déconvertes de Medecine.

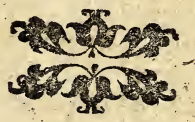

A $L Y=0 N$,

Chez THOMAS A MAULRY, ruë Merciere, au Mercure Galant.

M. DC. $L X X X V I I$.

AVE C PRIVILEGE DU ROY. 


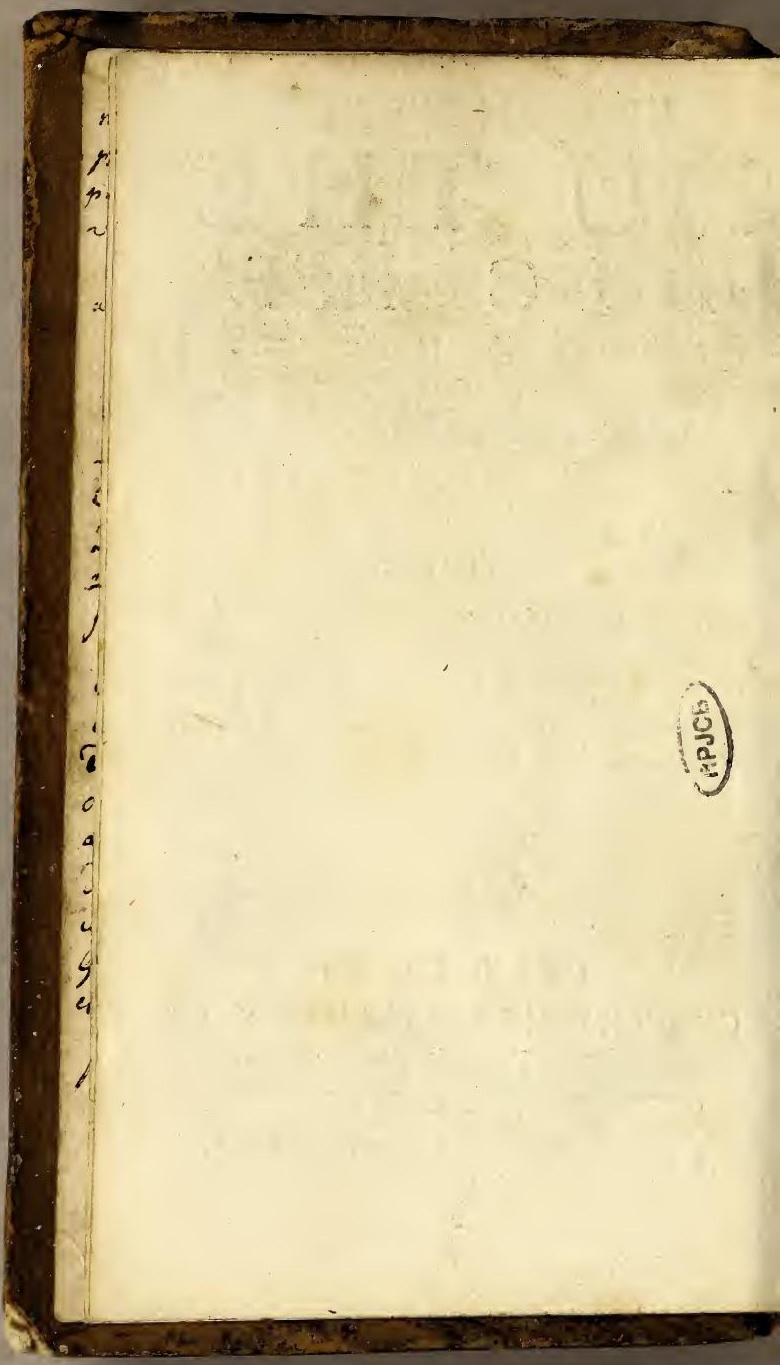




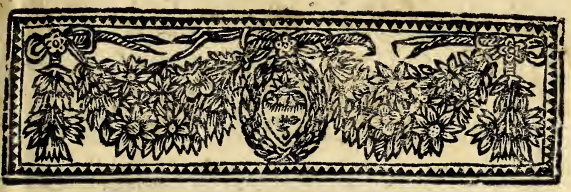

A MESSIEURS

\section{LES DOCTEURS} en Medecine des Facultez Provinciales \& Etrangeres, pratiquant à la Cour \& à Paris.

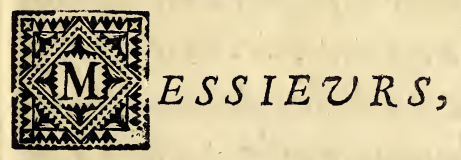

Aprés avoir ferienfement étudié Dôtre excellente pratique, pendant un grand nombre d"ană iij 


\section{E P I TR E.}

nêes queje me fuis attaché à vous fuivre : aprés avoir tiré de vos judicienx abis oo de vos doctes infructions, toutes las lumieres dont jabois befoin, pour meriter l'bonneur d'etre en correpondance avec vous; enfin aprês aboir penetré les rares qualitez qui vous rendent venerables à toutes les perfonnes de difcernement, $j$ aurois beaucoup à me reprocher, $f$ je n'avois recherché avec un extrême empreffement, l'occafion de vous rendre un bommage affez public, pour faire connoitre à tout le monde que je rous bonore, w combien. je fuis fenfible à la reconnoiffance que je rous dois. 


\section{E P I T RE.}

$C^{\prime}$ eft dans cette vî̈e, MESSIEVRS, que jay affemblé quelques parcelles de mes memoires, pour en former un corps d'ou- . vrage, or pour zousle confacrer. enfuitepar une dedicacetres-refpectueuse : pent étre que rous le regarderez comme une produotion informe qui a befoin d'etre rectifie dans toutes fes parties; maispent être auffi que vonsformerez en méme temps le deffein. de travailler vous mémes à cette rectification: trop beureux sil en arrivoit ainfí la feconde édition de ce Livreme donneroit le plaifir de voir paroître fous mone nom, un Ouvrage à l'épreuve de

$$
\text { â iiij }
$$




\section{E P I T RE.}

zoutes Cenfures, or contre lequel la plus Sevére Critique ne pourroit rien oppofer.

Ce prejugé que je tiens infaillible, eft fondé Jur de puiffantes confiderations: en effet pous cultivez avec tant de foin les beureux talens que la nature roous a. départis, que ne pouvant avoir de referve pour vous, elle eft contrainte (pour ainfi dire) de fe découvrir nuë à vos yeux, de vous rendre les confidens de Jes plus fecrettes démarches, ov de vous faire les dépofitaires de tout ce qui elle a de plus precieux; comme vous êtes devenius par tous ces avantages, les plus zelés ov 


\section{E P I TRE.}

les plus fermes partifans de la verité, vous avez ê̂ le bonbeur de vous attirer une eftime o une confiance fi générale, que vous avez toûjours èté Soûtenus par l'approbation des grands, par les. fuffrages des f̧avans, ev parla roye du peuple, contre toutes les attaques de vos ennemis les plus cruels \& les plus injuftes.

Auffi ont-ils ê̂ dans tous les temps le chagrin de vous voir. properer avec éclat, malgré toutes leurs cabales cor toutes leurs. intrigues; carç̧ a pre fque toûjours été d'entre vous, que les Papes, les Empereurs, les Rois, \& les autres Potentats del'Europeont tiré

$$
\text { A } y
$$




\section{E P I T TE.}

leurs premiers Medecins, cieft cette feconde pepiniere qui en a encore fourm pre qque generalemët à tous les Princes ơ Princeffes $d u$ Janig o des Cours étrangeres, aux grands seigneurs, or aux Camps, Hôpitaux \& armées du Roy: C'eft à cette Republique de litterature, que le public doit tant. d'Illuftres eleues \& tant de Li- pres excellens; enfin çeft de cette pifcine Jalutaire que les provinciaux of les étrangers malades, tirent un fecours quils ne pourroient recouvrer d' ailleurs, n'y. ayant que vous feuls quic connoiffez lewr confitution.

Mais pour ne parler que de 


\section{E P I T R E.}

l'état prefent des chofes, of fun tout de celles qui font fi fort exposées anx yeux de tout le monde, que la malice de vos ennemis s'iforceroit en vain de les cacher; $n^{3} e f t$-ce pas d'entre vous que le Roy, Monfeur, Mademoifelle de France, Mademoifelle d'Orleans, \& Madame de Guife, ont tiré les Medecins qui fervent actuellement prés de leurs perfonnes, dans la qualité des premiers, ou dans celles d'ordinaires, nieftes. vouspas vous mémes ceux. à qui l'on a recours dans le public, pour fecourir les malades qui ont été abandonnés, par ceux qui font cöffater toute la Medecine en trois 


\section{E P I T E.}

ou quatre remedes, quils prefcrivent fi indifferemment o $f i d a n$ gereufement en toutes occafions: en un mot n'eft-ce pas par vos ob. fervations o par vos experiences, quion a fait tant de découvertes utiles dans l'Anatomie, dansla Chynie, or generalement. dans toutes les parties de la Medecine, où l'erreur ó la confufion triomphoient, abant les importantes reformations que vous $y$ arvez faites.

Mais quels autres abantages le public ne tireroit il point de vôtre part, fil'envie ne s’oppofoit adec autant de pajfon que d'injuftice, à vos entrées dans 


\section{E P ITRE.}

les lieux où elle a du credit, au progrez de vos recherches, à limpreffor de vos Livres, à vos conferences publiques, of aux exercices de charité que vous pratiquez en faveur des paubres: certainement on verroit bien-tôt la Medecine dans ce baut point de perfection fi defiré de tout le monde, or $\int_{2}$ peu recherché de tant de Medecins, qui par une nonchalance puniffable, fe laiffent emporter au torrent des maximes d'u agge, or qui par une barbarie odieufe, oublient ce quils doivent à Dieu, au prochain do à eux-mêmes, pour facrifier à leur aparice ơ à leur anbition, ceux 


\section{E P I TR E.}

qui par une confiance anengle; sabandonnent à leur fatale ér indifcrette pratique.

Mais pour ni entrer plus avant dans ce pararelle: of pour ne point irriter des gens, dont les atteintes font toûjours auffi dangereusement que malicieusement. premeditées, je. dois rentrer dans mes premiers mouvemens, pour rous a Bürer, que perfonne ne peut étre avec plus de veneration. do plus d'ardeur que moy.

MESSIEURS,

Vôtre tres- humble \& tres- beiffant Serviteur,

DE BLEGNY. 


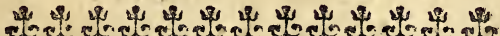

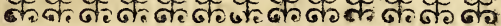

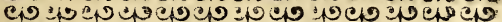

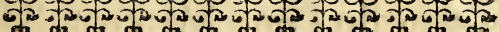

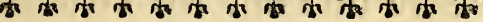

ADVERTISSEMENT。

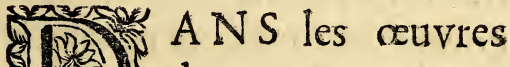
de nos Voyageurs, Chapitres qui traitent fepa-
Chane quelques rément du Thé, du Caffé \& du Chocolat. Quelques uns de nos Medecins de nos Simpliciftes, ont emprunté de ces Auteurs, les Relations \& les Figures qu'ils avoient données fur ces $\mathrm{Ma}$ tiéres, y ajoûtant même quelques obfervations $\mathrm{Me}$ - 


\section{Avertiffement.}

decinales ; \& Monfieur Sylveftre du Four Marchand à Lyon, fe donna la peine il y a environ quinze années, de donner au Public une compilation de ces relations $\&$ de ces obfervations, qu'il vient de faire imprimer en feconde Edition, laquelle peut paffer pour un ouvrage affez complet.

$1 \mathrm{l}$ 'a femblé neanmoins que cette mariere n'étoit pas épuifée, \& que du moins elle devoit être examinée \&z expliquée plus Phyfiquement, c'eft ce que je me fuis propofé de faire, \& c'eft ce 


\section{Ánertiffement.}

qui m’oblige de donner cét effay au Public, qui n'eft proprement que le projet d'une hiftoire plus comple. te à laquelle je ne pourray donner la derniere main, quaprès avoir reçû des Sçavans, la grace de me communiquer leurs obfervations.

Ce projet donc ne doit être confideré, que comme une fimple expofition des principes, fur lefquels je travailleray plus ferieufement dans un altre temps; mais qui ne laiffera pas d'avoir dés - à-prefent fes utilités, 


\section{Avertifement.}

puis quaprés avoir donné une idée affez diltincte de la nature des chof́es qui en font le fujet, je paffe jufqu'au bon ufage qu'on en doit faire, pour conferver la fanté lors qu'on la poffede, \& pour la reparer lors qu'on a eu le malheur de la perdre. Au furplus on trouvera auffi dans cet opufcules diverfes utencilles \& commoditez de nouvelle invention, qui fatisferont apparemment la curiofité des Lecteurs. 


\section{A VIS.}

T'AUTEUR ne craint pas 1 d'avertir, qu'il travaille actuellement à l'hiftoire naturelle du Tabac, car quand il feroit prévenu fur ces articles, il auroit toûjours dequoy encherir fur tout ce quion en pourra dire, auffi bien que fur ce qu'en a déja dit Monfieur de Prade, ayant en main des obfervations \& des experiences qui luy font abfolument particulieres.Cependant il prie les Curieux de luy communiquer celles qu'ils peuvent avoir faites fur cette matiere, fçachant bien qu'un feul homme ne pent tout obferver fur quelque fujer que ce foit. 
APPROBATION DE Monfeur Falconet, Confeiller Medecin ordinaire du Roy, Doyen du College des Medecins, or ancien Echevin de la Ville de Lyon.

T Es Ouvrages de MonLfieur DE BLEGNY, ayant eu toute l'eftime \& toute l'aprobation quil en pouvoit attendre, il n'en doit pas moins efperer du Livre qu'il a compolé fur l'Ufage du Thé, du Caffé \& du Chocolat, \& ayant eû ordre de Monfeigneur le Chancelier del'examiner, Nous l'avons approuvé \& nous l'avons 
jugé neceffaire au public, qui tirera fans doute beaucoup d'utilité, des nouvelles \& curieufes recherches qui s'y rencontrent, cét Auteur ayât découvert avec efprit \& expol'é avec beaucoup de clarté, plufieurs particularités également importantes pour la fanté, \& agréables pour lufage. DonNE' à Lyon, le I 8. Juin. 1686 .

Signé, FALCONET.

Extrait du Privilege du Roy. A $_{\mathrm{R}}$ grace \& Privilege dii
Roy, donné à Verfailles 
le 29. Juin 1686 . Il eft permis à Thomas Amaulry Marchand Libraire à Lyon, d'imprimer ou faire imprimer, vendre \& debiter par tout le Royaume, un Traité du Thé, du Caffé, \& du Chocolat, compofé par $\mathrm{N}_{\mathrm{I}}$ COLAS DE BLEG Y, Confeiller Medecin ordinaire de Monfieur, avec défenfes à tous Libraires, Imprimeurs \& autres d'imprimer faireimprimer vendre \& diftribuör ledit Livre; fous quelque pretexte que ce foir, méme d'impreffion étrangere $\&$ autrement, fans le confentement dudit expofant, ou . de fes ayant caufes, fur peine de confifcation des exemplaires contrefairs, mille livres d'amandes, dépens, dommages $\&$ interêts, ainfí qu'il eft 
plus amplement porté par les Lettres de Privilége.

Regifté fur le Livre de la Commanauté des Libraires \& Ims. primeurs de Paris, le 30 . Inillet 1686. Suivant l'Arreft du Parlement du 8. Avril 1653 . \& celuy dus Confeil Privé du Roy du 27. Février 1665 . Signé,

\section{A N GOT, Sindic.}

Achevé d'imprimer pour la premiere fois le $1 \mathrm{~s}$. Fevrier 1687 . 


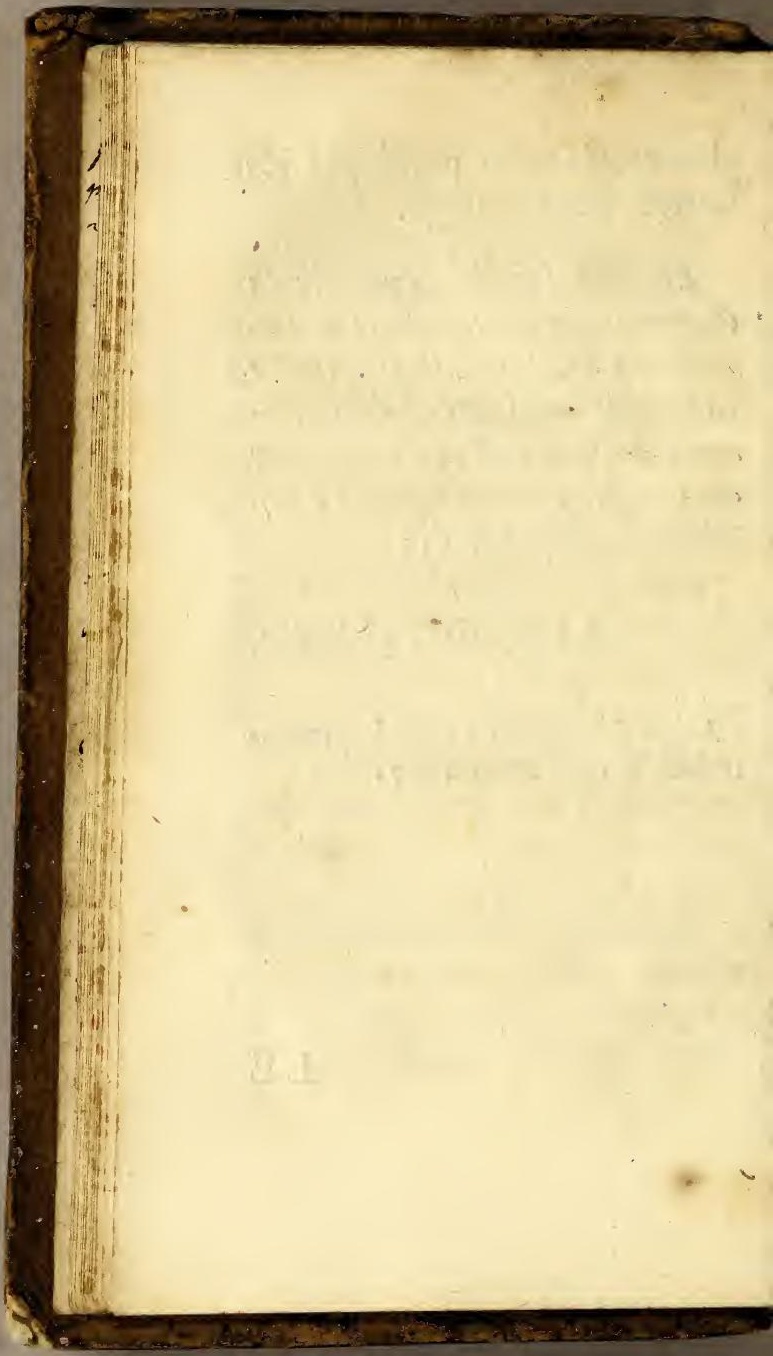




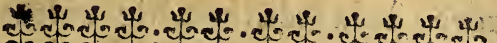

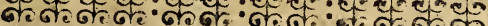

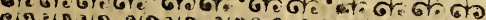

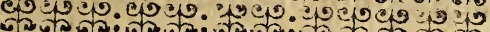

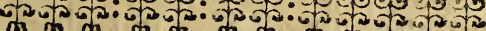

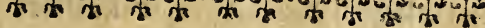

\section{LE BON USAGE}

DU THE', DU CAFFE'

E T

\section{DU CHOCOLAT.}

PREMIERE PARTIE.

Traitant de la Nature, des proprietés \& de l'usage du T' hé.

CHAP I T RE I.

De la forme exterieure du Thé, des lieux oi on le cultive, ${ }^{6}$ de des differentes

dénominations.

87as $N$ donne ici le nom

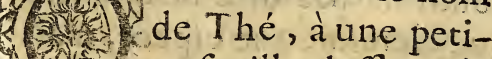
te feüille deffeichée qu'on nous apporte des Indes Orientales, \& $\mathrm{en}$ ? 


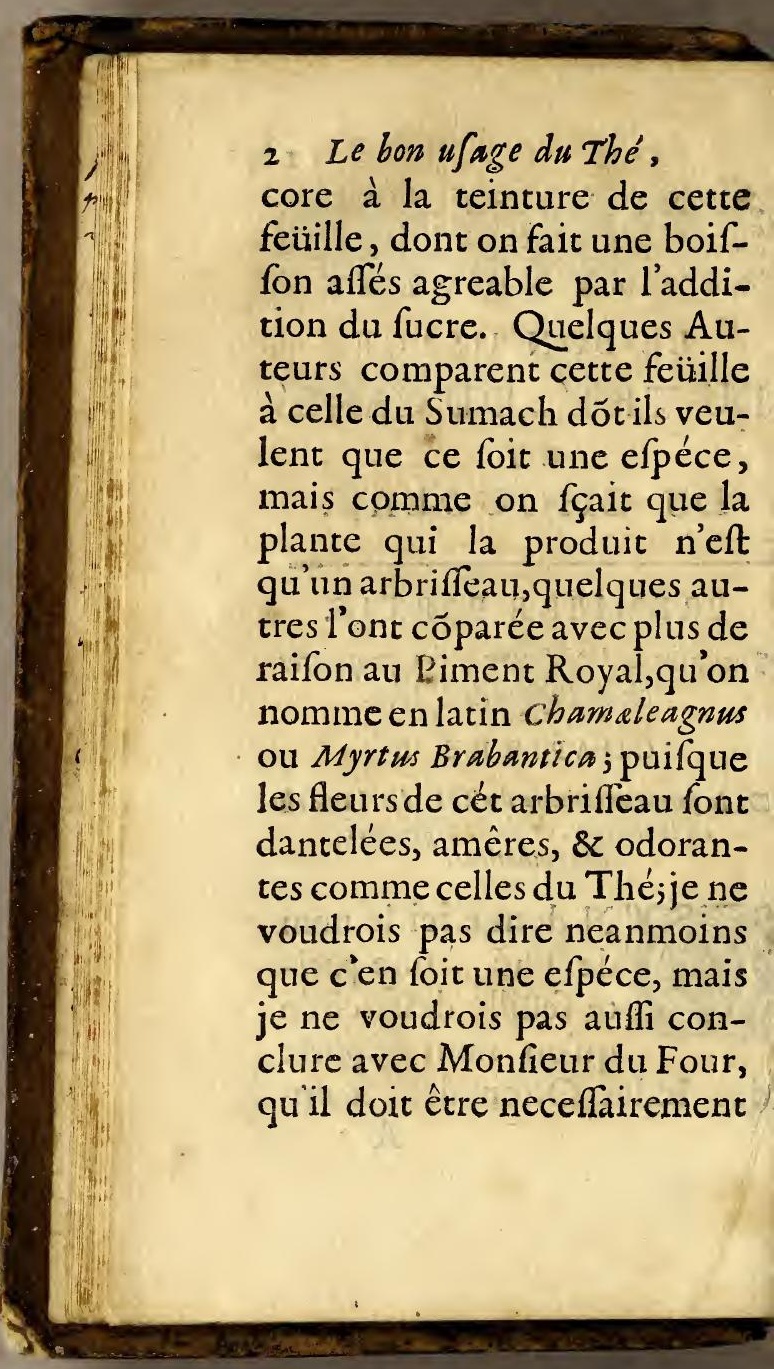


du Caffé, \& du Chocolat. 3 d'une nature diffente, par cette feule raifon qu'on le fait entrer dans la biére qui enyvre, \& qu'au contraire une des proprietés plus effentielles du Thé eft de des-enyvrer; car pour détruire l'objection de Monfieur du Four ; c'eft affés de dire qu'étant en Angleterre, i'ay pris plaifir a faire faire de la Biére feulement avec de l'Orge \& du Thé, qui étoit à la verité infinimét plus agreables que celle quon prepare en Flandres a vec le pimso Royal, mais qui avec cetre delicateffe de goût, ne laiffoit pas d'eny: vrer plus puiffamment.

En effet fi Monfieur du Eoub eût propofé cet objection à des Phificiens avant que de la publier, il auroit apris qu'elle A ij 
4 Le bon usage du The', peut d'autant moins fubfifter, qu'entre une fimple infufion $\&$ une liqueur fermentée, il y a cette difference, que l'infufion retient toûjours les qualités des ingrediens quiluy fervent de matiere, \& qu'au contraire une liqueur ne f̧çaroit foûtenir la fermentation, fans devenir differente de ce quelle étoit auparavant ; mais aprés tout, ces comparaifons de plantes me paroiffent d'autant plus inutiles, qu'entre certaines efpeces de nos plantes que nous raportons a un même genre, \& que nous comprenons fous un. même nom; il y a de notables differences dans leurs proprietez; tellemeat que quand il ferdit vray que nous aurions ici une forte de Thé, il feroit. 
$d u$ Caffé, \& du Chocolat. is d'autant plus different de celuy qu'on nous apporte des Indes, qu'outre la difference qui fe trouveroit dans les efpéces par rapport à la forme, il y auroit encore celle qui doit neceffairement refulter de la diverfité des climats: c'eft pourquoy je ne m'arrefteray pas à rapporter icy, ce qui a fait croire à quelques Auteurs qu'on pouvoit encore prendre pour des efpéces de Thé, la Betoine \& quelqu'autres plantes qui ont les feüilles dentelées, leurs reflexions n'étant à mon fens d'aucune confideration.

Mais je ne dois pas me difpenfer, de marquer les differences qui fe trouvent dans le Thé même, que nos negocians.

A iij 


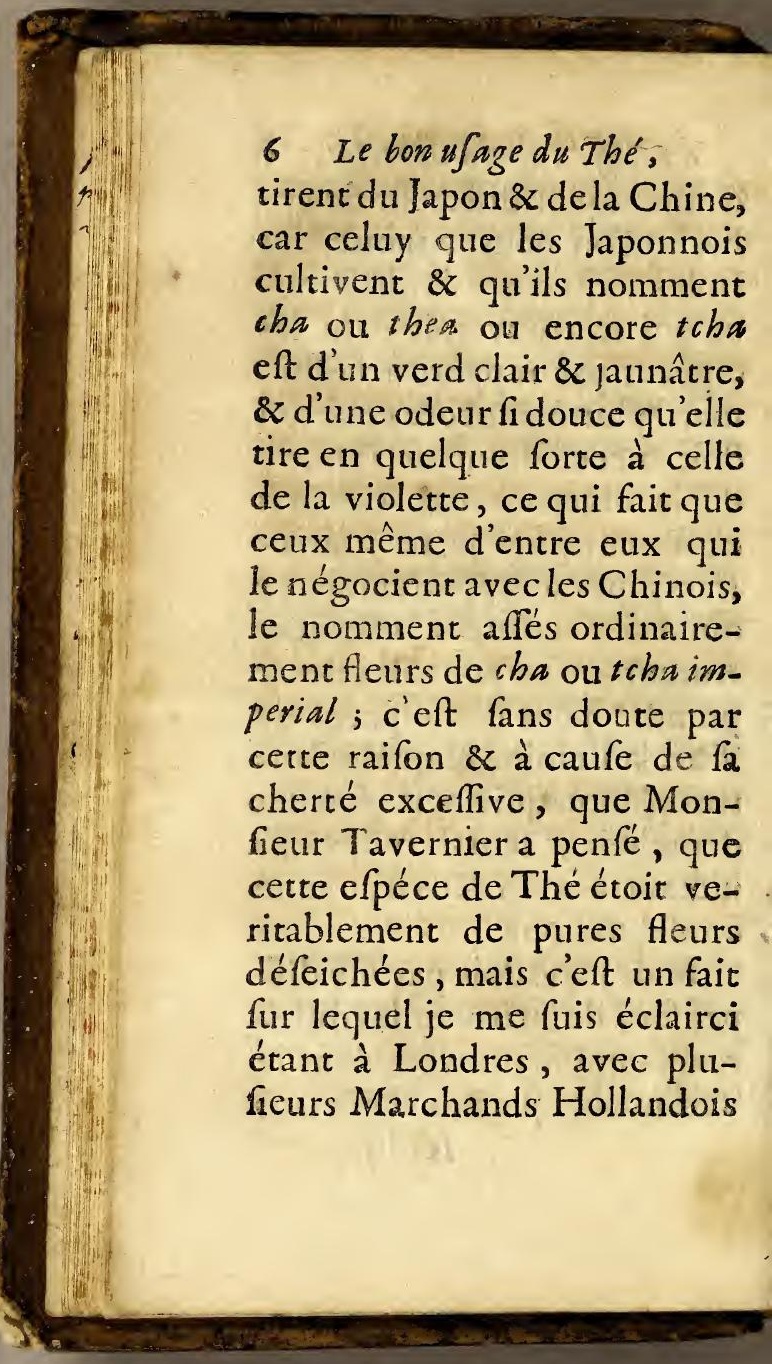


du Caffé, \& du Chocolat. 7 qui pratiquent le commerce du Thé, \& qui ont fait plufieurs fois le voyage des Indes Orientales, ayant appris d'eux que les Chinois \& les Japonnois font tant d'état de nôtre faulge, \& des autres denrées qui leurs viennêt de l'Europe, que pour les avoir par échange, ils prefentent toûjours à nos Marchands tout ce qu'ils ont de plus exquis, \& que cependant ils ne leurs ont jamais prefenté de ces pretenduës fleurs de Thé.

Ce n'eft pas que l'arbriffeau qui produit les feüilles de Thé, ne produife auffi une forte de fleur jaunâtre, \& à ce qu'on croit femblable à celle du fumach, mais il eft certain que cette fleur n'a jamais été

$$
\text { A iiij }
$$




\section{Le bon ufage du The',}

negotiée, \& il eft probable d'ailleurs qu'elle ne rendroit pas une teinture verte, ou que du moins le verd de cette teinture, feroit plus clair \& plus jaunâtre que celuy de la teinture que donne le Thé de la Chine, ce qui s'accorderoit encore moins avec les fentimens de Monfieur Tavernier, qui nous a voulu faire entendre que la Heurde cha, donnoit plus de verd a fa teinture que le Thé dont on ufe à la Chine.

Mais quoy que ce qu'on nomme fleurs de cha, ne foit veritablement que la feuiille du plus fin Thé du Japon, il eft certain que fa teinture eft infiniment plus agreable que celle du meilleur Thé de. 
du Caffé, \& du Cbocolat. :9 la Chine, \& quauffi it fe vend comme dit Monfieur Tavernier à un fi haut prix dans le païs même, qu'il y a lieu de croire que nos Marchands ne s'en chargeroient pas, s'ils êtoient obligés de l'achepter au comptant; mais il eft certain que par leurs échangesils en ont du plus excellent qui leur coûte affés. peu, pour le donnericy a beaucoup meilleur marché que les Marchands mêmes du Japon, $\&$ pour faire neanmoins un gain tres-confiderable dans ce commerce.

Pour revenir maintenant à la diftinction que je veux éta-. blir, je dois faire remarquer que le Thé de la Chine a fes feuilles plus grandes, d'un

$$
\text { A iiij }
$$




\section{Io Le bors ufage du Thé,}

verd plusbrun, \& d'une odeur beaucoup moins agréable que le cha du Japon, auffi la teinture de ce Thé, eft-elle plus verte $\&$ beaucoup moins plaifante, en forte même que l'infufion du plus commun, a un goût qui approche en quelque forte de celle du fené. A tout prendre, il y a neanmoins affés de rapport entre larbriffeau qui produit le cha duJapon, \& celuy qui fournit le The de la Chine, pour s'en faire une idée fufifante par l'infpection de la figure qui eft à la page qui fuit.
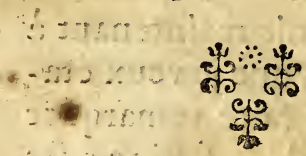


\section{du Caffe, or du chocolat. II}

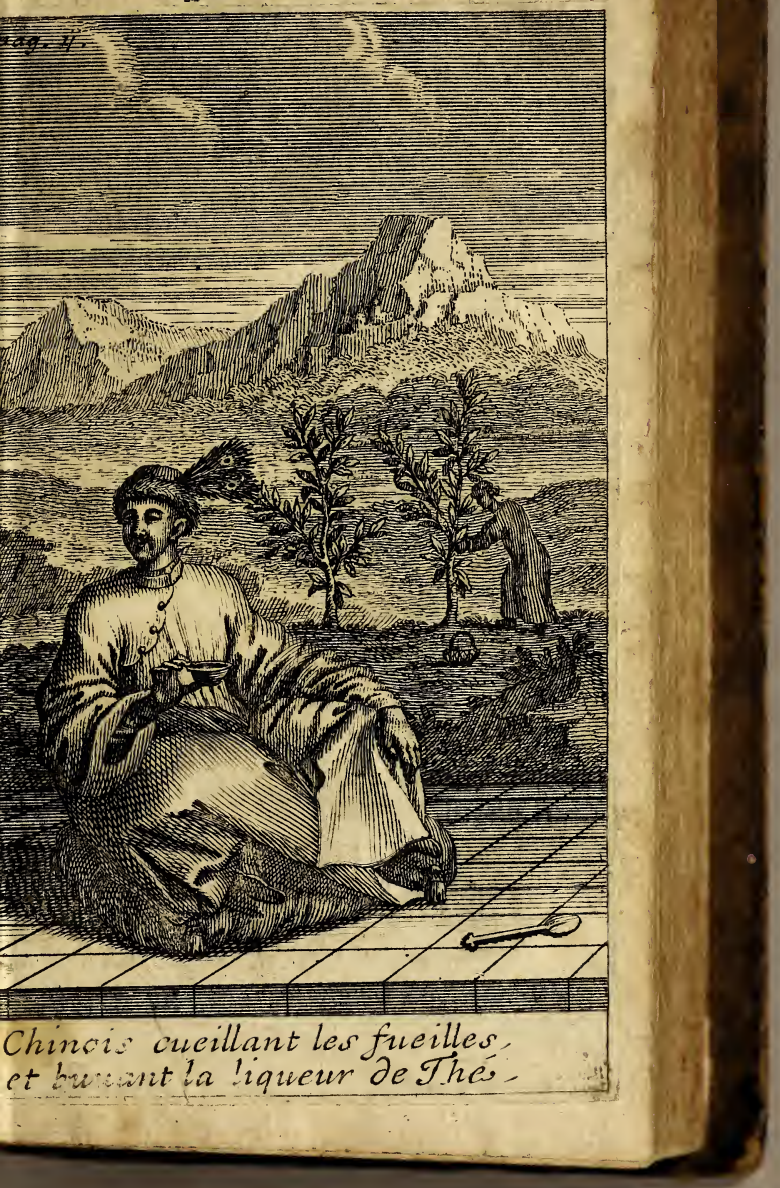




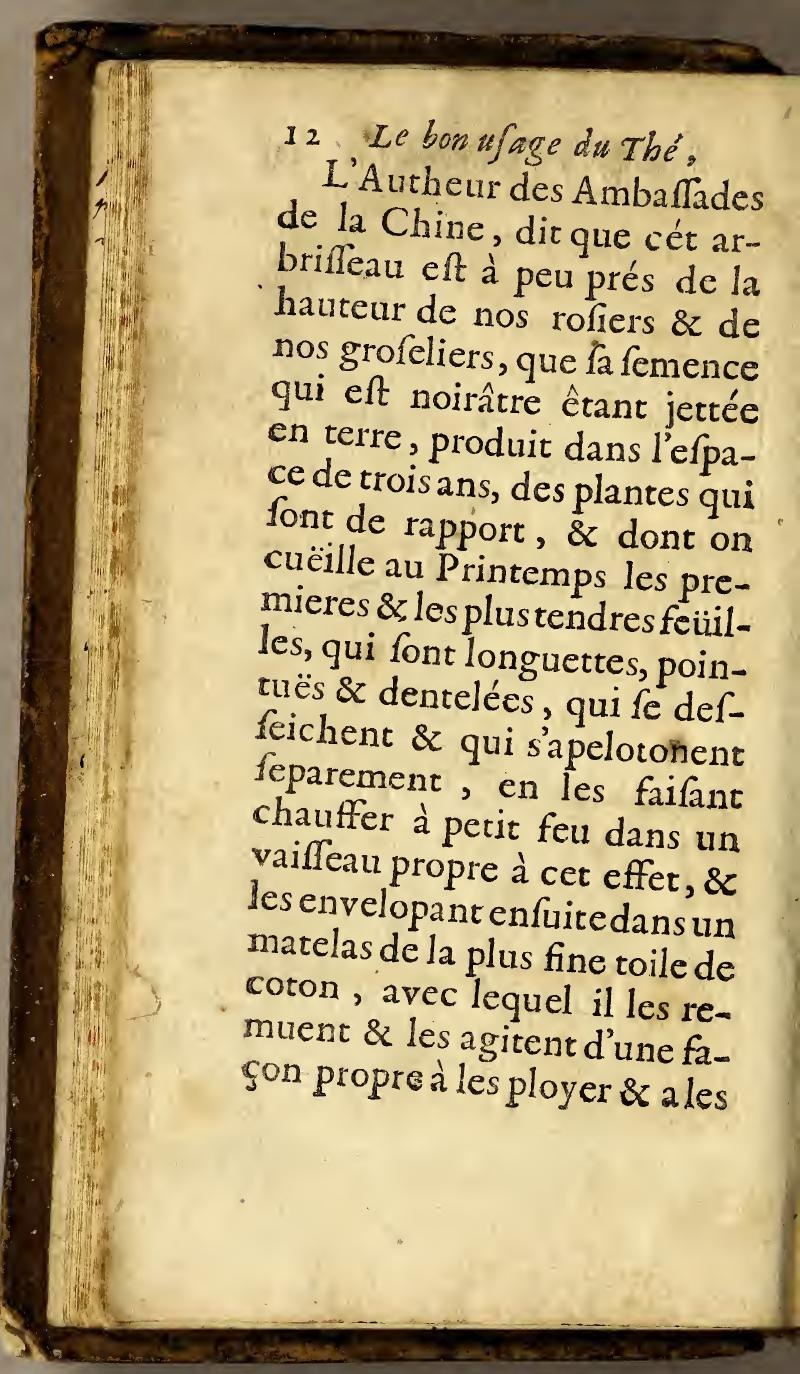


du Caffé, ou du Chocolat. I 3 entortiller, les faifant chauffer, les envelopant \& les remuant autant de fois qu'il eft neceffaire, pour être bien deffeichées \& bien entortillées, ce qui les rend propres au commerce, pour lequel on les conferve dans des vafes d'Etain, quion bouche \& quion fcele tres-exactement.

Si l'on en croit cét Auteur on pourroit efperer de cultiver cét arbriffeau, dans les endroits de l'Europe où l'hyver fe fait confiderablement reffentir : car il affure que la neige ny la gelée ne peuvét point empêcherqu'on n'en faffe tous les ans une copieufe-recolte; c'ef pourquoy ayant formé le deffein d'en faire l'eflay, je priay tres-inftamment un 
14 Le bon ufage du The', Marchand qui devoit faire voile aux Indes l'année derniere, de m'apporter de cette graine noirâtre cõfervée avec toute la precaution poffible, ce quil me promit de faire fous l'efperance de la recompenfe que je luy propofay; s'il me tient parole je fuivray mon deffein, \& je feray part

- atr public de tout ce qu'ily aura de remarquable dans cette épreuve, dont le fuccés eft cependant d'autant moins affûré, que plufieurs Auteurs affurent que le cha du Japon \& le Thé des Indes, ne fe cultivent pas à beaucoup prés dans toute l'étenduë de ces deux grands paîs; mais feulement dans quelqu'unes de leurs provinces. Il femble 
du Caffé, \& du Chocolat. is neanmoins par les obfervarions medecinale de Tulpius Medecin Hollandois, quon en cultive anffi depuis quelques temps dans le Royaume de Siam, c'eft furquoy nous pourroōs avoir quelques éclairciffemens par les Ambaffadeurs qui en font partis, \& qui fe doivent rẻndre inceffament auprés du Roy, pour complimenter \& pour faire de riches prefens à fa Majefté de la part de leur Souverain, qui a déja marqué avec tant d'éclat par des Ambaffades precedentes, l'extrême veneration quiila, pour les heroïques vertus de nôtre incomparable Monarque. 


\section{Le bon ufage du The',}

\section{CHAPITRE II.}

Duchoix of des differens prix du Thé.

T A difinction qu'on a dû faire dans le chapitre pre. cedent, entre le Thédu Japon \& celuy de la Chine, ne doit pas faire croire que quand il s'agit de choifir du Thé en Europe, on doive fe mettre fort en peine, des lieux d'où les Marchands ont tiré leur differentes efpeces du Thé, non feulement parce que celuy du Japon fe tranfporte fouvent à la Chine, \& que reciproquemét celuy de la $\mathrm{Ch}$ ne eft affés ordinairement envoyé au Japon, mais encore 
du Caffé, of du Chocolat. 17 par cette raifon plus effentielle, que le moindre Thédu Japon, ne vaut pas beaucoup prés le meilleur Thé de la Chine, qui n'eft inferieur qu’à cét excellent Thé du Japon, qu'on celebre \& qu'on diItingue de tout autre par le nom de fleurs de $c h s$, comme on appelle fleurs de Rhetorique les plus élegantes \& les plus excellentes façons de parler; c'eft pourquoy on obfervera affés de precaution dans le choix du Thé, lors qu'on sattachera à diftinguer fes degrés de bonté parles obfervations qui fuivent.

Le meilleur \& le plus excel, lent Thé, a la plûpart de fes feiilles petites \& delicates. Si on les obferve peu aprés 


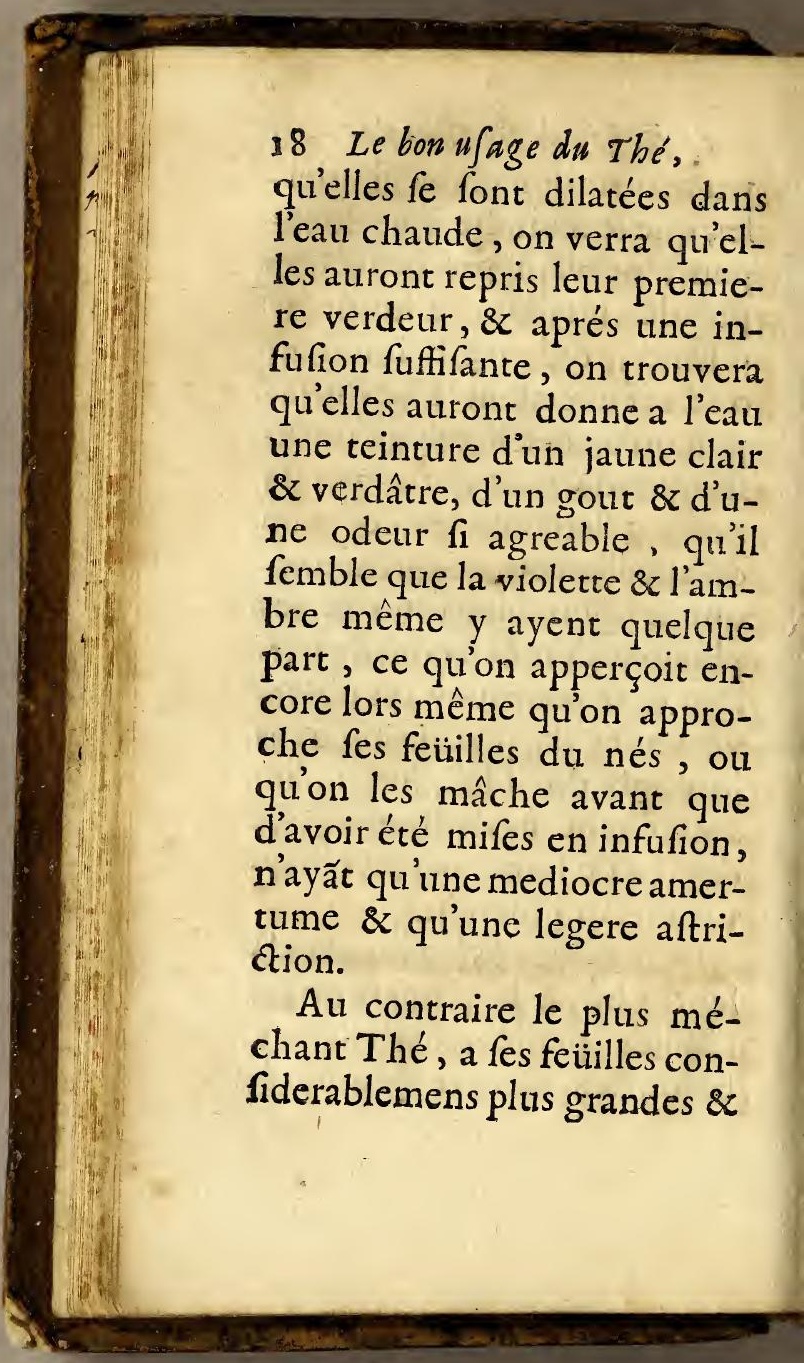


du Caffé, \& du Chocolat 19 plus épaiffes, \& qui demeurent d'un brun enfoncé. A prés même qu'elles fe font dilatées dans l'eau chaude, elles n'ont prefque point d'odeur, \& l'on découvre par la langue qu'elles ont beaticoup d'amertume \& d'aftriction. Elles rendent une teinture rouffe qui eft d'autant plus défagreable à l'odorat \& au goût, qu'elle approche en quelque forte de celle du fené, \& qu'une forte dofe de fucre ne la fçauroit corriger.

A prés ces remarques qui diftinguent tres-précifement le plus excellent Thé du plus commun, on n'aura pas de peine à reconnoître les differens degrés de mediocrité,qui fe peuyent rencontrer dans 


\section{Le bon ufage du The',}

routes les autres efpeces de Thé, qui ne peuvent être differentes ny entre elles n'y par rapport aux deux efpéces qui viennent d'étre defignés, que dans le plus ou le moins des bonnes ou des méchantes qualités de ces efpéces, ce qui établit toutes les differences quion peut trouver dans les divers prix du Thé.

Ces differences font d'autant plus confidetables, que $M^{r}$ Tavernier nous affúre, que la fleur de cha fe vend jufques à cinq cens francs la livre dans le Japon même, \& qu'on fçait neanmoins qu'on en trouve de la Chine à cinq ou fix francs, cependant il eft du moins certain que les Chinois même achettent affés ordinairement 
du Caffé, \& du Chocolat. 21 cette fleur de cha des Marchands du Japon, jufques a cent, cent cinquante $\&$ deux cens francs la livre, \& c'eft ce qui authorife nos Marchands a la vendre icy à peu prés fur le même pied, quoy qu'ils la pourroient donner à beaucoup meilleurmarché,les Japonnois \& les Chinois mêmes, l'échangeant toûjours volontiers poid pour poid, \& quelquefois encore plus advantageufement, contre les feüilles de nôtre faulge, en laquielles il trouvent de tresgrandes vertus: Pour ce qui eft du Thé commun ils en ont ordinairemét cent livres puur dix livres de faulge, ar c'eft. pour cela qu'en le donnant en gros à fix francs la livre, ils 
22 Le bon u age du Thé, ne laiflent pas dy gagner beaucoup.

Ordinairement il ne fe chargent que de ces deux elpéces de Thé; mais ils en font enfuite par un mélange differend, un grand nombre d'autres efpéces, felon qu'ils ajoûtent au Thé -commun plus ou moins de fleurs de cha: \& c'eft d'où vient qu'outre les prix qui viennent d'être marqués, on trouve encore du Thé à $10,20,30,40,50,60.8280$. francs la livre.

C'elt encore par cette raifon, qu'on trouve tant de difference dans la grandeur, $\&$ dans la confiftáce des feuiilles d'une même forte de Thé, mais il eft vray neanmoins que fouvent les trompeurs ont 


\section{du Caffé, \& du Cbocolat. 23}

grand part à cette difference, en ajoûtant au vray Thé les feuillles dentelées de plufieurs de nos plantes; en quoy il paroît qu'on ne fçauroit prendre trop de precaution lors qu'il s'agit de choifrr le Thé. Cependant il eft à remarquer que cette precaution ne doit pas toûjours s'étendre, jufques à refufer les parcelles menuës du bon Thé; car il eft affés ordinaire, que les plus delicates feüilles du Thé fe brifent de la forte, lors quilil eft remué par ceux qui le chargent.

On doit encore obferver que fouvent le plus excellent Thé, c'eft à dire celuy même quon nóme fleurs de cha, degenere en Thé commun, pour avoir 
24. Le bon ufage du The', êté trop long-temps gardé ou mal confervé, car dans cét état, encore que ces feüilles ayent confervé leur propre forme; fon gout, fon odeur \& fes vertus fe trouvent aneanties, par la diffipation de fes parties fubtiles \& fpiritueufes.

\section{CHAPITRE III.}

De la natureparticuliere du Thé.

F Ntre les qualités fenfibles du Thé, fon amertume \& fon aftriction étant les plus confiderables, je ne puis me difpenferderapporter en premier lieu, les obfervations que jay déja publiées dans mon livre du remede Anglois, \& qui expliquent en general la na-

ture 
du Caffé, o du Chocolat. 25 ture des drogues ameres, voicy donc à quoy fe reduifent ces obfervations. Les elemens des corps mixtes font les corpufcules acides, liquides, ignées, étherés \& terreftres. Entre ces corpufcules, il n'y a que les acides qui foient en droit de piquer la langue, \& il eft certain que tous.les amers la penétrent, en forte qu'ils y font vivement reffentir leur action; il faut donc conclure que les acides font tres-dominans dans tous les mixtes qui ont de l'amertume.

Il faut obferver maintenant, que les acides mellés avec beaucoup de corpufcules liquides, ne font que des liqueurs piquantes \& diffoluanes, commeles efprits de fel, de

$$
\text { - B }
$$




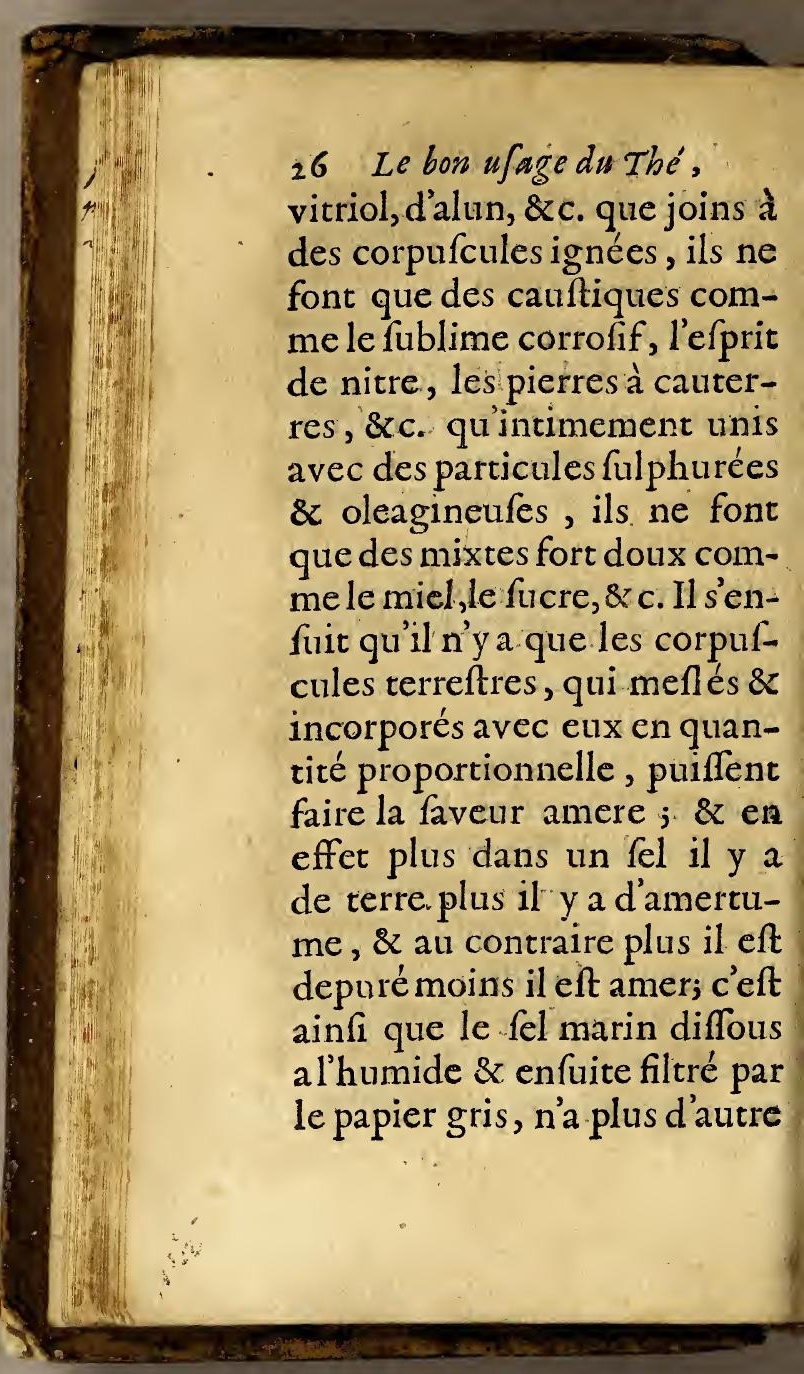


dis Caffé, of du Chocolat. 27 faveur que celle d'un efpric acide, quoyqu'avant cette diffolution \& cette filtration, il fût confiderablement amer.

Or comme entre les élemens que j'ay nommez, l'acide eft le plus pefant \& par confequét le plus froid, \& que fi le terrefre a moins de pefanteur que luy, \& même que le liquide, il en a plus auffi que l'Ignée $\&$ que l'etheré, on peut dire qu' il eft temperé, c'eft à dire d'une qualité mediocre entre les extremes, \& qu'ainfi étant avec l'acide prédominant dans un mixte, il ne fe peut que le mixte ne foit rafraichiffant, ou au moins fort propre à conferver la jufte temperature de nôtre corps.

Mais parce qu'il n'y a point B ij 
28 Le bon ufage du The', d'amers fimplement compofés de corpufcules acides \& terreftres, \& qu'il en eft dans lefequels ou les ignées ou les liquides entrent dans une quantité confiderable, il en eft auffi qui font plus ou moins amers \& même plus ou moins rafraîchiffans \& temperans. Or la feichereffe du Thé,nous fait comprendre qu'entre fes parties élementaires, il n'y a prefque point de corpufcules étherés n'y encore moins de liquides : pour ce qui eft de fon odeur elle nous découvre qu'il contient en foy des particules ignées volatiles \& fpi'ritueufes, mais la douceur \& la delicateffe de cette odeur, nous perfuade en même temps que ces particules n'y font que 
du Caffé, \& du Chocolat. 29 dans une mediocre quantité. Ces chofes préfuppofées, il feroit bien facile d'expliquer la nature particulietedu Thé, $\&$ les proprietés qui en dependent, car ayant pour parties furabondantes les acides, dont le propre eft de coaguler les liqueurs plus fubitancielles comme le fang le lait, \&c. \& encore les al kalis ou corpufcules terreftres, qui en abforbant l'humidité \& l'onctuofité qui relâchent les parties folides, refferrent \& fortifient ces parties, il eft de neceffité que cette feuille foit confiderablement ftiptique \& aftringente.Si on conclut aprés cela quayant auffi les particules ignées volatiles \& f firitueufes dans une quantité affés confi-

B iij 


\section{Le bos ufage du Thé,}

dérable pour fe faire apercevoir par l'odorat, il doit neceffairemét reparer les efprits \& reftituer les forces perduës, on aura pris une Idée aufli jufte que generale de la nature \& des proprietés du Thé, ce qui doit fuffire dăs ce chapitre, où je ne pourrois entrer dans le détail de fes proprietés particulieres, fans m'engager à faire dans les chapitres fuivans une ennuieufe repetition.

\section{CHAPITRE IV.}

Des differentes manieres de pren. dre du The.

A Vant que de maler dés Averus particulieres du Thé, j'ay dû m'expliquer fur 


\section{du Caffé, \&u du chocalat. 3 I}

fes proprietés generales, \&xtout de même avant que de traiter de l'ufage qu'on en doit faire dans les occafions particulieres,je dois érablir en generalles differentes manieres d'en ufer,

Ces manieres font bien plus nombreufes que bien des gens ne l'auroient pû penfer; car outre l'habitude commune de le prendre en teinture, on peut aufi ufer avec fuccés de fon eau diftillée, de fes fels, de fes frops, de fa conferve, de fon extrait \& de fa fumée même.

Sa Teinture \& fon infufion c'eft la même chofe. C'eft cette boiffon que tout le monde connoît \& qui eft generalement nommée Thé, aufi bien que la feuille dont elle eft tirée. Sa preparation eft tresB iij 
32 Le bon ufage du The', facile, il fuffit de faire boüillir dans un vaiffeau propre à cet effet, autant d'eau qu'on veut avoir de teinture, \& de la tirer du feu quand elle boult, pour y jetter les feuilles de Thé en quantité proportionelle, couvrant enfuite le vaiffeau, \& laiffant ainfi le Thé en infufion durant la troifiéme partie d'un quart d'heure, pendant lequel temps les feviilles du Thé s'affaiffent au fond du vaiffeau à mefure que l'eau en extrait la teinture, en forte qu'elle fe trouve entierement precipitée, lors qu'il s'agit de verler la liqueur dans les taffes, chiques ou gobelets qui fervent à la boire.

La forme des vaiffeaux à faire le Thé, eft auffi diverfe 
du Caffé, o du Chocolat. 33 qu'elle eft indifferente, car il fuffit qu'ils foient propres à refifter au feu, \& que leurs embouchures foient fermées par un couvercle bien jufte, ceft pourquoy outre que toutes les fortes de caffetieres \& de chocolatieres peuvent être employées à cét ufage,on voit aux Indes \& en Europe des pots particulierement deftinés au Thé, dans la matiere \& dans la forme defquels il fe trouve une notable difference, c'eft ce qu'on connoîtra mieux par la figure que jay fait reprefenter icy, où l'on trouvera les formes qu'on donne aux pots d'Argent, d'Etain ou de terre de la Chine.

B $\vee$ 


\section{Le bon usage du Thé,}

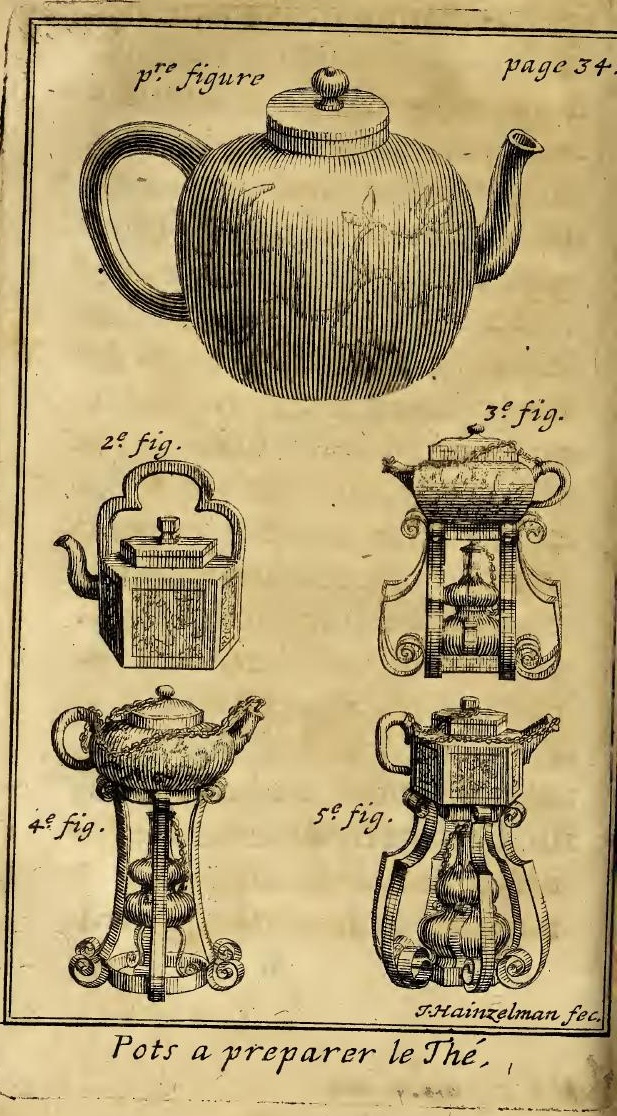




\section{du Caffé, \& du Cbocolat. 35}

La matiere \& la forme des taffes à boire le Thé eft pareillement diverfe $\&$ indifferente; neanmoins aux Indes \& en Europe, il eft affés ordinaire de preferer aux taffes ou gobelets d'A rgent ou de quelque autre metal que ce foit, les chiques de porcelaines ou de fayance, par cette raifon que leur bords ne brulent jamais les doigts, \& que la façon de tenir ces chiques paffe pour une efpéce de bienfeance. Ceux de qui cette façon eft ignorée la trouveront reprefentée à la premiere figure de ce traité.

Je ne dois pas ômettre de dire que la teinture du Thé doit être buë fort chaude, \& même pendant fa premiere 
36 Le bon ufage du The, chaleur, car lors qu'elle a êté refroidie \& enfuite rechaufée, elle eft auffi defagreable qu'inutile, tout de même que celle qu'on tire en deuxiéme lieu,des feüilles dont on a déja tiré la premiere teinture, qui ne peuvent fervir dans cét état qu'à l'extraction de fon fel fixe; c'eft pourquoy ceux qui font affez oconome pour ne vouloit rien perdre de leur Thé, \& qui ne veulent pas s'attacher à l'extraction de fon fel, feront 'mieux de fuivre la maxime de quelque Japonnois, qui reduifent le Thé en poudre fi fubile, qu'étant mis dans l'eau boüillante, il s'incorpore avec elle, en forte que ce mélange ne femble faire qu'une fimple teinture, qui 
du Caffé, ó du Chocolat. 37 n'eft ny plus chargée ny plus défagreable, que celle qui fe fait par infufion, ce qui eft dautant plus aconomique, que le Thé s'y met dans une quantité trois fois moindre, que celle de celuy qu'on fait fimplement infufer.

Pour revenir maintenant aux proportions qu'on doit garder, lors qu'on prepare la teinture ordinaire du Thé, on fçair qu'elle doit être differente, felon qu'on veut cette teinture plus ou moins chargée, mais à mon égard comme je fçay par experience qu'elle ne le doit être que fort médiocrement pour être auffi falubre quagreable, je tiens que fur quarre grandes taffes d'eau, qui pourroient faire en- 
38 Le bori ufage du Thé,

viron fix moyennes chiques de boiffon, on ne doit mettre au plus qu'une dragme de Thé, \& à proportion pour une moindre quãtité de Teinture. Il eft affés ordinaire à ceux qui ne craignent pas l'amertume de boire cette teinture fans addition, pretendant par cét ufage la rendre plus efficace, \& j’ay obfervé qu'en effet elle a beaucoup plus d'aftriction: mais c'eft un excés qui fait des altérations nuifibles \& que je ne faurois approuver; je fuis donc en cela pour l'ufage plus ordinaire, qui veut que dans une mediocre taffe de boiffon, on ajotute une bonne pinfée de fucre en poudre, \&z pour encherir même fur cér ufage, jay infinué à bien des 
du Caffé, o du Chocolat. 39 gens, l'habitude de fubftiruer au fucre les frops dont il fera parlé cy-aprés.

Quoyque l'ufage de l'eau diftillée de Thé, foit d'autant plus rare, que je crois être le feul Medecin qui l'aye mife en pratique, elle ne laiffe pas d'avoir des proprietés admirables, tant par rapport aux vertus du Thé qui en fait la principale matiere, qu'à caufe de l'ambre $\&$ du Cardamome que jy fais ajoûter, \& quil la rendent cordiale \& digeftive.

Quand à ce qui concerneles fels de Thé, la Medecine ne nous-en fournit point de plus generalement utiles, puifqu'ils font également efficaces pour lever les obftructions, pour diffoudre les humeurs coagu- 
40 Le bos ufage du The', lées, pour amortir les levains, \& pour abaiffer les vapeurs contre nature. Ces fels font au nombre de deux, fçavoir l'effentiel \&le fixe; je donneray bien-toft la maniere d'ex. traire le premier, en publiant dans le Journal de Medecine, le fecret de tirer les fels effenriels de toutes efpeces de plantes feches, \& à l'égard du deuxiéme, je le fais preparer comme tous les-autres fels fixes; c'eft à dire par incineration, l'exivation, filtration, évaporation, \& coagulation, $\&$ pour aconomifer fur cét article, je fais rechercher dans tous les Caffez de Londres, le Thé dont on a tiréla teinture, qui ne coutte prefque rien à mes correfpondáces, \& qui ne 
$d u$ Caffé, ou du Chocolat. $4 \mathrm{I}$ laiffe pas d'être auffi propre à l'extraction du fel fixe, que celuy qui n'auroit pas encore. fervy.

Pour ce qui eft des firops de Thé de mon invention, je les diftingue en firop fimple , \& firop Febrifuge; le fimple eft preparé avec la teinture du Thé ambrée, \& le febrifuge avec les fels dont il vient d'être parlé, \& encore avec ceux que je fais extraire du Caffé, $\&$ du cacao; il fera parlé en d'autres endroits de l'ufage qu'on doit faire de ces firops. Pour ce qui eft de la conferve de Thé,elle eft en forme de tablettes qui fe compofent avec le fucre fin ambre, \& les feüilles de Thé reduites en poudre impalbable; on les 
42 Lebon usage du Thé,

peut manger telles qu'elles font avec plaifir, ou en faire furle champ une fort agreable boiffon, en les diffoluant dans l'eau boưillante, où il ne faut ajoûter ny fucre ny firop, ce qui fait une efpéce de teinture beaucoup plus cordiale que la teinture commune.

Je diray peu de chofe en cét endroit de l'extrait de Thé, qui n'eft que le refidu de l'evaporation d'une bonne quantité de fa teinzure, mais qui ne laiffe pas que d'avoir des utilités comme il fera dit cy-aprés.

Refte à parler de la fumée de Thé, que plufieurs prennent plaifir à recévoir par la bouche cốme on fait celle du Tabac, aprés avoir allumé les feinilles de Thé dans l'embou- 
du Caffé, \&o du Chocolat. 49 chure d'une pipe, ce qui fortifie le cerveau autant que le tabac l'affoiblit.

\section{CHAPITRE V.}

Des vertus particulieres $d u$ Thé.

A Prés avoir expliqué la A nature du Thé, \& avoir donné une idée generale de fes proprietés, je dois maintenant appliquer ces obfervations generales, aux effets particuliers qui refultent de fon action; \& comme entre ces effets le plus confiderable $\& z$ le plus univerfellemét connu, eft celuy de rendre fupportables, les veilles que la nature ne pourroit foûtenir fansaccablemśt;il eft jufte que je com- 
44 Le bon usage du Thé. mence par l'explication de ce phœnomene. Pour le mettre dans toute l'evidence qu'on peut fouhaitter; ll eft à propos de rapporter icy, les obfervations que jay communiquées au public fur les caufes de la veille \& du fommeil, dans l'hiftoire naturelle de l'opjum, qui a été ajoutée à la defcription du remede Anglois; voicy comment je m'en fuis expliqué.

L'état de l'homme qu'on nomme veille, \& dans lequel le corps eft capable de toutes les fonctions qui dependent de la volonté, ne fubfinte que par un écoulement continuel des efprits animaux dans tous les nerfs, \& par confequent dans ceux qui conftituent les orga- 
du Caffé, o du Chocolat. 45 nes des fens, fi bien que la diffipation de ces mêmes efprits, \& tout empêchement formé à leur paffage, font les caufes du fommeil, quon peut définir, une difpofition en laquelle les fens exterieurs font affoupis, au point d'être incapables des perceptions qu'ils donnent à l'ame, \& en laquelle toutes les autres parties du corps font affoiblies, relâchées, \& impropres à toutes les actions volontaires aufquelles la nature les a deftinées : car le fommeil eft toûjours imparfait en ceux qui ont les yeux ouverts, qui marchent, ou qui font toutes aures fortes de fonctions en dornant, qui femblent être dependantes de la volonté, puifqu'elles fuppofent le gontle- 
46 Le bon ufage du The', ment, la force, en un mot le mouvement des nerfs, qu'on ne peut' raporter quà celuy des efprits dont ils font alors penetrés \& occupés.

Cela fuppofé, il ne fera pas difficile de comprendre, pourquoy on s'endort naturellement aprés un rude travail ou aprés une longure veille; car comme ces deux chofes diffipent beaucoup d'efprits,il s'en trouve à la fin une trop petite quantité pour remplir tous les nerfs, pour foutenir le corps; $\&$ pour le rendre propre à la fenfation \& au mouvement; de telle forte qu'il demeure comme neceffairement immobile \& infenfible, jufqu’à ce quele fang depuré \& fubtilifé par une nouvelle circulation, 
du Caffé, \& du Chocolat. 47 aye depofé dans le cerveau une quantité d'efprits équivalente, à celle de la diffipation qui devoit être reparée.

On peut expliquer avec la même facilité, l'affoupiffemét qui eft fi ordinaire pendant la digeftion des alimens; car comme elle ne fe peut faire fans quil en refulte des vapeurs qui montent au cerveau, qui embaraffent les efprits, \& qui font une efpece d'obftruction aux embouchures des nerfs, ce n'eft pas merveille fi les extremités du corps demeurent languides, foibles \& affoupies, puifqu'elles ne peuvent être robuftes \& propres à leurs fonctions, fil'influence des efprits vers elles, n'eft continuelle \& $x$ abondante. 


\section{Le bon uJage du Thé,}

Si aprés ces obfervations, on reflechit fur ce que jay dit de la nature du Thé, on comprendra tres - facilement comment il peut empêcher le fommeil \& rendre la veille fu-: portable, car fon amertume le rendant fixatif \& aftringent, il doit en amortiffant les levains contre nature, \& en referrant l'orifice fuperieur de l'eftomach interrompre l'elevation de toutes les fortes de vapeurs groffieres, qui pourroient embaraffer les efprits \& obftruer les nerfs, \& ayant d'ailleurs beaucoup de parties tres-volatiles \& fpiritueufes, il doit promptement reparer les efprits animaux, qui ont été diflipés par le travail $\&$ par la veille, \& caufer par confequent 
du Caffé, \& du Chocolat. 49 quent une nouvelle influence de ces efprits dans les nerfs qui reftituent à toutes les parties, la puiffance d'executer de nouveau les fonctions de l'ame fenfitive.

On doit conclure tout de même, que le Thé en détruifant les levains, en arrêtant les fermentations contre nature, en rectifiant la digeftion, en abforbant les humidités fuperfluës, \& en prevenant la generation des crudités, doit furvenir à toutes les maladies de la tête, de l'eftomach, \& des inteftins, \& par confequent à la cephalée, à la migraine, aux cacharres , aux fluxions particulieres, aux maladies foporeufes, \& encore à toutes les indifpofitions 


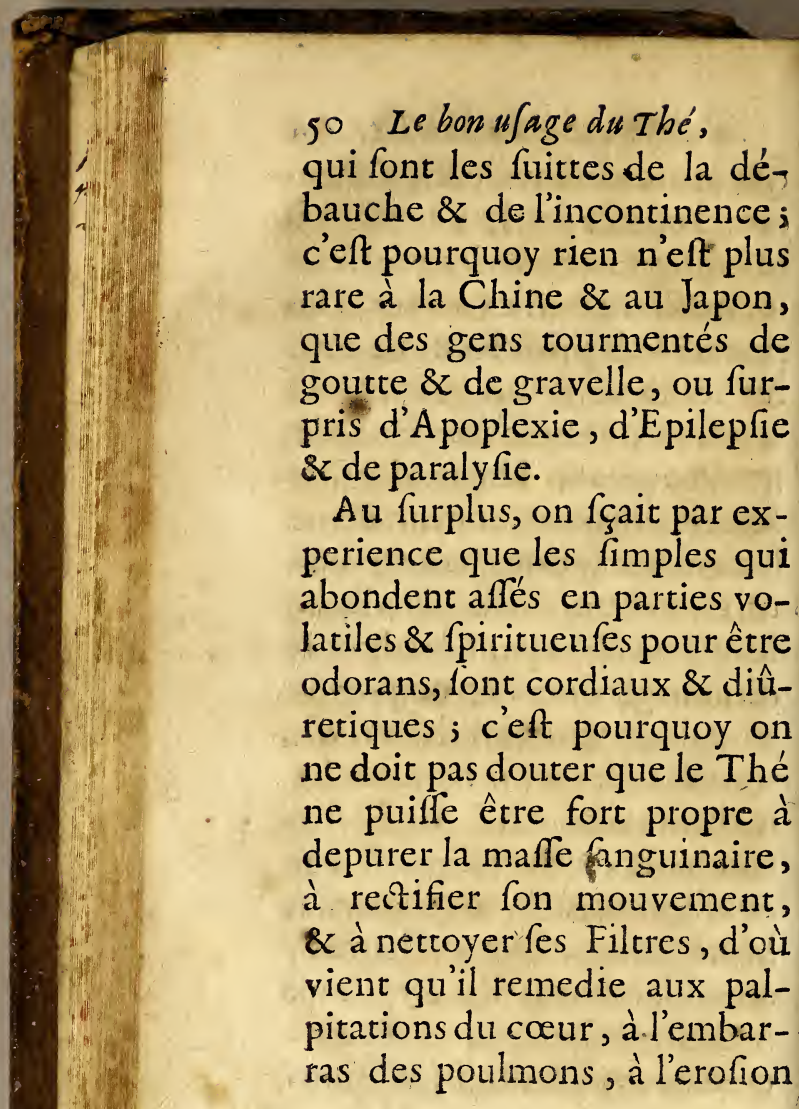


du Caffé, \& du Chocolat. II de leurs vaiffeaux, aux fiévres intermitantes, \& à la colique Nephretique.

Refte à dire, que quand on prend le Thé feulement comme aliment \& par regal, ou à deffein de conferver la fanté, $\&$ de prevenir les maladies dont il vient d'être parlé ; fon ufage eft fi arbitraire \& f $f$ indifferent, qu'on le peut prendre fans inconvenient, à la quantité que l'appetit peut fuggerer \&s indiftinctement en tout temps, fi ce n'eft lors qu'on veut s'abandonner au fommeil; mais lors qu'on en ufe à deffein de fe delivrer de quelques indifpofitions, il eft bond'obferver ce qui fera cyaprés remarquable.

Lors quil s'agit d'appaifer $\mathrm{C}$ ij 
52 Le bon ufage du The', quelques douleurs de tête, ou d'arrêter quelque fluxion que ce foit, on doit toûjours mettre en place de fucre dans chaque prife de Thé, une cueillerée de firop de vanilles, dont je donneray la defcription dans la troifiéme partie de ce livre. Ce même firop, ou à fon défaut, celuy de capilaires fera preferé au fucre, dans les inflâmations des poulmons, dans les palpitations de coeur , \& dans les autres maladies de la poitrine, \& l'on fera bien dans ces occafions de faire infufer le Thé dans le lait de vache boiiillant \& un peu écrêmé.

Pour remedier aux flux de ventre, à la diffenterie, aux corruptions qui engendrét des vers, \& generalement à tou- 


\section{du Caffé, \& du Chocolat. 53}

tes les maladies dependantes de l'indigeftion, il fera bon de mettre dans chaque taffe de boiffon une ou deux goûtes d'effence d'ambre, ou à fon défaut d'effence de canelle, \& de fubftituer au fucre le firop de fleurs d'oranges, ou à fon défaut celuy de grenades.

Contre la goutte \& contre la colique Nephretique, le firop de Caffé doit être preferé, il en fera parlé dans la deuxiéme partie de ce livre.

- Enfin contre les fiévres intermittantes, on employera avec fuccés, le firop febrifuge dont je prefcriray l'ufage dans le chapitre fuivant.

\section{接}

C iij 


\section{Le bon usage du Thé,}

\section{CHAPITRE VI.}

Du firop de The Felrifuge.

T E travail dans lequel je Lm'engageay en 1682 . pour connoître par une analyfe exacte, la nature \& les proprietés du Thé, du Caffé, \& du Cacao, me fit trouver un nouveau moyen pour tirer les fcls effentiels des plantes deffeichées, ce qui medonna lieu d'obferver, que ceux qu'on peut tirer de ces trois fimples, étant reünis avec leurs autres principes, compofoient un remede également facile, prompt , \& affuré, pour la guerifon de toutes les efpeces de fiévres intermittantes; 
du Caffé, oo du Chocolat. 55 . jen fis alors des épreuves qui eurét tout le fuccés qu'on pouvoit fouhaitter, \& contant de cette découverte, j'étois prêt à la publier dans le Journal de Medecine, lors quedesadverfaires jaloux, firent fufpendre l'impreffion de ce Journal par un arreft furpris, qui n'avoit pour fondement que des fuppofitions; ce qui ne m'empêcha pas de travailler au bien public, \& de faire diftribuer cét excellent Febrifuge, par les artiftes qui travaillent fous ma direction en conformité des intentions du. Roy, à la recherche \& verification des nouvelles découvertes de Medecine.

Les naturaliftes qui font affés experimentés pour juger des

$C$ iiij 
56 Le bon ufage du Thé, mixtes par leurs qualités fenfibles, nauront pas de peine à croire que le Thé \& le Caffé, qui ont un goût amer, âpre $\&$ aftringent, ayent une vertu Febrifuge, fur tout a prés avoir refléchy furce qui a êté dit dans les chapitres precedens; mais il n'y a point de raifonnement détaché de l'experience, qui puiffe nous faire prefumer cette vertu dans le Cacao; c'eft pourquoy fans m'engager dans des raifonnemens fuperflus, il feroit mieux de donner icy la defcription du frop dont il s'agit, \& d'exhorter les arriftes à le mettre à diverfes épreuves; mais comme le plus grand myitere de fa preparation, confifte principalement en l'extraction des 
du Caffé, \& du Chocolat. 57 fels effentiels dont je dois remettre la publication à un autre temps, il feroit inutile de donner quant-à-prefent, un formule qui ne peut être executé, quaprés la revelation d'un fecret que je me fens obligé de referver. Cependant comme le firop dont il s'agit eft déja fort renommé; \& que nos artiftes en font une ample diftribution, je ne fçaurois me difpenfer de décrire icy", en quoy confifte le bon ufage quion en doit faire.

Pour cela je dois premierement faire obferver, que la baze de ce frop peut être incorporee dans la conferve de The, dans le firop de Caffé, ou dans la pâte de Chocola fans rien perdre de fa vertu, 
g\& Le bon ufage du Thé.

2. que dansle vin \& dans toutes autres fortes de liqueurs fermentées elle n'a pas une efficacité fuffifante, 3.qu'il n'y a aucuns fels ny fixe ny effentiels plus ftomachiques, plus temperans, \& plus diffolvans que ceux quion tire a la fois du Thé, du Caffé, \& du Cacao.

Le premier ufage que je fis de ces fels effentiels \& fixes, fut de les ajoûter à unopiâte cordial, que je donnois dans les maladies qui dependent de la depravation du fang; mais je ne fûs pas long-temps fans. m'appercevoir, quils avoient rendu cét opiate en quelque forte Febrifuge.

Cette obfervation me donna des vuës pour la reunion 
$d u$ Caffé, \& du Chocolat. 59 de ces mêmes fels, avec les principes actifs dont ils avoiét êté feparés; c’eft pourquoy je les joignit avec les extraits Philofophiques de leurs propres fujets, \& $j$ 'incorporeray enfuite le tout dans la pâte du Chocolat degraiffé, de laquelle je fis former des tablettes dozées, aufquelles je donnay le nom de Chocolat Febrifuge.

Quoyque l'ufage de cestablettes ent tout le fuccés que je pouvois fouhaitter, je jugeay à propos de reduire ce febrifuge lous la forme de frop, pour en faciliter l'ufage. On peut prendre ce firop feul à la quantité d'une oncé pour chaque prife, \& on peut enicorele mettrten même do. 


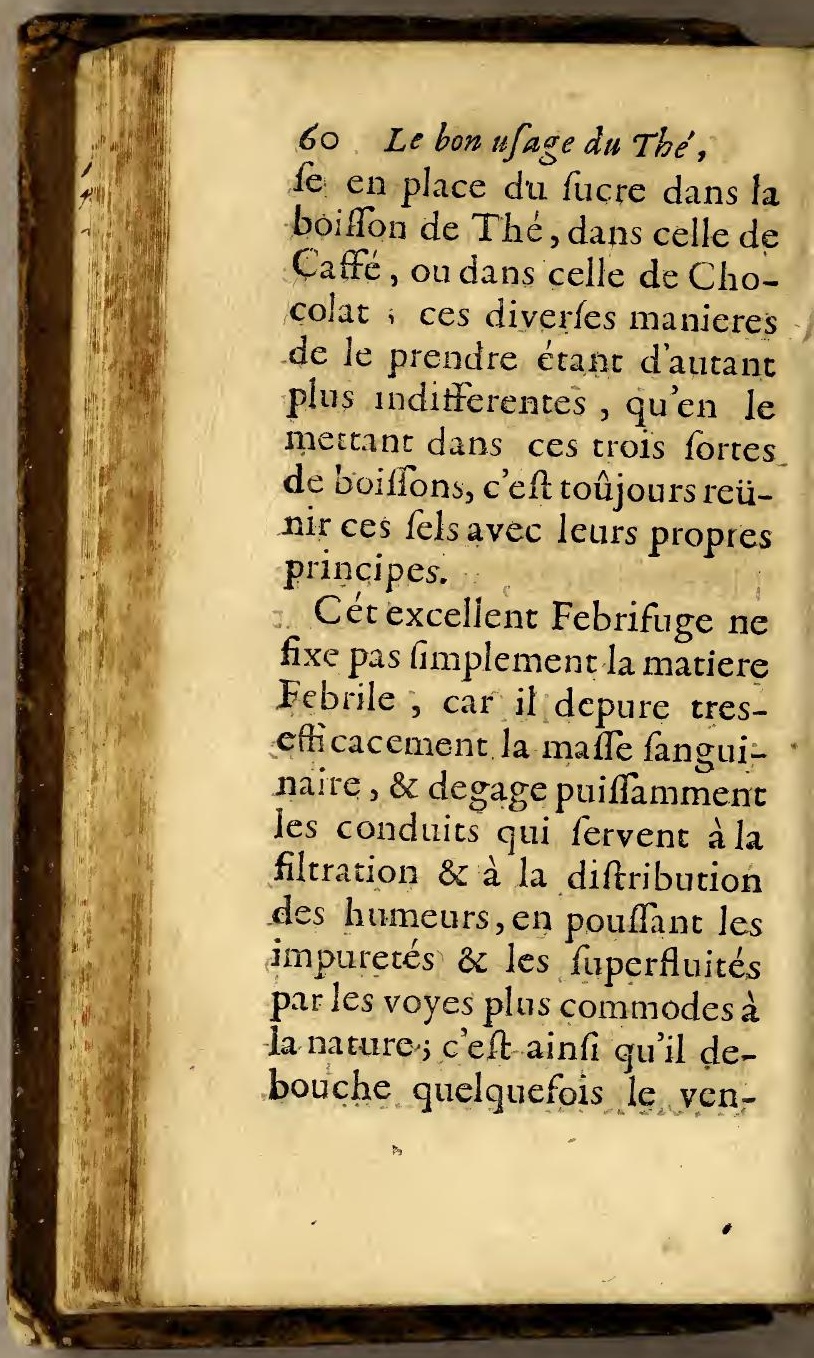


du Caffé, ou du Chocolot. 61 tre, quil décharge d'autrefois la bile par le vomiffement, \& qu'il pouffe fouvent la matiere morbifique par les urines, \& $z$ plus ordinairement encore par les pores, en provoquant une fueur ou du moins une moiteur fenfible.

Il n'y a rien de plus furprenant que les bons effets qui refultent de ces évacuations; comme elles font totijours les fuittes de l'action de chaque prife de ce Fcbrifuge, elles procurent fi promprement \& fi heureufement la guerifon fouhaittée, qu'aprés la troifieme prife, les fiévrestierces \& doubles tierces fe trouyent infailliblement terminées, \& les quartes \& doubles quartes aprés la fixiéme, ce quil luy 


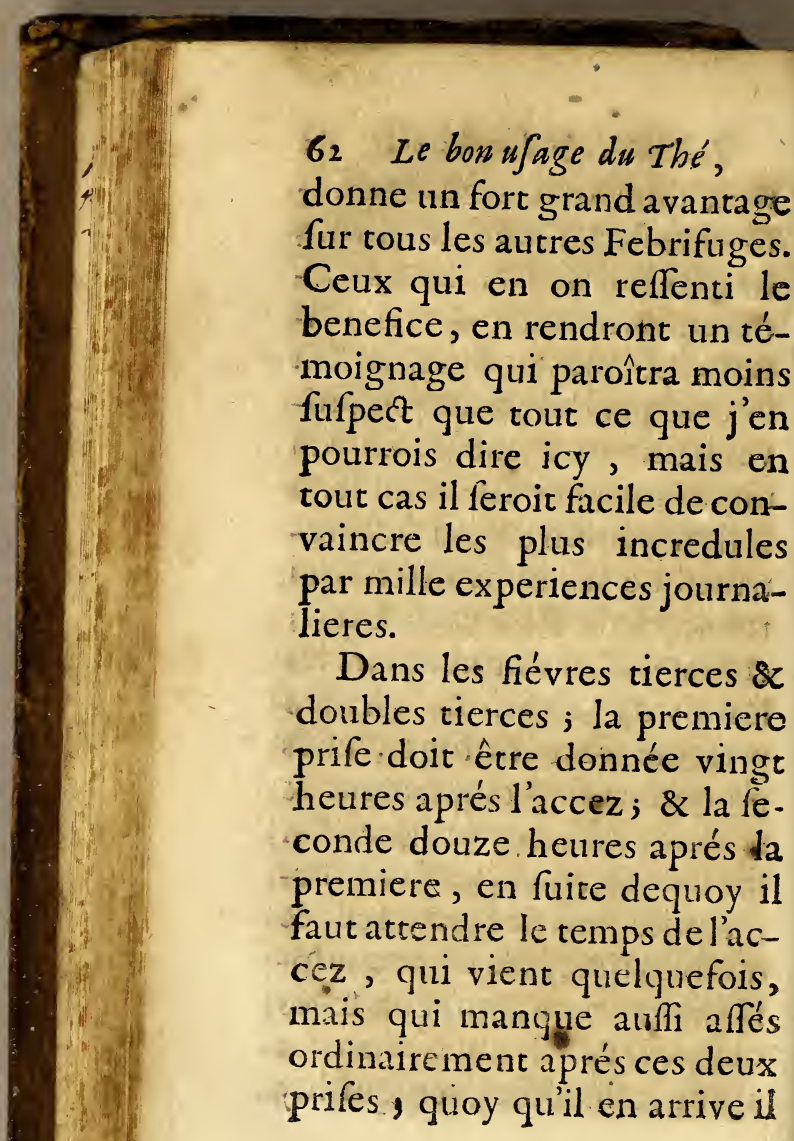


du Caffe, \& du Chocolat. 63 faut que le jour de l'accez fuivant, le malade prenne le matin à fon reveil la troifiéme prife, qui ne manque point de terminer le mal.

Pour les fiévres fimples quartes, il faut prendre la premiere \& la feconde prife du Febrifuge, dans le temps marqué au chapitre precedent, \& la troifiême le lendemain matin à jeun; ce qu'il faudra repeter une feconde fois au refpect du deuxiéme accez, vingt-heures avant (equel on prendra la quatriéme prife, douze aprés la cinquiéme, \& le lendemain $\$ a$ fixiéme, foit que l'accés foit venu à lordinaire, foit quie le malade ait été exempt de fiévre. 


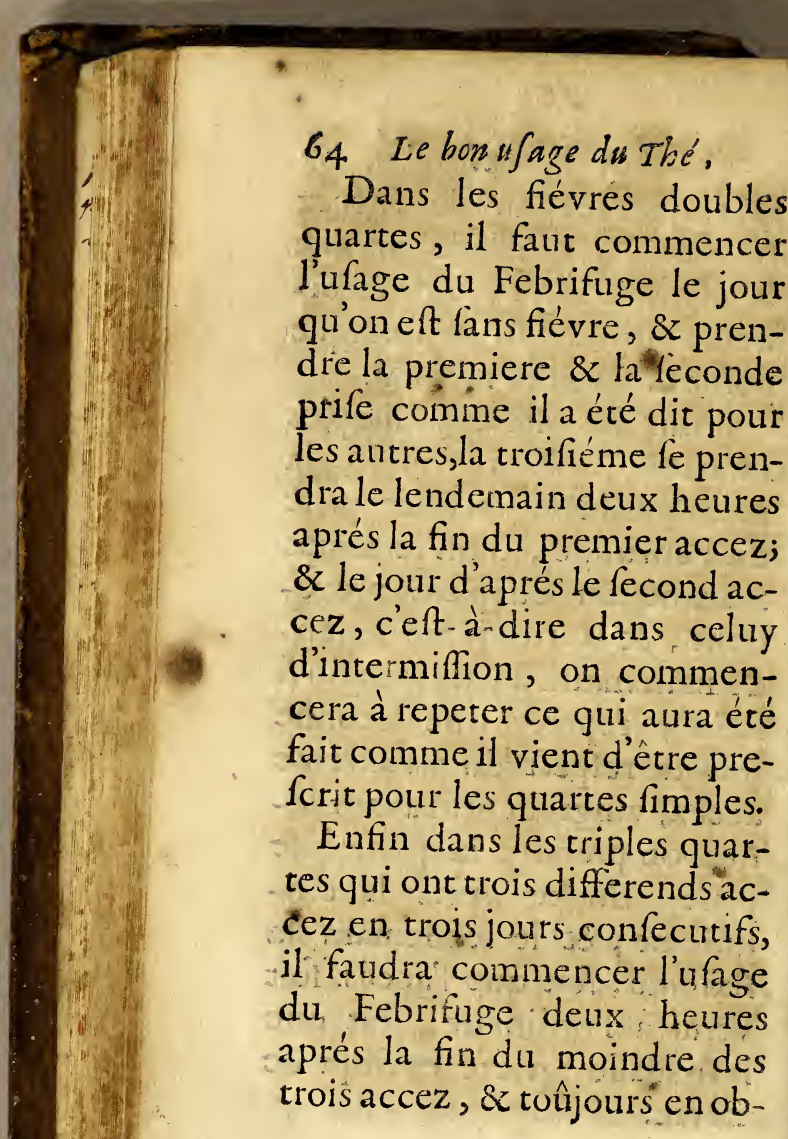


$d u$ Caffé, of du Chocolat. 65 fervant tant dans la premiere difpenfation que dans la repetition, de prendre une nouvelle prife deux heures aprés la fin de chaque accez, en forte que les fix prifes neceffaires pour la guerifon, foient données en fix jours confecutifs, \& à chaque fois deux heures aprés l'accez.

Que fi dans les derniers jours le malade n'avoit plus d'accez, il ne laifferoit pas de regler le temps des dernieres prifes, fur celitiy auquel les accez manqués auroient dû finir.

Les femmes groffes qui one paffé le troifiéme mois, peuvét fans aucun fcrupule prendre le Febrifuge en même dofe ; mais à l'égard de celles 


\section{Le bon ufage du The',}

qui font encore dans le cottrs des trois premiers mois, comme il fe pourroit faire que la nature fe trouveroit difpofée à pouffer la matiere febrile par le vomiffement, \& que I'Eftomach ne peut être foulevé fans êbranler la matiere, on ne leur en donnera gue demie once pour chaque prife; mais à condition de le reïterer, en telle forte que la confommation du remede foit toûjours équivalente, c'eft à dire qu'elle foit de fix demies prifes pour les fimples \& doubles tierces, \& de douze pour les quartes fimples \& cornpofées, en obfervant les regles cy-devant prefcriptes, tant pour les premieres prifes que* pour les repetitions. 
du Caffé, ó du Chocolat -67 Ce qui vient d'être prefcrit pour les femmes qui font dans les premiers mois de leur groffeffe, convient pareillement aux enfans qui ont paffé l'âge de quatre ans; mais à l'égard de ceux qui font encore à la mammelle ou qui ne font fevrez que depuis un an ou environ, il eft mieux de ne leur donner que deux ou trois gros de Febrifuge pour chaque prife.

Le Regime qui convient à ceux qui ufent de ce remede, comprend les regles qui peuvent être reduites fous deux ordres differens : car les unes font generalement utiles dans l'ufage de quelques Febrifuges que ce foit; \& queles autres regardent feulement la 


\section{Le bon ufage du Thé,}

propre difpenfation du firop de Thé Febrifuge.

Les Regles du premier ordre, font celles mêmes que jay prefcrites dans mon traité de la guerifon des fiévres; voicy à quoy fe reduifent les plus effentielles.

1. Le porc qui eft fort indigefte \& le veau qui eft mufilagineux \& relachant, font des viandes de l'ufage defquelles il faut s'abftenir, ainfi que des autres de même qua-
lité.

2. Les boüillons, les tizanes, les émulitions, les eaux de veau \& de pouler, les liqueurs rafraichiffantes à la glace, \& generalement les chofes actuellement ou potentiellemét froides," affoibliffent la natu- 
du Caffé, \& du Chocolat. 69 re, \& énervent la vertu des Febrifuges.

3. On ne doit donner aucune hourriture folide dans toute la durée des accez.

4. Il ne faut faire au plus qu'un ufage tres-refervé de la patifferie, des legumes rafrầchiffans, des falades \& du poiffon, car chez les Febricitans, il ne fe fait qu'un mauvais chyle de ces fortes d'Alimens.

5. Le vin eft pour les Febricitans, la meilleure de toutes, les boiffons ufuelles, pourveu qu'on le prenne fans excez ou pur, ou avec de l'eau fui- vant l'habitude.

6. La Biere quoyque mojns bonne que le vin, ne laiffe pas d'être preferable à toutes 


\section{Lebon usage du The',}

- les efpeces de tizannes, car plus un remede tient de l'aliment plus il eft falutaire, c'eft pourquoy l'eau policrefte que jay inventée \& qui nourrit - comme l'eau commune, eft aprés le vin la meilleure de toutes les boiffons ufuelles qu'on puiffe prendre, pendant l'ufage des bons Febrifuges.

7. Les bons alimens \& fur tout ceux que la nature femble demander, contribuent prefque autant que les remedes, à la victoire qu'elle remporte fur le mal.

8. On peut comprendre fous - le genre des bons alimens folides, le bœuf, le mouton, toutes efpéces de volatilles domeftiques, \& de gibier, ( à l'exception du fanglier) les cufs 
du Caffé, \& du Chocolat. $7 \mathrm{I}$ frais qui ne font ny bilieux ny échauffans, comme le penfent ceux qui font prevenus des erreurs populaires, les fruits fecs ou cuits avec une petite quantité de fucre, \& même les legumes qui ont beaucoup de parties firitueufes, par exemple les artichaux \& les afperges.

A l'égard des regles particulieres que les Febricitans doivent obferver, par rapport à la difpenfation du firop Febrifuge, voicy à quoy elles fe reduifent.

I. Il faut tellement regler le tems des repas que l'eftomach foit vuide lors qu' on prend le remede, c'eft fur quoy les malades fe doivent eux-mêmes confulter, la digeftion étant plus prompte ou plus tardive, 
72 Le bon ufage du Thé, fuivant que l'action du levain digeftif eft plus ou moins efficace.

2. Il faut auffi aprés avoir pris le remede, paffer du moins trois heures fans manger, pour donner le temps neceffaire à fa diftribution, qui fe fera mieux fi on fe tient dans la veille \& dans l'exercice.

3. Une regle qui refulte de ces deux premieres; eft que depuis la premiere jufqu'à la feconde prife, il n'y a environ que cinq heures dans lefquelleston puiffe fouper, dîner ou faire d'autres repas, fçavoir 3 , $4,5,6, \& 7$ heures aprés la premiere prife; mais dans cét efpace de cing heures, on peut manger jufques à deux fois \& même affés confiderable-

mene 


\section{du Caffé, \& du Chocolat. 73}

ment, l'abftinence étant plus prejudiciable que ptofitable dans ces occafions.

4. Lors que dans cét efpace de temps on ne fait quiun repas, il eft bon quelques heures devant ou aprés, de prendre felon l'inclination quelques chiques de Caffé volatile, ou de Chocolat dégraiffé, deux boiffons qui n'ont point les méchantes qualités du Caffé ny du Chocolat ordinaire.

5. Il ne faut jamais boire dans le friffon; mais dans le chaud on peut boire une mediocre quantité de vin, foible de luy même ou affoibli avec de l'eau.

6. Les femmes groffes doivent éviter pareillement l'u- 
74 Le bon ufage du The', fage des légumes qui font aperitifs, comme les artichaux $\&$ les afperges, \& à l'égard des enfans à la mamelle, ils ne doivent teter, quà peu prés dans le temps qui ont êté marqués pour les repas des adultes.

Par l'obfervation de ces regles tant generales que particulieres, on affurera efficacement le fuccés de la cure fouhaittée, mais au refte avec beaucoup moins de regime, cét excellent Febrifuge ne laiffera pas d'arréter la fiévre, tant il eft vray que les bons remedes, contraignent pour ainfi dire la nature à fe porter aux determinations les plus falubres.

Les remedes auxiliaires qui 


\section{du Caffé, \& du Cbocolat. 75}

concourent en quelques fortes à l'amortiffement \& à l'expulfion du levain febrile, font ceux qui peuvent hâter la depuration da fang, lever les obftructions, diffoudre les matieres coagulées, \& les poûfer dehors par les voyes ordinaires, ces bons effets, fans doute doivent contribuer beaucoup à rendre la cure plus prompte \& plus affurée. O dinairement on comprend les vomitifs fous le genre de ces remedes, \& l'on fçait mênie qu'ils font generalement utiles dans les lienx où la péfanteur de l'air, épaifit $\&$ arrête la pituite dans des parties qu'elle ne doit pas orcuper, par exemple dans l'eftomach, d'out elle eft mieux tirée par le vomif-

D ij 
76 Le bon usage du The',

fement que par toute autre évacuation, auffi bien que la bile retenuë dans fa veficule, par l'obftruction des meats, cholidoques; cependant comme il fe trouve des gens en qui la foibleffe, \& les autres difpofitions particulieres de la poitrine \& de l'eftomach, rendent les vomitifs tres-dangereux, ils ne doivent être donnés qu'aprés de ferieufes reflexions, avant l'ufage de quelques Febrifuges que ce foit, mais ceux qui font traitez avec le firop de Thé Febrifuge ont cét avantage, qu'il ne faut point examiner files vomitifs leurs convic nnent ou non, car ce remede eft luy même fi utilement vomitif, qu'il n'excite le vomiffement 
$d u$ Caffé, \& du Chocolat. 77 qu'en ceux en qui la nature fent le befoin quelle a de fe décharger par cette voye : ainfi fans donner icy de regles particulieres pour l'ufage des vomitifs, je prefcriray feulement celles des diûretiques \& des purgatifs, qui font les feuls auxiliaires, dont les determinations ne font pas contraires aux mouvemens de ce Febrifuge.

On nomme diûretique ce qui paffe par les urines. L'Eau policrefte dont il a êté parlé, produit cér effet efficacement \& même entretient la liberté du ventre. Ceux qui n'en pourront pas avoir commodement, mettront dans chaque peinte de l'eau commune qu'ils boiront, une dragme

D iij 
78 Le bon ufage du The', de fel de chicorée on d'aigremoine.

Ces Remedes font feulement propofés, pour les perfonnes accommodées qui ne craignent pas la dépenfe, \& qui vueillent recouvrer promptement l'embompoint \& les forces perduës; les autres s'en pourront palfer fans inconvenient \& ne laifferont pas de guerir ; car le Febrifuge fait l'effentiel de la cure, puifqu'il agit toûjours efficacemét fans le fecours des auxiliaires, qui ne font icy propofez que comme des remedes confirmatifs de l'effet du Cpecifique.

Il en faut dire autant des purgatifs, qui ne laiflent pas neanmoins d'avoir leurs utilitez, c'elt pourquoy je rap- 


\section{du Caffé, \& du Chocolat. 79}

porteray en abregé les regles que j’ay déja prefcrites touchant le bon ufage quion en doit faire dans mon traité de la guerifon des fiévres.

1. Les medicamens qui pouffent pas le ventre ne font pas les feuls purgatifs, il nimporte par ou l'on chaffe les impuretez \& les fuperfluitez, pourveu que les voyes qui fervent à leur expulfion foient les plus commodes à la nature, \&. en favear defquelles elle femble fe déterminer.

3. Il eft phifiquement impoffible, qu'ils ayent aucune prife fur les matieres heterogenes qui font confonduës dans la maffe fanguinaire, \& qui font les caufes immediates des fiévres.

D iiij 


\section{Le bon ufage du The?,}

4. On doit quelquefois reparer par les purgatifs les mauvaifes difpofitions du corps, mais leur ufage doit ordinairement preceder celuy du fpecifique, le relachement du ventre êtant toûjours contraire à fon action.

5 . Les purgatifs amers ou leurs extraits étant en quelque forte Febrifuges, doivent être preferés à tous les autres.

6. Quand aprés avoir arrefté la fiévre, on veut s’affurer par la purgation du côté de la recidive, il eft mieux qu'elle foit repetée, que d'en donner des prifes plus fortes. \& en moindre nombre.

A ces obfervations generales qui conviennent a tous 
du Caffé, \& du Clocolat. $8 \mathrm{I}$ les Febrifuges, on doit ajoûter une regle particuliere qui eft importante dans l'ufage de celuy-cy.

7. Ce n'eft pas affés d'obferver beaucoup de mediocrité dans la dofe des purgatifs qu'on donne aprés la cure, il faut encore que par un long efpace de temps, on fe foit affutré du côté de la recidive avant que de purger; car il eft affez ordinaire que la purgation caufe le retour de la fiévre en depravant la chylification, \& remuant les matieres fermentatives.

Au refte, pour la purgation qu'on dôit faire avant ou aprés la cure des fiévres intermitantes, on peut ufer avec fuccés du vin purgatif que DV 
84 Le bon uJage du Thé, j'ay décrit dans mon livre dit remede Anglos, \& qui fe prepare avec l'hiere pigre: mais l'ext ait pu gatif de nos artiftes luy elt preferable. Son ufage eft dautant plus facile, qu'on le donne en petite dofe \& qu'il n'a point de mauvais goût. On peut neanmoinc le faupoudrer de fucre ou l'envelopper dans du pain azime, dans la pelure de pomme cuitos, ou dans quelques femblables chofes; outre qu'on le peut dilfoudre dans un peu de vin ou de boüillon. Il fuffit pour les plus robuftes d'en donner grosicomme une aveline \& pour les autres à proportion. Aux femmes grofles on en donnera feulement demie dofe, \& aux petits enfans 


\section{du Caffé, \& du Chocolat. $8_{3}$}

une quatriéme partie dans quelque confiture que ce foit.

Quoy quil foit rare de voir des recidives, quand on a traité \& guery les fiévres intermittantes, fuivant les regles qui viennent d'etre prefcrites; on f̧ait neanmoins par experience, qu'il eft des gens en qui il fe trouve diverfes fortes de levains, de façon qu'aprés avoir éteint celuy qui faifoit une certaine efpece de figre, il arrive quelquefois qu'une autre fe fermente à fon tour \& fait une nouvelle fiévre, fi par precaution on n'a pas foin de l'amortir \&z do le chaffer; c'eft pourquoy ceux qui vueillent saffurer davantage, doivent huit jours apres la ceffation de la fievre 


\section{Le bon ufage du Thé,}

prendre une nouvelle prife, \& pour mieux faire encore, une autre quinze jours aprés celle-là, ou du moins quelques prifes de l'extrait de Thé, qui fera même prefe. rable pour les perfonnes delicates.

Quoyque cette precaution foit utile, il ne faut pas croire neanmoins qu'elle foit abfolument neceffaire, puifque fans l'obferver, il ne fe trouve pas un malade entre cent qui tombe dans le cas de la recidive, \& qu'au pis-aller lors de cét inconvenient, il fuffit de repeter ce qu'on avoit fait, ce qui eft d'autant moins chagrinant, que le remede eft tres-facile \& fon prix tres. modique. 
du Caffé, of du Chocolat. 85 Au refte les prifes de ce remede étant en petic volume $\&$ en petit nombre, il eft fi propre à être tranfporté, quion peut même l'envoyer par la pofte à tres - peu de frais, foit dans les Provinces. foir dans lés Royaumes étran. gers, outre qu'étant en confiftance de firop, le fucre le rend tellement inalterable, qu'on peut même l'envoyer dans les Indes, fans craindre que le temps ny la mer luy ôtent rien de fa vertu. 


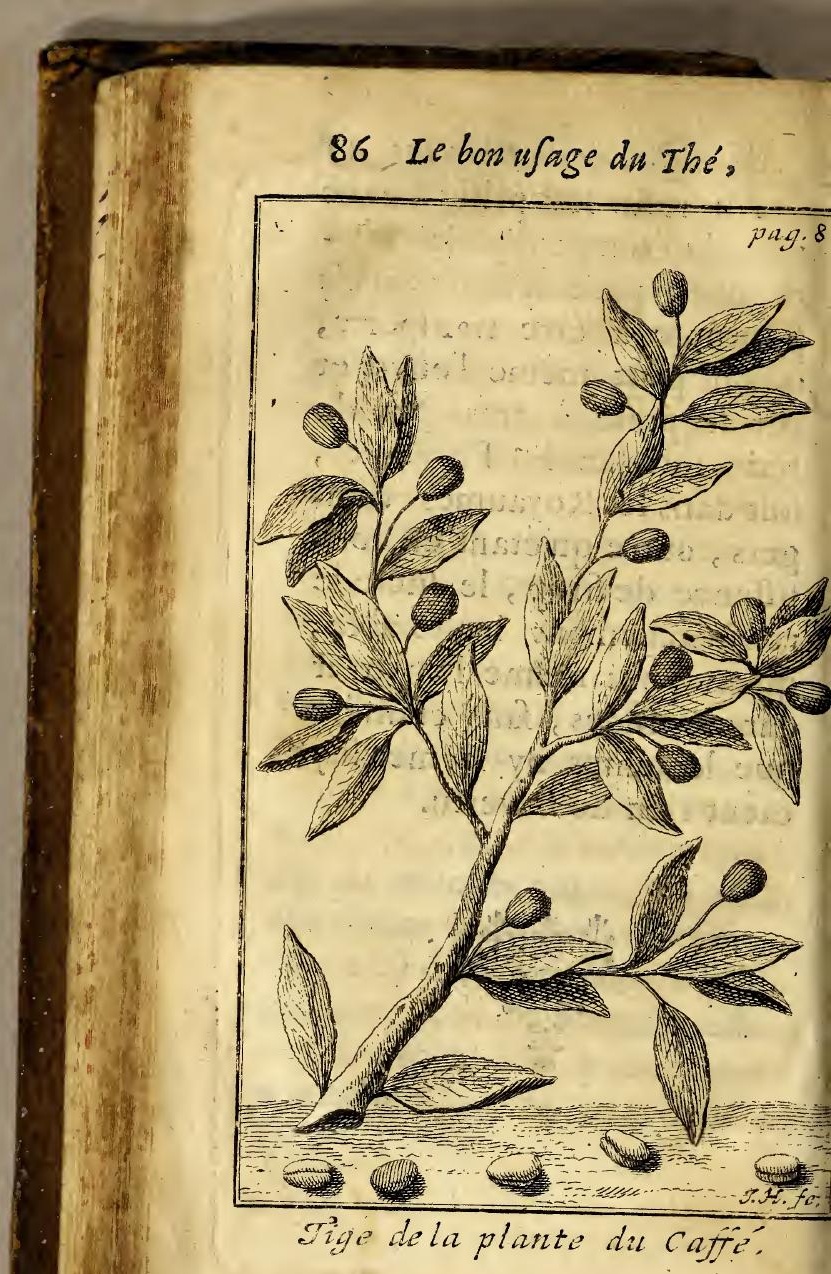




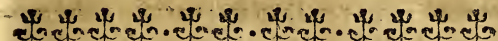

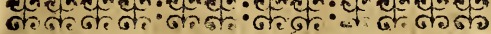

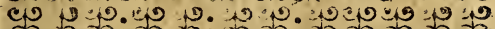

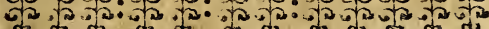

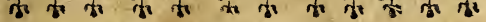
LE BON USAGE DU THE', DU CAFFE' E. T

\section{DU CHOCOLAT.}

SECONDE PARTIE.

Traitant de la Nature, des proprietés of du bon unfage du Caffé.

C.HAPITRE 1 .

Des lieux ò̀ on cultive le Caffe, de fa forme, ó de Jes differentes denominations.

7w e Caffé eft une plante qui croît en abondance dans le Royaume d'Yemen qui fait partie de l'A rabie heureufe, \& encore felon quelquies Au- 


\section{Le bon usage du Thé,}

teurs aux environs de la Mecque. Ses feüilles reffemblent en quelque forte à celles du cerifier, mais elles ont enco. re plus de rapport à celles de l'évonime qu'on nomme encore fufin, ou bonnet de Prêtre, avec cette difference neanmoins qu'elles font plus épaiffes \& plus dures, $\&$ qu'elles confervent toûjours leur verdeur. Le principal corps de cette plante, eft une forte de tige qui reffemble affez bien à celles de nos fèves domeftiques, \& en effet fon fruit qui eft affés du goût \&, de la confiftance de nos feverolles, eft renfermé au nombre de deux grains dans une petite efpéce de gouffe; c'eft pour cela qu'on 
du Caffé, o du Chocolat. 89 reconnoît ce fruit en Europe pour une efpece de fève Indienne. Quoyquil en foit, chacun en decidera cornme il luy plaira aprés l'infpection de la tige \& de la graine qu'on a fait reprefenter à la premiere page de cette feconde partie.

Cette plante fut reconnuë par les premiers Auteurs qui en ont traité, fous le nom de bon ou fous celuy de ban en bonchum, ou felon quelquiuns buncho \& buncha. Les Egyptiens l'appellent aflés ordinairement Elkaric, \& les Arabes Cachua, comme pour faire un diminutif de leur Cachaundiano, \& dont ils croyent qu'elle eft il'efpéce la plus menuë, \& c'eft apparemment 
90 Le bon ufage du Thé, par cette raifon quils ont nommé Caoua fa teinture, qui eft leur plus delicieufe \& plus ordinaire boifion, cepen-

- dant cette teinture à été plus generalement nommé Caphé ou Caffé, \& même à prefent on donne indiftinctement ce nom à la drogue \& à fa teinture.

Ce nom a neanmoins reçeu quelque corruption parmy certaines nations, car par exemple les Allemans écrivent plus volontiers Coffi ou Caffé; les Anglois Coffé, \& les Turcs Chaube, mais plus ordinairement Cabué, à caufe dequoy ils donnent aux lieux où il eft debité en détail, un nom Turc qu'on traduit en François Cavehannes, \& je

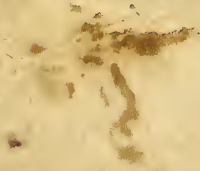


du Caffé, \& du Chocolat: , I ne doute pasau refte, que cetplante n'aye recer encore d'aurres noms en Europe ou ailleurs, mais rien ne m'engage à les rechercher tous pour es rapporter icy, \& le Lecteur era fans doute contant, quand aprés ce qui vient d'être dit; il apprendra que pour maccommoder à nôtre ufage, je comprendray dans ce traité fous le nom de Caffé, la plante, la graine, \& la teinture dont je dois parler.

A l'égard de la graine, elle a tant de folidité qu'on ne peut ny l'amollir ny la cuire, coit en la faifant tremper, foit en la faifant boüillir dans l'eau; c'eft pourquoy s'il étoit poffible de tirer de toute $f a$ fubftance une efpéce d'ali- 
92 Le bon usage du Thé, ment, il feroit beaucoup plits pefant \& plus indigefte que les differends ragoûts quon fait avec nos féves. J'ay obfervé neantmoins qu'elle n'eft qu'à peine un jour ou deux dans l'eau froide, fans jetter une efpéçe de germe, \& fans rendre une teinture verdâtre; ce qui détruit l'opinion de ceux qui pretendent que les Arabes la paffent fur le feu avant que de la negocier, à deffein d'en détruire le germe, \& d'empêcher par cette precaution, qu'elle ne foit cultivée dans d'autres païs; adjoûtez que cette obfervation eft foûtenuë de l'experience ; car Monfieur d'Errers qui fait icy un fort grand commerce de Caffé, affure qu'un 
du. Caffé, \& du Chocolat. 93 Gentilhomme de fes amis, en femé \& en cultive avec fuccez prés de Dijon depuis plucieurs années, qui vient dans a même forme que celuy d'Arabie dont il n'eft differend que par l'odeur, qui n'eft: pas beaucoup fi forte ny fi agreable.

\section{CHAPITRE II.}

\section{De la nature du Caffé.}

T E Caffé qui eft infipide lors quil eft encore en graine, ne laiffe pas d'avoir confiderablement d'amertume \& d'altriction, lors qu'il a été preparé pour l'ufage comme il fera dit cy-aprés, c'eft pourquoy je ferois obli- 
94 Le bon usage du Thé, gé d'expliquer icy la nature des amers, fi je ne métois acquité de ce devoir dans la premiere partie de cét opufcule, où je renvoye le lecteur, pour ne le point ennuyer par d'inutiles repetitions. Cependant pour ajoûter à la doctrine generale des amers, ce qui conftituë l'effence particuliere du Caffé, voicy ce que je dois faire remarquer. Si le Caffé en graine n'a point d'amertume, \& s'il n'en a. même que tres-mediocrement lors qu'il eft preparé pour l'ufage, il n'a auffi dans fa compofition qu'une tresmediocre quantité de particules acides; mais aufi comme il eft fort folide \& fort pefant il a pour principe predomi- 
du Caffé, \& du Chocolat. os nant, des particules terreftres que j’ay encore nommées Alkalis, ce qui n'empêche pas qu'il n'ait beaucoup de parties fubtiles, fermentatives \& tres-faciles à fe détacher. On l'a dû comprendre par ce qui a êté dit de la couleur verdâtre qu'il rend dans l'eau froide, \& il feroit difficile de le demontrer plus clairement, qu'en preparant cette teinture brune \& favoureufe qu'il rend dans l'eau bouillante, aprés qu'il a été roti \& pulverifé ; puifqu'elle fe fait dans un moment, \&z qu'il ne faut qu'une tres-petite quantité de poudre pour la rendre confiderablement chargée.

Par cette teinture brune on
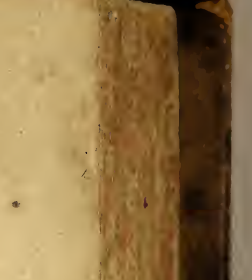


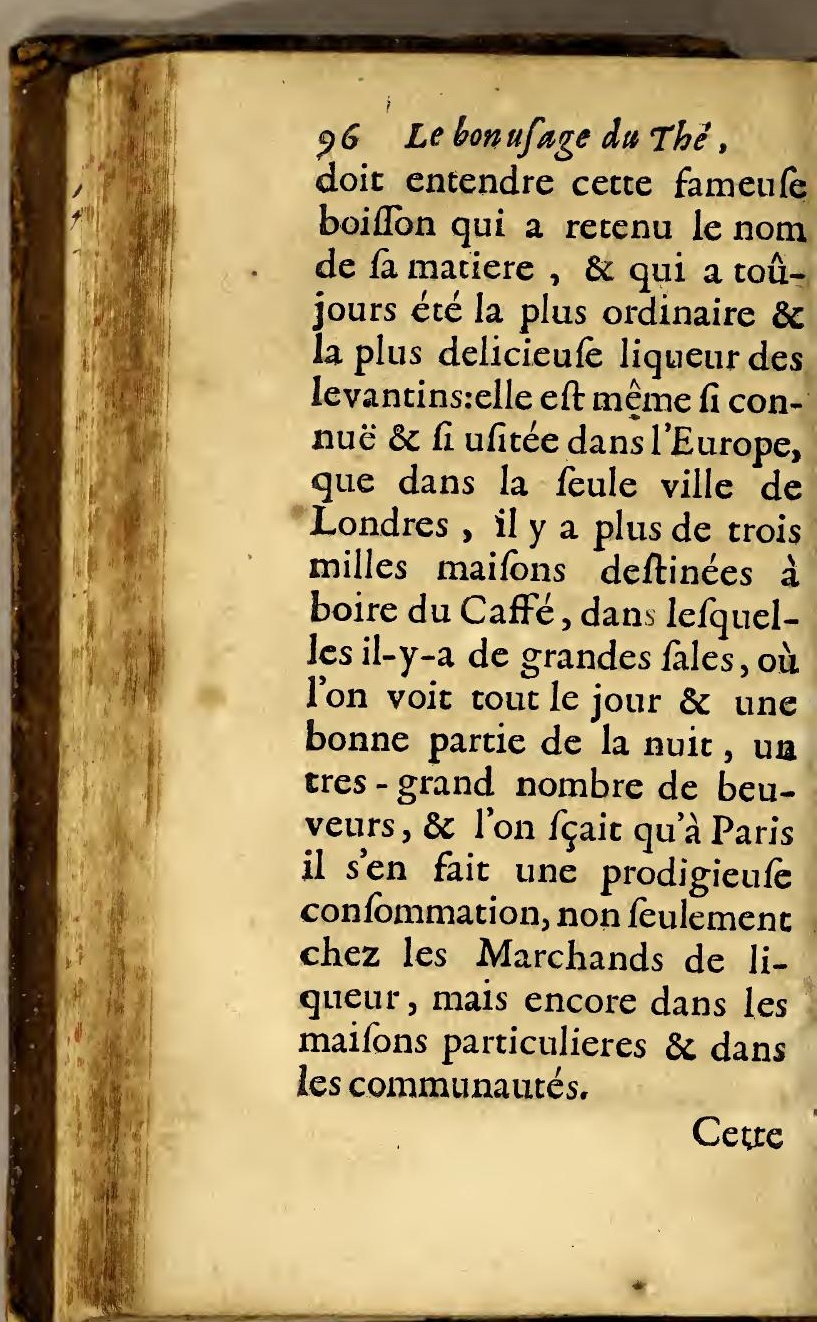


du Caffé, \& du Chocolat. 97

Cette boifion toute fimple qu'on ne prend que comme nourriture ou par forme de regal, ne laiffe pas d'avoir des proprietés medicinales, quila doivent faire confiderer au moins comme un aliment medicamenteux ; c'eft pourquoy elle feroit beaucoup mieux entre les mains des Artiftes que dans celles des Limonadiers, qui ne font pas affez experimentés dans la preparation des fimpleses pour conferver les parties plus effentielles de ceux qui paffent par le feu, ny affez fçavans dans l'art de guerir, pour être en état d'en prefcrire le bon ufage.

$\mathrm{Si}$ on obferve la couleur, l'odeur, la faveur \& la confiftance de cette boilfon, prin-

E 
98 Le bon usage du Thé, cipalement lors qu'elle eft preparée avec le lait, on fe perfuadera aifement, que les parties fubtiles \& delicates du Caffé font grafles \& étherées, puifqu'elles donnent à cette boifion une douceur en quelque forte onctueufe, \& qu'elles s'uniffent analogiquement avec les parties butireufes du lait fans les feparer de fa ferofité, ce qui arriveroit infailliblement, s'il y avoit dans cette teinture, aucuns autres principes predominans que les corpufcules étherez.

En effet la feichereffe du Caffé, nous perfuade qu'il n'a prefque point de corpufcules liquides; le peu de fel fixe quion en tire par l'incineration, nous allure qu'il n'eft pas 
du Caffé, \& du Chocolat 99 beaucoup chargé d'acides, la vertu qu'à fa teinture de defalterer $\&$ de defenyvrer,nous marque affés qu'elle n'eft pas abondante en corpufcules ignées; \& s'il eft vray qu'il foit dans fon tout beaucoup chargé de particules terreftres, les parties graffes \& étherés s'en détachent fi facilement dans l'extraction de fa teinture, qu'elles ne retiennent qu'une tres-petite quantité des plus legeres, \& que le refte fe precipite au fond du vaiffeau en forme de marc ou de foeres.

Voicy maintenant ce qu'on doit inferer generalement. parlant desobfervations precedentes.

- I. Le Caffé pris en fubranE ij 
100 Le bon ufage du Thé, ce fatigueroit extraordinairement l'eftomach, diminueroit le mouvement \& la fluidité de la maffe du fang, \& cauferoit neceffairement des obftructions dans les vifceres qui font pleins de vaiffeaux capilaires comme le foye \& la ratte.

2. Sa teinture mal depurée c'eft-à-dire trop chargée de fes parties terreftres, peut caufer les mêmes indifpofitions par un ufage continué.

3. Au contraire cette teinture preparée avec toute forte de precaution, doit être d'autant plus falubre, qu'elle ne contient que les parties plus fubtiles, plus douces \& plus étherées du Caffé, du moins fil l'on en excepte quel- 
du Caffé, \& du Chocolat. I o ques corpufcules ignées qui volatilifent fes parties, quelques particules acides qui font la faveur de fa teinture, $\&$ une tres-petite quantité de corpufcules terreftres qui fervent à lier fes fubftances volatiles, \& à leurs donner, que confiftance, fans quoy elles fe diffiperoient auffi-toft qu'elles ferolent agitées par l'air, ce qui narrive pas.

4. Les parties deliées, \& volatiles de cette teinture, ne fçauroient être agitées par le ferment de l'eftomach, fans être fublimées vers la tête en confiftance de vapeur, elles ne \{çauroient s'y porter, fans enlever avec elles le peu de particules terreftres qui leur donnent cette confiftance, \&

E iij 
102 Le bon ufage du The', les unes \& les autres ne fçauroient par cette fublimation abandonner les plus péfantes, c'eft-à-dire les plus terreftres $\&$ les plus folides, fans que celles-cy foient precipitées avec celerité dans les inteftins, jointes à l'eau qui avoit fervy à l'extraction de fa teinture, à laquelle elles fervent de vehicule, d'où refultent tous ces effers furprénans, qui caufent l'admiration des naruraliftes \& de ceux qui pratiquent actuellement l'ufage du Caffé.

5. Quoyque le plus ordinaire effet de la boiffon du Caffé, foit de corriger toutes efpeces d'intemperies; on voit neanmoins des perfonnes qui fe fentent échauffées par fon 
du Caffé, \& du Chocolat. 103 ufage, \& ils s'en trouvent d'autres au contraire, qui n'en fçauroient boire fans fouffrir des indigeftions, fans fe trouver univerfellement affoiblies, en un mot fans reffentir toutes ces incommodités, qui font ordinairement caufées par les alimens \& par les remedes qu'on dit être potentiellement froids.

Mais il ne faut pas croire que cette derniere obfervation, foit particulierement applicable au Caffé; on en peut dire autant des plus fimples \& des meilleurs alimens, qui rencontrent quelquesfois dans les parties ou dans le fang, des difpofitions qui ne s'accommodent pas avec leurs qualitez : c'eft pourquoy je E iiij 
104 Le bon ufage du Thé, tiens quil n'y a perfonne qui ne doive s'affurer fur l'ufage du Caffé, avant que de fe refoudre à le continuer, puifqu'il fe poumoit faire qu'il fe trouveroit des difpofitions particulieres \& contraires à fon action dans ceux mêmes à yui l'on pouirroit croire qu'il conviendroit le mieux, par rapport à leur conftitution univerfelle.

Je ne f̧̧aurois donc dire avec quelques Auteurs que le Caffé eft chaud, \& qu'il ne convient qu'à des perfonnes flegmatiques; ny avec d'autres, quil eft froid \& qu'il ne convient quaux bilieux \& aux fanguins; ny encore moins avec ceux qui veulent qu'étant de qualité tempe- 
du Caffé, \& du Chocolat. Iof rée, il foit generalement utile à toutes fortes de perfonnes; car je fçay au contraire quil fe trouve indifferemment entre les bilieux, les fanguins, les pituiteux, \& les melancoliques, des perfonnes à qui il fait du bien, \& d'autres à qui il fait du mal: c'eft pourquoy, bien qu'il foit vray quil $y$ aye peu d'alimens ny de medicamens fi generalement bon que le Caffé, chaque particulier doit examiner dans les premiers effais, fi par quelques difpofitions interieures \& inconnuës, il ne feroit point à fon égard dans le cas de l'exception. En un mot je ne fçaurois donner icy de regle plus generale \& tout enfemble plus raifonnable que celle E v 
106 Le bon ufage du The, de dire que chacun doit en continuer ou cefler l'ufage, fuivant le benefice ou les incommodités qu'il en recevia.

Cette regle generale a neanmoins comme toutes les autres fes exceptions; puifqu'il eft des perfonnes qui fans faire, aucune épreuve, peuvent s'affurer que le Caffé ne leurs conviendroit nullement, car par exemple celles en qui la nature à befoin d'une chaleur extraordinaire, ou (fi l'on ofoir ainfi parler) d'une efpéce de fiévre, pour faire la digeftion \& l'expulfion des impuretez ou des fuperfluitez dont elle eft opprimée, fe doivent abftenir de fon ufage, par cette raifon qu'il amor. 
du Caffé, \& du Chocolat. 107 tit les levains, au moyen defquels cette chaleur eft excitée. Ceux qui ont des infomnies caufées par une matiere inherente aux parties interieures de la tête, en doivent auffi être privez, puifqu'il augmenteroit ou que du. moins il entretiendroit trop long-temps le mouvement de ces matieres. Ceux qui font fujets aux crachemens de fang, ne pourroient en boire fans danger une confiderable quantité, puifque l'action de fes parties volatiles d'une part, \& celles de fes parties referrantes de l'autre, cauferoient des expectorations \& peutêtre des foulevemens d'eftomach qui les meneroient à des facheufes recidives celles 
ros Le bon ufage du The', en qui l'eftomach eft tresfoible, quile fentent pefant, \& à qui il donne des aigreurs $\&$ de rots, ne pourroient er ufer habituellement, fans s'attirer une facheufe indigeftion; car il ne fe pourroit que fes parties terreftres qui luy donnent la vertu d'amortir les levains, naffoibliffent le ferment digeftif. Les femmes enceintes qui font encore dans les premiers mois de leur groffeffe, \& celles qui font fujettes aux pertes de fang, n'en doivent faire pareillement qu'une ufage tres: refervé, car on fçait par experience qu'il a la vertu de pouffer puiffamment par la matrice.

On pourroit faire avec rai- 
du Caffé, of du Chocolat. 109 fon quelques inftances contre cette derniere obfervation ; fi aprés avoir dit que le Caffé n'a que tres peu defel fixe, je ne. rapportois la caufe de cette vertu Hyfterique à un autre principe, c'eft pourquoy je dois faire remarquer; qu'il ne faut pas conclure de cette petite quantité de fel fixe, que le Caffé aye trop peu de particules acides pour être un grand aperitif; car étant abondanten particules étherées \& volatiles, il ne fe pourroit que la plus grand part de fes acides, ne fuffent enlevées par fes parties volatiles lors de fa calcination, quand même on le brûleroit avant que d'en avoir excrấr la teinture; \& c'eft d'où vient que lors de certe 
I o Le bon ufage du Thé, extraction, la plus grand part de fes acides, fe détachent conjointement avec les particules étherées \& s'étendent avec elles dans le liquide, de maniere que cette teinture n'eft à proprement parler, que la diffolution \& l'extenfion d'une efpéce de fel volatile; Orfi on $f$ çait par experience, que les fels volatiles detachez de toute autre principe, font diaphoretiques \& fudorifiques; on fçait auffi qu'ils font diuretiques \& Hyretiques, lors qu'il fọnt unis comme däs la teinture du Caffé, avec des particules terreftres \& pefantes qui les precipitent.

Aprés ces obfervations, on comprendra facilement pourquoy le Caffé a toutes les ver- 
$d u$ Caffé, \& du Chocolat. III tus que j'ay attribuées au Thé, \& plufieurs autres encore qui luy font particulieres, \& que je deduiray incontinent; mais comme ce que j'en dois dire regarde l'ufage du Caffé, je dois auparavant parler du choix quion en doit faire, de fa bonne preparation, \& de quelques autres chofes auffi utiles; mais qui ne tiendront lieu que de fimples acceffoirs.

\section{CHAPITRE III.}

Du choix, de la torrefuation of du prix de la graine de Caffé.

E choix de la graine de Caffé ne confifte qu'en 


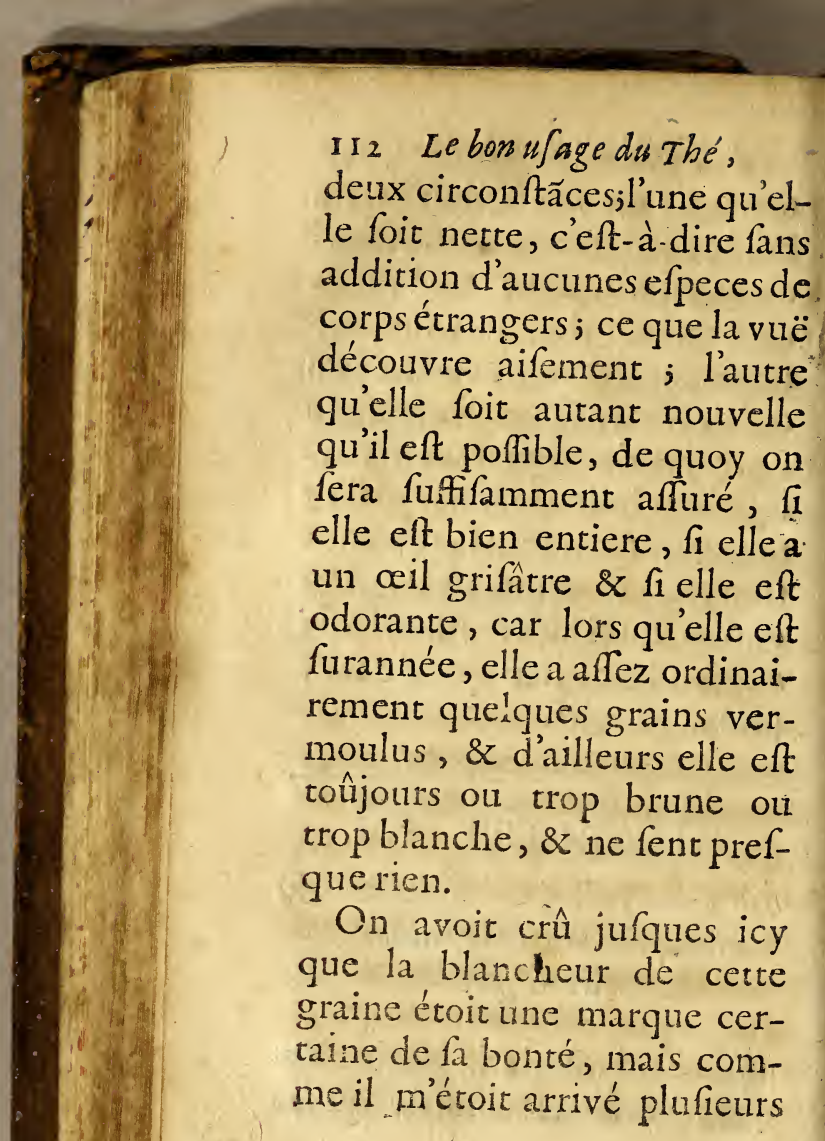


du Caffé, \& du Chocolat. I 13 fois d'en trouver de cette forte qui n'avoit pas la mointre odeur, \& dont la teinture étoit prefque infipide, je m'avifay d'engager un de mes amis qui étoit à Marfeille, de m'en envoyer de tout' frais debarqué \& de la meilleur forte, ne pouvant pas douter que celuy-là ne fut de beaucoup plus recent que celuy que nos droguiltestirent de Holandepar Rouen, par cette raifon que le premier eft tranf porté en trespeu de temps, de l'A rabie au grand Caire \& du Caire à Marfeille par la Mediteranée, au lieu que l'autre eft le plus fouvent un année entiere fur la grande Mer, \& beaucoup plus de temps encore dans les magafins des Holandois, pen- 
II 4 Le bon usage du Thé, dant quoy l'action de l'air peut bien enlever fa couleur grifâtre, que j’ay toûjours trouvée à celuy que jay fait venir de Marfeille, \& auquel jay trouvé moins de blancheur, mais beaucoup plus d'odeur, plus de goût \& plus d'efficacité, que dans celuy que je tirois auparavant de Roüen, d'où il en vient neanmoins encore une autre méchante efpéce qui eft d'un gris affés brun, \& qui n'a acquis certe couleur, que pour avoir êté expofée pendant plufieurs années, à toutes les ordures \& à toute la vermine du Magafin.

Quant à ce qui regarde le

* prix de cette graine, il y a quelque temps qu'elle fe negocioit en gros fur le pied de 
$d u$ Caffé, $\mathcal{e}$ du Chocolat. I's quarante jufqu'à foixante livres le cent, mais deptis cing ou fix mois, elle a monté jufqu’à quatre vingt; \& celle de la bonne fortefe vend dans le détail vingt quatre \& vingt cinq fols la livie, ce qui fait que les trompeurs font obligés de l'augmenter par l'addition des poix pour y trouver leur compte; car la preparation de la poudre de Caffe eft maintenant fi generalement connuë, que tous ceux qui en ufent habituellement fe feroient donné la peine de le preparer, fi les Marchands n'eufient reduit fon prix à quarante fols, fur lequel ils ne feroient prefque aucun profit, sils employoient du Caffé pur à vingt-quatre fols la livre, 


\section{6 Le bon ufage du Thé,}

trois livres de ce Caffé,ne produifant gueres plus de deux livres de poudre bien preparée.

Ce calcul joint à la fortune de quelques gens qui font commerce de Caffé m'ayant fait foupçonner cette fophiftication, je formay le deffein d'en découvrir le myltere, \& pour cela je fis brûler \& je tiray de la teinture de toutes nos efpéces de féves; \& en fuite de toutes nos fortes de pois. Je trouveray que nos fèves romaines, ou d'aricot donnoient une teinture tres-defagreable, \& qui n'approchoic en rien de celle du Caffé ; \& jobfervay que celle de nos grofles féves en approchoit un peu plus, celle de nos feve- 
dis Caffé, or du Chocolat. I I 7 roles, encore davantage, \& beaucoup plus encore celle de nos pois jaunes, \& fur tout ceux qui ne cuifent point.

Aprés cela ayant affecté en diverfes rencontres, d'entrer en converfation avec quelques gens faifant commerce de Caffé , \& de leur faire comprendre que je fçavois ce qui fe pratiquoit à l'égard de cette fophiftication, je me confirmay \& je me rendis même plus fçavant dans ce que j’avois prefumé, car plufieurs m'avoüerent qu'ils ajoûtoient en effer au Caffé une troifiéme partie de pois, mais qu'à cét effet ils preferoient les pois d'Efpagne, qui font jaunes comme les autres mais beaucoup plus petits. 
118 Le bon u fage du The',

Quant à la torrefaction du Caffé, la maniere dont elle fe fait ordinairement eft tresdeffectueufe. On met feulement cette graine fur un feu de charbon dans une baffine de cuivre étamé, ou dans une terrine de terre vermiffé, \& on la remuë continuellement avec un inftrument de fer, jufqu'à ce qu'elle foit fuffifamment rotie, c'eft-à-dire à peu prés à demie brulée, ce qui luy donne une couleur tannée fort obfcure. Alors on la tire du feu, \& on prepare enfuite la poudre, en la maniere qui fera expliquée dans le chapitre fuivant; mais je dois dire auparavaut que le Caffé en peut être rôti par cette methode, fans caufer la diflipa- 
du Caffé, \& du Chocolat. 1 I9 tion de fes parties plus étherées; plus volatiles, \& plus falubres; puifque cette diffipation eft neceffairement excitée parle feu, \& que ces rotiffoirs n'ont rien qui la puiffe empêcher, tellement que cette forte de Caffé, ne peut rendre qu'une teinture indigefte \& prefque ineficace.

11 y a deux fortes de perfonnes, qui ne reconnoiffent que trop fouvent cette verité par leur propre experience, fçavoir celles qui ont l'eftomach foible \& delicat \& celles qui ont de tres - puiffans levains \& de tres - fortes vapeurs, car dans les unes; le Caffé ainfi mal preparé caufe des indigeftions, des naufées, 


\section{Le bon usage du Thé,}

\& quelquefois le vomiffement même, \& dans les autres, il n'empêche prefque jamais la fublimation ny l'effet des vapeurs, c'eft ce qui a fait dire à Monfieur Sylveftre du Four, que ceux qui pourroient trouver le fecret de rotir la graine de Caffé, fans caufer la diflipation de fes parties volatiles, en tireroient une teinture de beaucoup plus agreable \& plus falubre, que celle de celuy qui eft roti en la maniere vulgaire; auffi avonsnous appris de Monfieur Bernier qui a beaucoup voyagé au Levant, qu'au Caire qui eft une des plus grandes Villes du monde, où il s'en confomme une prodigieufe quantité, les conmoiffeurs luy avoient affuré 
du Caffe', \& du Chocolat. $13 \mathrm{I}$ affuré qu'il n'y avoit que deux hommes qui euffent le fecret de le bien preparer, \& qui fuffent en reputation pour cela.

Quelques gens qui ont recherché ce fecret, ont inventé une forte de rotiffoir qui fe tourne à la broche, \& donc on fe fert dans la plûpart des grands Caffez de Londres; mais comme ces ro.tiffoirs, font de cuivre rouge, qui peut communiquer une tres-méchante qualité au Caffé , \& qu'ils fonc parfemez de troux dans toute leur étendü, bien loin d'empêcher la diffipation des parties volatiles du Caffé, on peut dire qu'ils y contribuent en quelque forte, car la broche dont ils font 
132 Le bon usage du The, traverfés étant placée devant le feu \& fur des chenets, comme celles qui fervent à rốcir la viande, il arrive que pendant qu'on la tourne, les parties du feu qui entrent par les trous qui font du côté de la cheminée, pouffent directement les parties volatiles du Caffé vers les trous qui leurs font oppofés, où elles ne rencontrent que les parties de l'air, qui ne peuvent pas refifter à l'action d'un auffi puiffant impulfeur qu'eft le feu; de forte qu'elles fe diffipent continuellement, fans même qu'aucunes d'elles puiffent être reverberées fur leur matiere, au lieu qu'en remuant le Caffé, dans une fimple poële, on oblige toûjours quelqu'unes de ces 
du Caffé, \& du Chocolat. I 33 mêmes parties à rentrer dans la maffe dont elles étoient iffuës.

Il eft vray que quelques perfonnes ayans reconnu ces inconveniens, ont fait faire ces rotiffoirs de fer \& non troiés, mais elles ont été bientốt contraintes d'en rejetter l'ufage, parce qu'elles ne pouvoient ainfi rotir le Caffé fans un fort grand feu, ce qui luy faifoit fentir le brulé d'une maniere tres-des-agreable.

A mon égard j'ay inventé une nouvelle maniere de rotir le Caffé, dont le lecteur profitera fans doute avec plaifir; elle confifte à un double rotiffoir qui eft auffi à la verité traverfé par une broche, \& troüé en bien des endroits, mais qui fe place dans un four- 
134 Le bonusagedu The', neat de reverbere conftruit exprés, en forte que fon amplitude n'excede le volume du. rotiffoir, que de l'efpace de trois doigts dans toute $f a$ circonference; outre que d'ailleurs les trous des deux tuyaux de ce rotiffoir, font difpofés de telle façon, que ceux du premier tuyau ne font pas visa-vis ceux du fecond, étant au contraire directement oppofés aux efpaces pleines qui font entre ceux-là; Si bien que ces efpaces reverberent la plus grande partie des particules volatiles qui en fortent, \& que quand les autres fe viennent prefenter aux trous du fecond tuyau, elles font en quelque forte repouffées au dedans, par les parties 
du Caffe, \& du Chocolat. 135 du feu qui agiffent continuellement fur toute la furface pendant même que la broche tourne, au moyen du reverbere dont le fourneau eft couvert.

Au furplus, commeles fourneaux du reverbere confervent parfaitement bien la chaleur, on n'eft pas obligé dans celuy - cy de rotir le Caffé avec un feu ardent, \& l'on peut même (comme jay'fait) trouver fi juftement la quantité, le degré, \& le temps du feu qu'on doit donner, qu'aprés fon entiere confommation, le Caffé fe trouve precifement roti au degré qu'il le doit être; d'où refulte deux avantages confiderables : la premier que le Caffé roti a 


\section{Le bon ufagedu Thé,}

une douce chaleur, n'a point cette facheufe acrimonie quion trouve ordinairement dans celuy qu'un feu violent a impregné de particules ignées: P'autre que le Caffé torrefié fans aucun excez dans le plus ny dans le moins, eft d'autant plus falubre que quand il l'eft trop peu, fa teinture eft pefante \& indigefte, \& qu'au contraire quand il l'eft trop, elle eft amere terreftre \& par confequent aftringente dans un degré excedent.

Au furplus, je donneray bien-toft au public une nouvelle machine, qui fera encore preferable à celle icy done par cette raifon je me difpenferay de donner la figure. 


\section{du Caffé, \& du Chocolat. 137.}

\section{CHAPITRE I V.}

Du choix, de la confervation, \& du prix de la poudre, ou farine de caffé.

T Es regles que jay données dans le chapitre precedent, pour le choix de la graine du Caffé, font plus que fuffifantes pour ceux qui ne veulent point être trompés à cét égard; mais il n'eft pas à beaucoup prés fi facile, de les mettre en état de precaution, contre les furprifes de ceux qui vendent la poudre fophiftiquée en la maniere qui a êté ditte; puifqu'on ne peut principalement diftinguer cette poudre, de celle qui a été

F iiij 
1.38 Le bon usage du Thé, fidellement preparée, que par une odeur particuliere, fur laquelle il m'eft impoffible de m'expliquer clairement, \& fur laquelle il ny a que la deliçateffe de l'odorat \& une longue experience, qui puiffent établir une connoiffance certaine; ainf tout ce que je puis dire à cét égard, eft que fi on la trouve fort odorante, \&z quion puifle reconnoitre par fa couleur, fi la graine na été trop, ny pas affés rotie, on pourra croire qu'elle eft du moins paffable; mais le meilleur feroit de n'en prendre quo de gens dont on foit affurés, ou du moins de la preparer foy-même.

Pour y proceder avec toute la precaution polfible, il ne 
du Caffé, of du Chocolat. i 39 faut pas à l'exemple de quel'ques gens, la piler fimplement dans un mortier, \& la paffer dans un tamis découvert, car de cette façon, on ne conlerve pas bien fes parties volatiles; c'eft pourquoy il eft beaucoup mieux de la broyer dans ces fortes de Moulinets qu'on fabrique exprés, \& qu'on trouve chez les Quincalleurs, encore faut-il quaprés avoir mis la graine de Caffé dans un de ces moulinets, on recouvre fon embouchure, avec un couvercle de tolle de fer ou au moins de fer blanc, ayant des bords comme le couvercle d'une boëte, \& ayant un trou dans fon milieu feulement affés grand, pour donner paffage a 


\section{Le bon ufage du Thé,}

la tige du moulinet.

C'eft encóre une negligence blamable, que de mettre fimplement un plat, une terrine, ou quelque femblable vaiffeau au deffous du moulinet pour recevoir la farine, comme on le pratique affez ordinairement, car de cette maniere, cette farine fe trouve expofée à l'air durant un temps afrés confiderable, pour perdre beaucoup de fes parties volatiles; c'eft pourquoy il eft mieux d'avoir une bourfe-de cuir, dont l'entrée foit attachée à la circonference du culdu moulinet, en forte que la farine qui y tombera, ne puiffe être atteinte en autcune façon par les parties de lair. Il faut tout de même 


\section{du Caffé, \& du Chocolat. I 41} qu'elle foit mife enfuite dans un tamis exactement couvert, \& que les parties groffieres qui nont pû traverfer les pcres du tamis, foient de nouveau broyées dans le moulinet avec les mêmes precautions, ou du moins pilées dans un mortier exactement couvert; en un mot on ne f̧̧auroit donner trop de foin pour conferverces parties volatiles, qui rendeni le Caffé bien prepar é auffi falubre \& aufli agreable, que celuy qui eft negligemment aprefté eft dégoutant \& pernicieux.

$$
\text { Aptés avoir dit tant de fois }
$$
que les parties volatiles du Caffé, fe détachente tres-facilement de fes parties plus materielles, \& quil eft nean- 


\section{Lebonufage dia Thé,}

moins tres-important de prevenir ce detachement partoute forte de moyens, le lecteúp a dû comprendre, que ce n'eft pas affez d'avoir preparé fa farine avec toutes les circonRtances prefcriptes, mais qu' il faut encore la conferver pout l'ufage avec de nouvelles preeautions, en quoy les Marchands de Caffé ont accousumé de pecher, car aprés avoir pefé cette farine par demy livres, ils fe contentent de l'envelopper dans un fimple papier gris, \& de l'expofer ainfi dans leurs boutiques. Il eft beaucoup mieux de la conferver dans les poches de cuir à donbles coutures \& bien fermées, comme on faifoit il y a gruelque temips, \& 
du Caffé, \& du Chocotat. 143 encore mieux comme on fair maintenant dans des boëtes d'Allemagne fermant; a vis, \&x doublées de plomb \&a de cuir rouge, mais avec tout cela il eft encore à propos que les Marchands \& les particuliers ne saprovifionnent pas trop de cette farine, \& qu' à chaque fois ils n'en preparent quautant quil en faut, pour la confommation quils en peuvent faire en deux ou au plus en trois mois.

Jay déja dit que le prix ordinaire de la poudre de Caffé, eft de quarante fols la livre, \& que ce prix eft trop modique pour la fubfiftance des Marchands quila preparent fidellement, c'eft-à-dire avec la meilleure graine \& fans au- 
I44 Le bon ufage du Thé, cune addition; ainfi ceux qui feront affurés de la probité de ces Marchands, ne doivent pas hefiter à la payer un écus ou au moins cinquante fols la livre, à moins qu'ils ne fuffent dans les lieux où la graine de Caffé foit moins chere quà Paris. Les artiftes de nôtre Laboratoire, qui rotiffent le Caffé avec le rotiffoir \& dans le fourneau dont il a été parlé, $\&$ qui par cette raifon diftingue fa poudre par le nom de Caffé volatile, en ont fixé le prixà un écu la livrę.

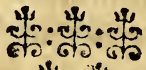

$$
\begin{aligned}
& \text { ส้. ने के } \\
& \text { }
\end{aligned}
$$




\section{du Caffé, \& du Chocolat. 145}

\section{CHAPITRE V.}

De la preparation de la teinture ou boiffor de caffé, do de for ufage en general.

T Es precautions qu'on doit prendre pour conferver les parties volatiles du Caffé, fedoivent étendre jufque à la preparation de fa teinture. Pour cela il faut obferver.

I. De ne mettre la poudre dans la Caffetiere que quand l'eau commence à bouilliri car en la mettint avec l'eau froide, il ne fe pourroit que beatcoup de ces mêmes parties ne fuffent diffipées, avant que le feu eut excité le premier boüillon. 
I 46 Le bon ufage du Thé,

2. D’empécher que l'écume qui monte incontinent aprés ce premier boüillon, ne fe repande hors de la Caffeterie, ce quion évite en la tenant exactement bouchée \& en la remuant de moment à autre, deux chofes qui fervent merveilleufement à faire rentrer dans la liqueur, les parties fubtiles qui s'élevent pendant l'ébullition au deffus de fa fuperficie.

3. De ne la faire boüillir qu'environ la troifiéme partie d'un quart d'heure, une trop longue ébullition,forçant toûjours quelques parties volatiles à s'échapper par les jointures du couvercle.

4. En un mot qui voudroit aller la deffus au dernier raffi- 
du Caffé, or du Cborolat. I 4.7 nement, devroit preferer au feu de bois ou de charbon, celuy de.la flâme de l'eau de vie rectifiée, quion fait brûler. commodement à cét effer dans des fourneaux d'argent ou de fer blanc, aufquels font jointes leurs Caffetieres, \& qui font fi legers \&z en fi petit volume, qu'un voyageur les peut porter conhmodement dans la poche, avec la taffe, le Caffé, le fucre \& l'eau de vie. Ceux de fer blanc qu'on tire d'Angleterre font beaucoup mieux travaillez que ceux qu'on trouve à $\mathrm{Pa}$ ris, outre que le fer blanc des Anglois, eft Eftamé avec une Eftoffe beaucoup plus fine que le nôtre, ce qui fait qu'il refifte mieux au feu, mais 


\section{Le bon ufage du The',}

aprés tout, ils n'ont en France \& en Angleterre qu'une même forme, que $\mathrm{j}$ 'ay fait reprefenter icy en faveur des perfonnes de Provinces qui n'en ont pas encore vî, non feulement tels qu'ils font lors que toutes leurs piéces font affemblées; mais encore d'une façon propre à faire voir diftinctement chacuhe de ces piéces, dont on expliquera l'ufage à la fin de ce livre, auffi bien que de toutes les autres figures que jay données.

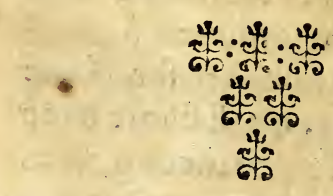


Iso Le bon ufage du The',

Outreces Caffeteries à four. neaux de la façon commune, j'er ay encore inventé d'une nouvelle efpéce qui font plus portatives, \& dont on fera bien aife de voir icy la figure, en attendant que jaye publié la machine dont jay déja parlé, \& dont ce fourneau portatif n'eft qu'une legere idée, l'ufage de celle-là etant infiniment plus étendu, ainfi qu'on l'apprendra par l'explication que je feray publier.

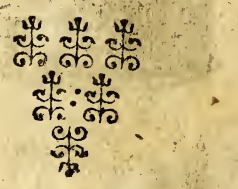




\section{du Caffé, of du Chocolat. I5! .}

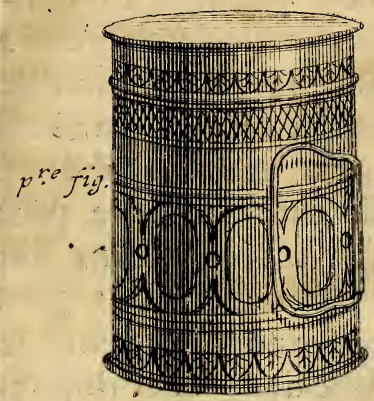

pug. 152

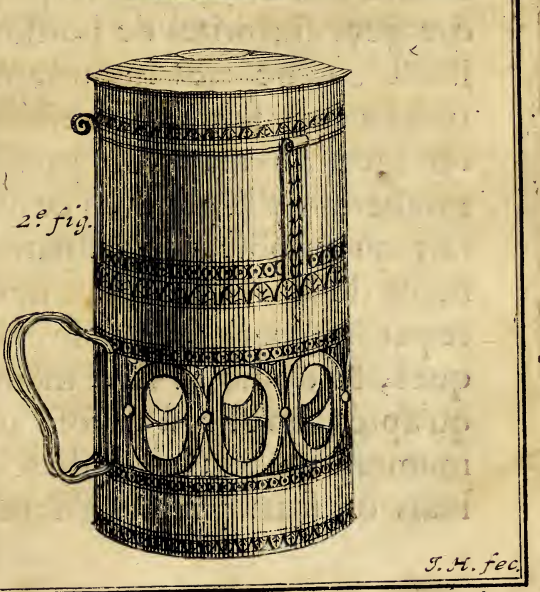

etiere portatiue pour la preperation our l'viage du cajé se. 
IS 2 Le bon ufage du Thé,

Ce n'eft pas affés de conferver les parties volatiles du Caffé dans la preparation de fa teinture, car pour rendre auff legere aufi diftributive \& auffi falubre qu'elle peut l'être, il faut qu'elle ne foit que mediocrement chargée; c'eft pourquoy il fuffit de mettre une demy once de poudre pour fix prifes de boilfon; il eft encore tres-important, qu'elle ne foit aucunement chargée du marc ou parties groffieres de la poudre; ce qui fait qu'on obferve ordinairement de la verfer doucement \& par inclination dans le chiques, \& de ne le faire même quaprés qu'elle à repofé un moment uu peu loing du feu; mais on fçait par experience 
du Caffe, 20 du Chocolat. I 53 que ces precautions ne font pas fuffifantes, pour avoir une teinture bien depurée, à caufe de quoy je me fers encore de deux moyens dont il eft bon que le public foit informé. Le premier eft d'accelerer la precipitation de ces parties groflieres, en jettant quelques goutes d'eau froide dans la Cafferiere au moment quion la retire du feu; lautre eft de preferer à toutes efpéces de Caffetieres, une forte de Caffetiere de fer blanc que jay inventée, \& qui eft conftruite de telle forte, qu'elle a vers fon fond une amplitude, qui fert merveilleufement à retenir le marc de fa teinture, lors qu'on la yerfe dans la chique, \& de plus 
I5 4 Le bon ufage du Thé, encore une efpéce de filtre à fon bec, qui ne donne paffage quaux feules parties de la liqueur. La premiere figure de la planche qui fuit, reprefente cetre efpéce de Caffetiere, \&. les autres figures defignent la forme de toutes les autres efpéces de Caffetieres qui font en ufage, \& qui peuvent auffi bien que celles-là, indifferemment à la preparation du Thé \& du Chocolat, ce quion comprendra mieux par ce qui en fera dit dans la troifiéme partie de ce livre.

Cette 


\section{Is 6 Le bon ufage du The',}

Cette liqueur feule a une amertume \& un goût de brûlé, qui la rend tres-defagréable, fur tout à ceux qui n'y font pas habitués; c'eft pourquoy ordinairement on y ajoûte pour chaque prife une demie cueillerée defucre en poudre; ce qui fait une liqueur à laquelle on n'a pas de peine à s'accoûtumer : neanmoins ceux qui par une faulle prévention, croyent que le fucre eft échauffant de quelque maniere qu'il puiffe être pris affectent de ne la point fucrer, croyant que de la forte elle eft beaucoup plus falubre; mais ils reviendroient bien-tôt de cét erreur, s'ils avoient auprés d'eux de veritables Medecins, qui leurs fiffent comprendre 
$d u$ Caffé, \& du Chocolat. 1,57 que le fucre eft une efpéce de fel effentiel, que les acides font les principes dominans de toutes efpéces de fels, que la proprieté effentielle des acides eft de rafraîchir, \& que fi la Chimie nous fournit des efprits acides qui font caufiques \& brûlans, comme l'efprit de Nirre \& l'eau forte; c'eft parce que ces efprits font des efpéces de mixtes, qui abondent d'ailleurs en particules ignées, qu'on peut écarter \& affoiblir fuffifamment, pour faire de ces mémes efprits des liqueurs tres-rafrầchiffantes, en y ajoûtant un volume d'eau confiderable: car aprés cela ces Medecins leurs perfuaderoient aifément, que les mêchans effets de lu-

$\mathrm{G}$ ij 
I 8 Le bon usage du Thé, fage immoderé du fucre, dependent de la vertu relâchante \& affoibliffante de fes parties mufilagineufes, \& que cette vertu eft fuffifamment détruite, lors que ces mêmes parties font defunies \& écartées par un certain volume de liqueur; outre que la vettu aftringente \& refervante du Caffé, eft tellement oppofée à celle que je viens de dire, qu'il ne peut refulter de ce mé. lange qu'une qualité moyenne; celt pourquoy on peut fans inconvenient confulter fon goût, fur l'agrément qu'on veut donner au Caffé par l'addition du fucre; mais il eft meilleur qu'on l'aye auparavant reduit fous les differen- 
$d u$ Caffé, \& $d u$ Chocolat. 159 tes formes de firops dont il fera parlé cy-aprés.

On feroit beaucoup plus mal fi à l'exemple de quelques perfonnes voluptueufes; on ajoûtoit à la Boiffon de Caffé l'effence d'Ambre, les poudres de Canelle, de Gerofles \& de Cadamome, ou quelques efpéces de Parfums ou de drogues aromatiques que ce foit; parce que le mouvement de leurs parties volatiles, prévalant fur celuy de celles de Cáffé, elles en interrompent l'action, \& privent ceux qui en ufent des bons effets qu'ils en efpérent.

Au refte on ne prepare ordinairement la boifion de Caffé, que dans le temps méme qu'on veut en ufer, \& à la $\mathrm{G}$ iij . 
160 Le bon uJage du The', verité on fait bien d'obferver cette maxime, la plus nouvelle faite étant toûjours la meilleure; mais on pourroit neanmoins fans beaucoup d'inconvenient à l'exemple des Marchands de liqueur, préparer cette boiffon le matin, \& la garder pour fervir au befoin pendant toute la journée, pourvî qu'elle foit toûjours entretenuë chaude dans une Caffetiere exactement fermée ; car lors qu'elle a été une fois refroidie, elle perd. fon bon goût \& fes qualités, quiil n'eft pas poffible de luy reftituer en la réchauffant, ny même en la faifant boüillir de nouveau. C'eft pourquoy comme on fait un affés grand ufage de cette boiffon 
du Caffé, o du Chocolat. I G:I en nôtre laboratoire, auffi bien que de celle du Thé \&z du Chocolat, j’ay inventé une forte de fourneau qui au moyen d'une lampe à trois petites mêches, peut entretenir fort chaudes pendant tout le jour ces trois fortes de boîffons, \& cela d'autant plus commodément que cette chaleur eft toûjours égale, \& quielle eft entretenuë à peu de frais. Les curieux feront fans doure bien aife de trouver icy la figure de ce fourneau que jay fait reprefenter icy pour leur fatisfaction.

G iij 


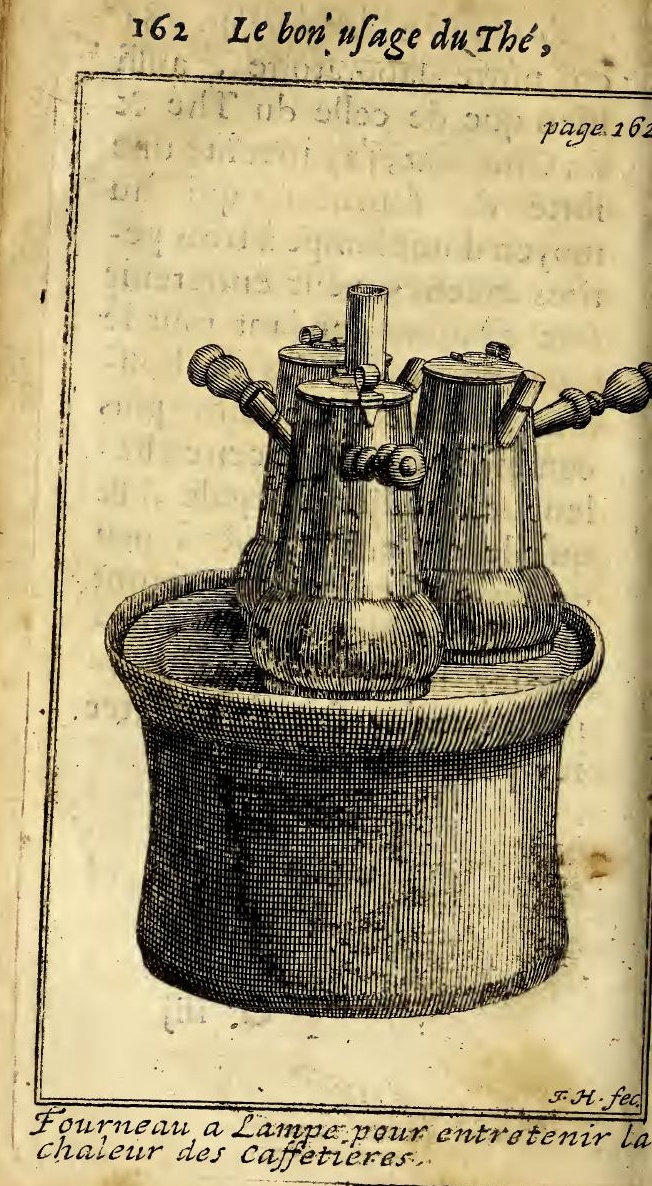


du Caffé, \& du Chosolat 163 Si la boiffon de Caffé qui eft entretenuë chaude durant un temps confiderable par ce moyen, ou par quelques autres équivalents, n'eft guere moins bonne que celle qui eft faite fur le champ, il n'en eft pas ainfi de celles que préparent les Marchands interefiès, avec le marc dont on a déja tiré une premiere teinture; car on ne peut tirer de ce mare qu'une purée indigefte, obAtuante \& fans aucune vertu; il eftvray que ces Marchands ajoûtent ordinairement à ce même marcun peu de nouvelle poudre; mais cette addition ne fere quà brendre un peu moins mauvalife une chofequi de foy feroit déteftable, n'y ayant aucun aliment dont G y 
I64 Le bon ufage du Thé, l'ulage foit plus à craindre que la boiffon de Caffé, renduë indigefte par une préparation negligée; c'eft pour cela que les Peuples du Levant n'obfervent pas feulement la maxime de ne la point laiffer refroi ir; mais encor celle de la boire auffi chaude qu'il eft pofible, \& même doucement $\&$ à diverfes reprifes, pour ne point fatiguer l'eftomach:c'eft de cette maniere de la prendre dont Thevenot entend parler dans la Relation de fes Voyages, quand il dit que dans les Caveannes du Levant, on entend une affez plaifante Mufique de humerie; mais outre cette Mufique. Hl eft encore des Caveannes en Turquie, où les Maîtres entre- 
du caffé, \& du Chocolat. 165 tiennent une fimphonie de voix \& d'inftrumens pour donner du plaifir à leurs Buveurs.

Cependant on ne peut douter que le Caffé dont ils ufent ne foir beaucoup plus chargé ( que celuy qu'on nous apporte ) des parties volatiles qui en doivent faire toute la bonté \& toute la delicatefle ; \& en effet Monfieur. Bernier qui n'avoit pû s'accommoder de celuy qu'on luy avoit prefenté plufieurs fois en Egypte, trouva fi excellent celuy quil but dans les Ports de l'Arabie Heureufe, qu'il en prenoit tous les jours avec plaifir cinq ou fix taffes. Ce Medecin affure que dans les Indes \& dans la Perfe on n'en ufe que trespeu \& feulement dans les Ports 


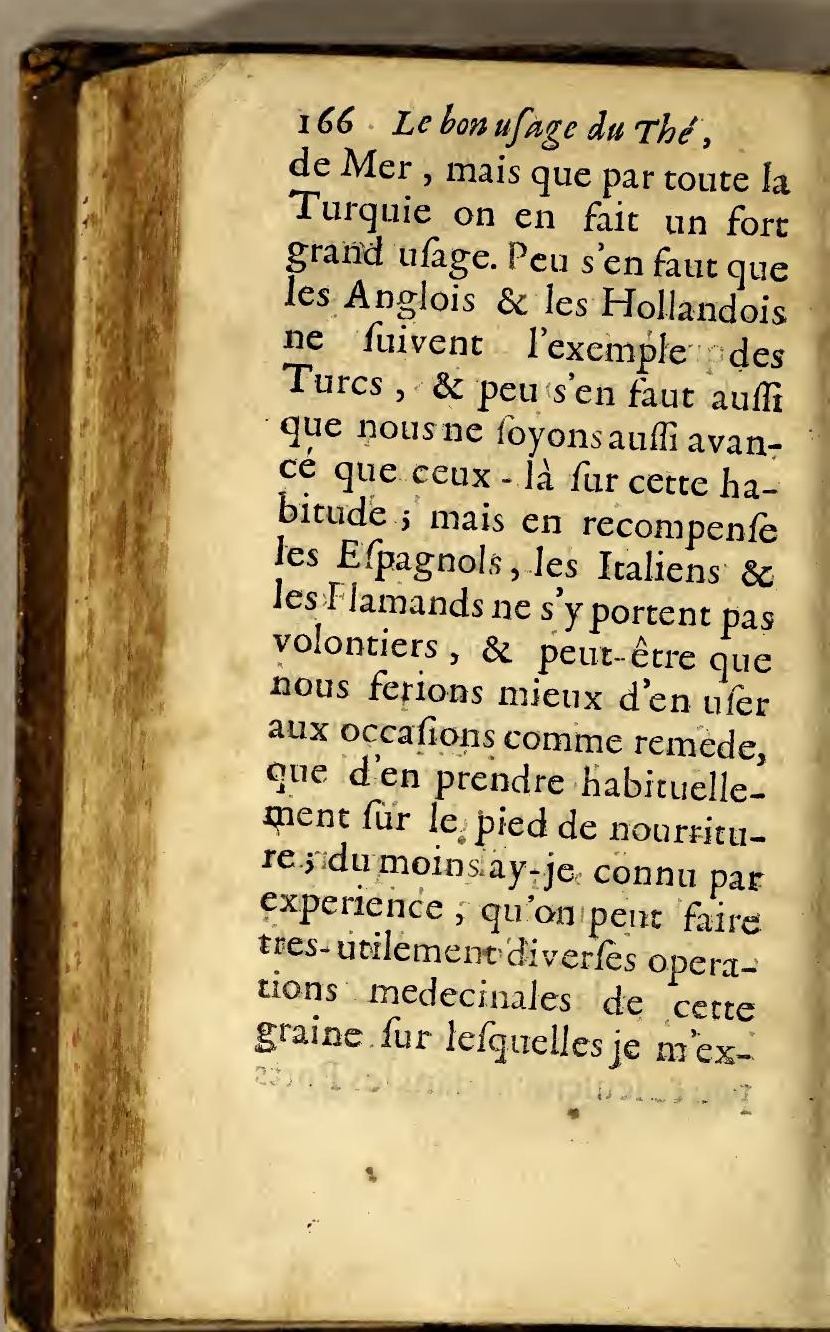




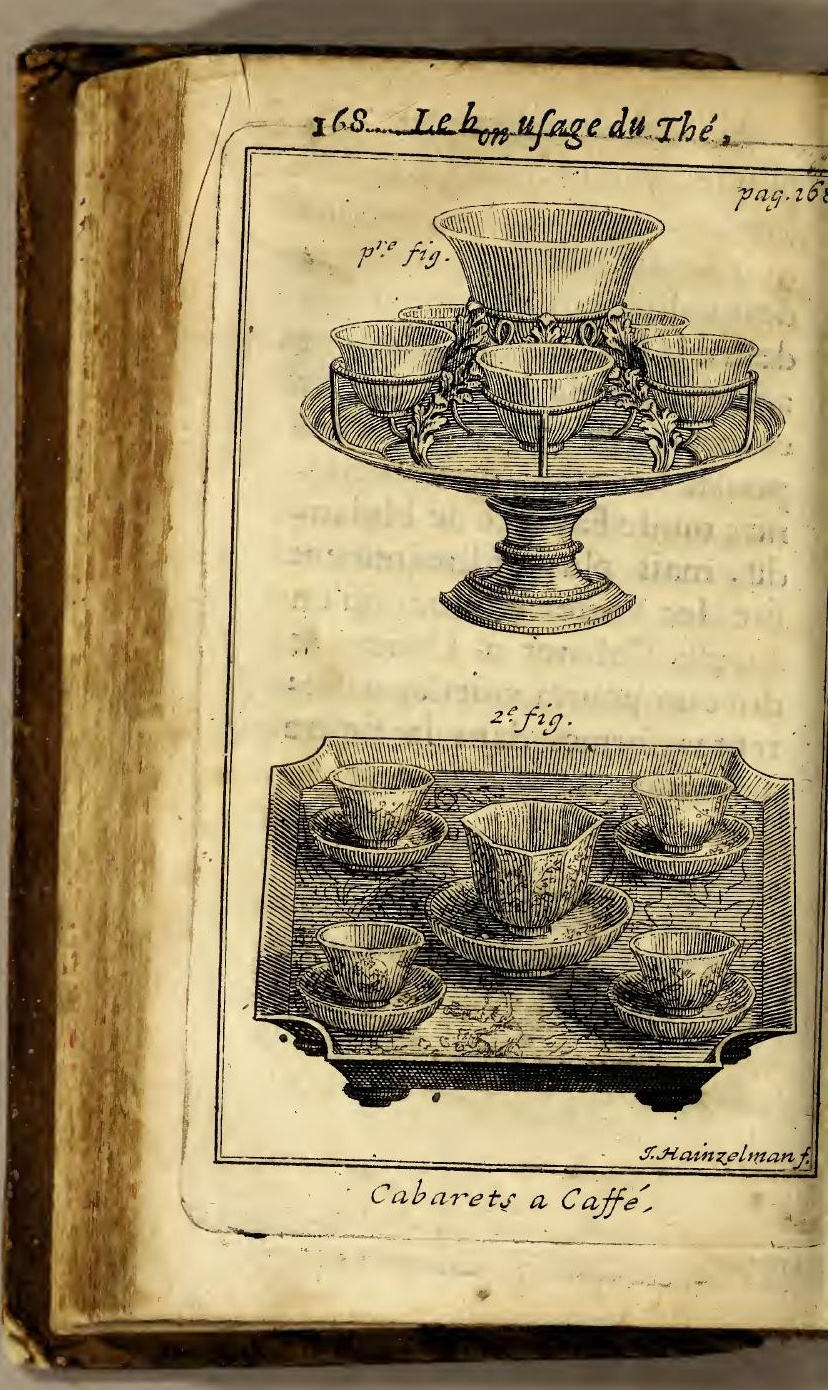


du Caffé, \& du Cbocolat. I 69 Au furplus c'eft l'opinion de plufieurs grands perfonnages que la boilfon de Caffé ( non plus que les autres breuvages familiers ou domeftiques ) ne rompt point le jeûne, pourvî. qu'on la prenne par une efpéce de neceflité, \& nullement à deffein de faire fraude aux Commandemens de l'Eglife; fi bien que les perfonnes foibles, \& celles qui font tombées dans une efípéce d'inanition, en peuvent tirer un fecours d'autant plus confiderable dans les jours d'abftinence, qu'elle émouffe la faim, \& qu'elle foutient le coeur plus que toute autre buiffon, c eft peut-être par cette raifon que les Turcs qui fe picquent d'être fort religieux, croi- 
I70 Le bon ufage du Thé, roient avoir rompu leur jeûne, s'ils en avoient fenty la fumée pendant le Rhamadan, qui eft l'efpéce de Carême ordonné par Mahomet.

\section{CHAPITRE VI.}

Des preparations Medecinales: du caffé.

\section{-1 anour du Caffé}

Es preparations mediciL nales du Caffé que jay inventées, \& que jay mifes en pratigue avec beaucoup de fuccez, fone fes fels, fon huile fixe, fon eau diftillée \& fon frop : jay défa parlé de fosfels dans le traité du Thể, où je nie fuis refervé à donner dans le Journal de Medecine, la matiere d'extraire l'effen- 
du Caffé, \& du Chocolat. I7I iel, \& où j’ay dit que le fixe e tiroit comme tous les aures par incineration, l'exivaion, filtration, evaporation $x$ cryftalifation, ce qui doit uffire à cét égard, puifque ien n'eft plus familier aux ariftes que ces operations, \& quapparemment nulle autre perfonne ne fe voudroit donner la peine de le pratiquer.

Quant à l'huile fixe du Caffé ; voicy la maniere de la preparer. Prenez une livre \& demie de graine concaffée, rempliffez-en les deux tiers d'une cornuë de verre bien luttée, placés-la au fourneau de reverbere, adaptés-y un grand bâlon ou recipient, \& aprés avoir lutté exactement les jointures, donnés le feu par de- 
172 Le bon ufage du The', grés, il en fortira premierement un flegme comme de l'eau, puis des vapeurs d'un jaune tirant fur l'Oranger, \& enfuite une matiere terreftre \& noirâtre, qui eft l'huile dont il s'agit, aprés l'extraction de laquelle vous laifferés refroidir les vaiffeaux, \& les ayant deluttez, vous feparerez cette huile parle filtre, puis fi vous voulez la rectifier, vous en ferez une forte de pâte avec une quantité -fuffifante de fable que vous mettrez dans une cornuë, \& l'ayant placée dans un fourneau à feu nud, yous en ferez la diftillation felon lare.

C'eft un bon remede con-: tre les maladies hyfteriques. On la donnera prefque toû- 
du Caffé, of du Chocolat. 173 jours avec fuccés à la quantité dé fix ou huit gouttes avec trois onces d'eau d'armoife dans la fuppreffion des menftruës, dans la jauniffe ou jcterite, \& dans toutes les efpéces de fuffocations de matrice : jay connu méme par experience que fa feule vapeur receuë par le nez abaiffe tresefficacement les vapeurs uterines. Elle n'eft pas moins bonne pour refoudre les tumeurs froides, \& pour diffperles douleurs des jointures, êtant mêlée avec une troifiéme partie de nôtre efprit de vin Corallin, \& appliquée fur les parties tumefiees ou douloureufes.

Pour ce qui eft de l'eau diftillé, elle eft d'une prepara- 


\section{Le bon trage du Thé,}

tion tres-facile. Jettez dans deux pintes d'eau boüillante, une dragme de fel fixe de Caffé, \& trois onces de fa poudre ou farine, faire boüillir le tout durant un bondemy quart d'heure, puis l'ayant tiré du feu, \& le marc étant affaiffé, verfés par inclination cette teinture dans un Alembic de verre, \& y ayant adapté un chapiteau \& un recipient, \& lutté les jointures avec de la colle \& du papier ; diftilés au Bain-marie, \& gardés pour l'ufage dans une fiole bien bouchée, l'eau que vous trouverés dans le recipient. On peut s'en fervir en place d'eau d'armoife avec l'huile de Caf$f^{\prime}$, contre toutes les maladies Hyfteriques dont il vient d'ê- 
du Caffé, or du Chocolat. 175 tre parlé. Il arrive auffi quelquefois qu'en la donnant au poids de quatre onces au commencement de l'accez, elle guerit en affez peu de prifes les fiévres intermittantes; c'eft pourquoy il feroit difficile de trouver un Vehicule plus ef- * * ficace, lors qu'il s'agit de donner le firop de The febrifuge.

A l'égard du firop de Caf$f^{\prime}$, voicy la maniere de le preparer ; tirez la teinture d'une once \& demie de Caffé, avec une pinte d'eau \& une dragme de fon fel fixe, en la maniere cy-devant expliquée, \& par la même methode tirés pareillement la teinture d'une once de fleurs de Noyers avec une pinte d'eau, \& une drag- 
I 76 Le bon usage du The', me de fel effentiel de Caffé, puis ayant niélé vos teintures, \& y ayant ajoûté dix clouds de Gerofles, \& fix grains de Cardamome, paffés le tout par un double linge, ou par une chauffe claire \& netre, puis l'ayant mis dans une baffine avec cinq livres de fucre fin, cuifez vôtre firop jufqu'en bonfiftance, obfervant de le cien "écumer, mais fans autre clarification.

On le peut prendre feul a la quantité de deux cueillerêes; mais la plus ordinaire $\&$ la meilleure façon d'en ufer, eft de le mettre en la place de fucre dans le Thé, ou dans la boiffon même de Caffé, environ à la quantité d'une cueillerée pour chaque prife. 
du Caffé, \& du Chocolat. $I 77$ Comme il tient du moins autant de la nature de l'aliment que de celle du remede; on peur le prendrede l'une ou del'autre maniere indifferemment à toutes.les heures du our; mais il eft neanmoins d'un effet plus fenfible lors qu'on le prend de matin à eun, ou dans d'autres témps aprés que la digeftion eft faite. Il remedie tres-efficacement dans les deux fexes, à toutes lês efpéces d'indifpofitions qu'on attribuë aux vapeurs du foye, de la ratte, \& de la matrice, \& par confequent awx maladies hypocondriaques \& aux fuffocations de matrice, ou maux de mere, aux fureurs uterines, \& generalement à toutes les pafions

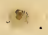




\section{Le bon ufage du The',}

hyfteriques : ce qui vient de la vertu qu'il a de lever puiffamment les obftructions, \& d'amortir promptement les levains, qui caufent dans ces vifceres des fermentations contre nature.

C'eft pourquoy on en peut encor ufer̀ avec beaucoup de fuccés dans les fiévres intermittantes, dans les maladies des reins \& de la veffie, dans les Coliques bilieufes, dans la Goutte, dans les Rhumatif- mes, dansle Scorbut, dans les Ecroïelles, dans la Migraine, dans toutes autres efpéces de maux de têre, \& même dans les inquietudes, \& dans les infomnies qui font caufées par une ferofité irritante, dans laffoupiffement, dans les laf-

- fitudes. 


\section{duc Caffé, \& du Chocolat. I79}

fitudes fpontanées, \& generalement dans les maladies qui dépendent de la diffipation des efprits, du mouvement dépravé des humeurs, ou de l'aigreur \& de la force deslevains.

\section{CHAPITRE VII.}

Des proprietés particulieres de la boiffon de Caffé.

T'Ay affecté exprés de donner la preparation du firop de Caffé, avant que de parler des vertus de fa teinture, par cette raifon que ce firop \& cette teinture font enfemble une boiffon beaucoup plus agreable \& en même temps 
180 Le bon usage du The', beaucoup plus efficace, que celle quion prepare fimplement avec le fucre.

La tefte eft la partie de tout le corps fur laquelle le Caffé produit de plus confiderables effets; car par fon ufage ordinaire, on prévient prefque feurement l'A poplexie, la $\mathrm{Pa}$ ralifie, la Létargie, \& prefque toutes les autres maladies foporeufes, en préparant fa Boiffon comme il vient d'être dit avec le firop de Caffé. Elle guerit même ordinairement le vertigo, les Catharres, la Phrenefie \& les fluxions \& maux de dents, fur tout fi pour ces indifpofitions, on prefere au firop de Caffé ce- Iuy de Vanilles, dont il fera parlé à la fin de la troifiéme 
du Caffé, \& du Chocol at. I 8 I părtie de ce Traité.

Mais foit quion la prepare avec l'un ou l'autre de ces fiops, elle diffipe fi efficacement les fumées du vin \& des entrailles, qu'elle defenyvre ur le champ, \& qu'elle abbat orefque avec la méme prompitude les vapeurs qui caufent es infomnies, les affoupiffenens, les inquietudes, la miraine, \& prefque tous les aures maux de tête, ce qui fait qu'en dégageant les efprits mbaraffés, elle fortifie la menoire \& le jugement, \& qu'ele donne à la volonté une lierté entiere pour diriger toues les actions volontaires, ou ectifiant toutes les difpofiions taciturnes \& mélancoliques, ce qui a été premiere$\mathrm{H}$ ij 
I82 Le bon ufage du Thé, ment obfervé par les Bergêr: d'Arabie, qui remarqueren avant qu'on eût fait aucun ufa. ge du Caffé, que quand leur: moutons avoient mangé de cette efpéce de legume, ils gambadoient d'une maniere extraordinaire.

C'eft pourquoy la vertu qu'on attribuë au Caffé, de rendre chaftes \& pudiques le: perfonnes qui en font un ufage habituel,eft purement ima. ginaire; car outre qu'elle n'a jamais été foûtenuë par aucunes obfervations aufquelles on puiffe ajoû́ter foy, la fecondité des femmes du Levant: prouve d'autant plus évidemment le contraire, qu'on fçait que cette boiffon leur eft familiere, \& qu'elle porte tant d'ef- 


\section{du Caffé, \& du Chocolat. ${ }_{1} 8_{3}$}

prits vers les parties genitales, que les femmes n'ont point de remede plus prompt \& plus affuré que cette boiffon pour faciliter l'accouchement, pour provoquer les régles retenuës, pour corriger les pertes blanches, \& pour appaifer ces fortes de tranchées qu'elles fouffrent affez ordinairement pendant les couches.

Il eft vray que l'on auroit pû dire jufques icy, que la plus grande part des parties plus fpirituelles \& plus efficaces du Caffé, fe diflipent par le tranfport qu'on en fait de l'Arabie en Europe; mais maintenant qu'on le peut préparer avec fon firop même, qui en augmente autant la ver$\mathrm{H}$ iij 


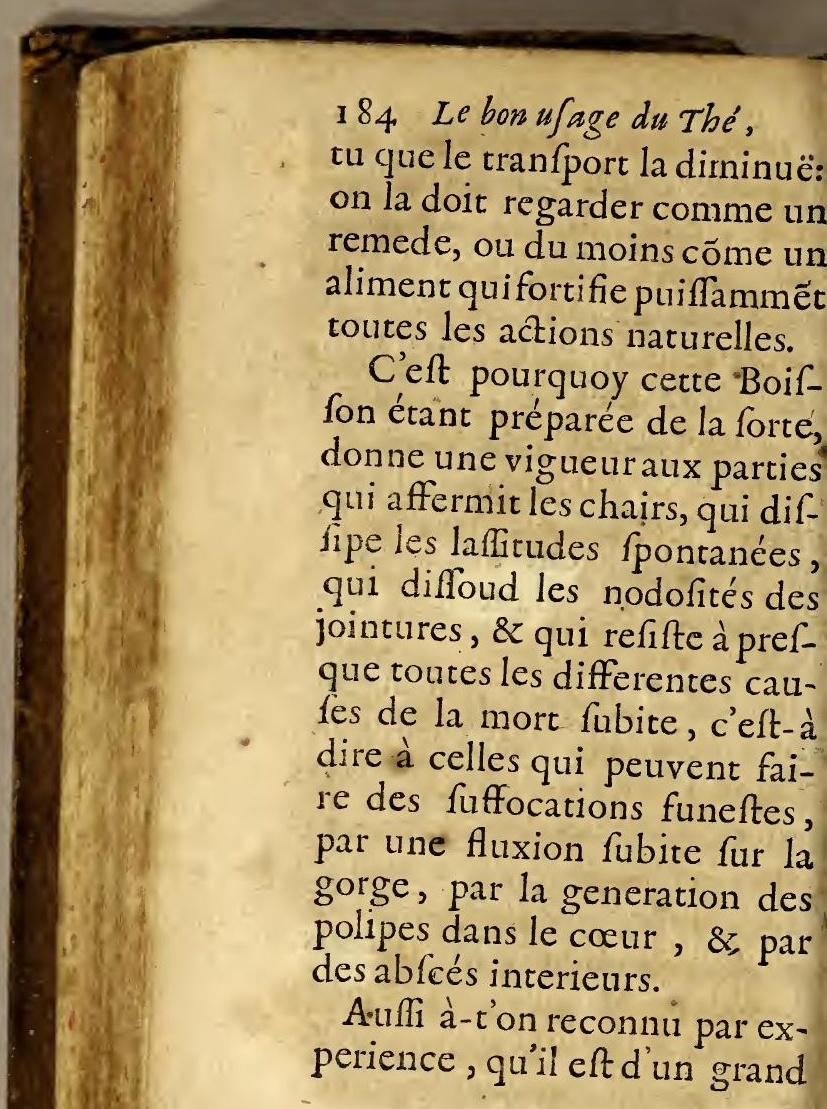


du Caffé, \& du Chocolat. is s fecours à ceux qui font incommodés par la repletion. univerfelle du corps, par la groffeur particuliere du ventre, \& par l'embarras qui fe fait dans les reins, \& qui devient la caufe generative des Pierres \& par confequent des Coliques Nephretiques \& des fuppreffions d'urine.

C'eft à peu prés par la même raifon, que la fimple boiffon de Caffé eft fi falutaire aux goutteux \&z anx Scorbutiques, que les Medecins Anglois \& Holandois affurent que la goutte \& le Scorbut, regnent infiniment moins dans leurs païs depuis qu'elle y a été dans un grand ufage, ce qui fe confirme en quelque forte par l'experience particuG iiij 


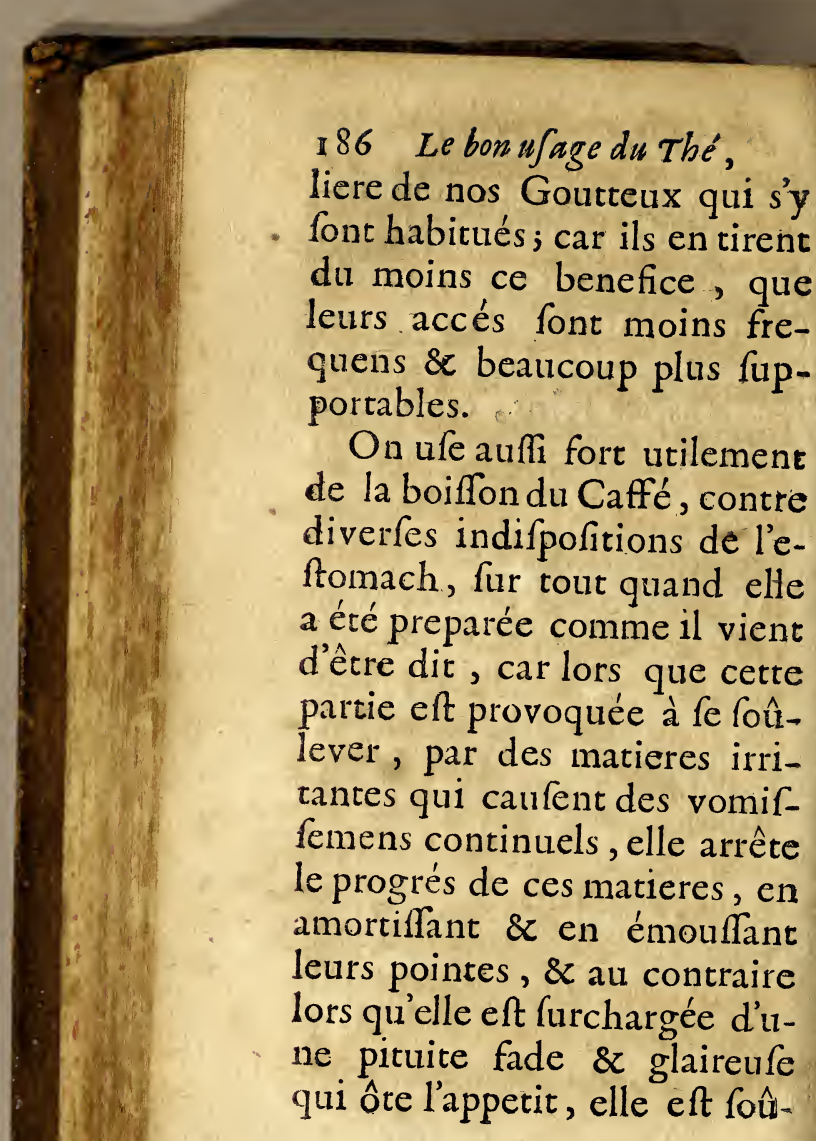




\section{du Caffé, \& du Chocolat. 187}

levée fi efficacement par l'action du fel de Caffé, qu'elle eft incontinent déchargée par le vomiffement.

J'ay obfervé encor que quand la digeftion eft affoiblie par le relâchement des fibres de l'eftomach, le Caffé les referre par une action qui luy eft commune avec toutes les autres drogues qui ont une éfpéce d'amertume, \& qu'aus contraire il relâche fes fibres, \& ceux même du canal inteftinal, lors que dans la conftipation du ventre ils font refferrés, ce qui eft une proprieté effentielle à fes parties étherées \& oleagineufes, c'eft d'où vient que plufieurs perfonnes qui étoi ent incommodées d'une conftipation habi-

$\mathrm{H}$ y 


\section{88 Le bon ufage du Thé,}

tuelle, ont changé cette méchante difpofition, en s'affujettiffant à prendre chaque jour, deux chiques de Caffé incontinent aprés avoir dîné.

Cela n'empêche pas neanmoins que la vertu fortifiante du Caffé, ne contribuë beaucoup à la guerifon du flux de ventre \& du flux de fang ; car il refifte puiffamment à ces fortes de corruptions dí ventre qui dépravent le chyle \& qui aigriffent les humeurs, d'où il arrive que fon ufage habituel prévient la generation des vers, \& prefque toutes les efpéces de Colique.

Il eft auffi tres-efficace pour dépurer la mafle du fang, \& pourmondifier les Poulmons; c'eft pourquoy fa boiffon pre- 
du Caffé, o du Cbocolat. 189 parée avec le firop de Limons, appaife la foif des Febricitans \& addoucit la rigueur de leurs accés \& de leurs redoublemens, gueriffant même quelquefois radicalement les fiévres intermittantes, \& preparé avec le firop de Vanilles, elle eft d'un effer merveilleux pour ceux qui ont la poitrine, naturellement foible, ou accidentellement affoiblie par le Rhume, par la Toux inveterée, par une Pulmonie naifante, \& par ces autres efpéces de fluxions qui rendent la voix rauque, \& qui caufent l'Afthme \& la courte haleine.

Au refte, ce que jay dit de la vertu du Caffé contre les affoupiffemens \& contre 


\section{Le bon ufage du Thé,}

les infomnies, n'eft pas à beaucoup prés fi contradictoire qu'on pourroit le penfer; car outre l'experience, il eft d'ailleurs tres-probable qu'avec un même remede, on peut calmer les efprits agitez qui empêchent le fommeil, \& diffiper les vapeurs par lefquelles les fonctions de l'ame fenfitive font interrompuës.

Je finis en advertiffant qu'il fe pourroit faire que la rebellion de quelqu'unes des maladies dont il a été parlé, dépendroit de la retention de quelques excretions, c'eft pourquoy ceux qui auront enzrepris de s'en délivrer par l'ufage du Caffé, ne s'endoivene - rebuter qu'aprés avoir inutilement tenté d'aider fonaction 
du Caffé, \& du Chocolat. I 9 I par celle d'un purgatif, en y ajoûtant de temps en temps en place des firops cy-devant fpecifiez, une cueillerée de firop magiftral pour chaque prife, ou de quelques autres firops équivalens.

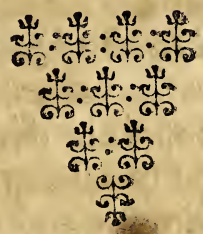




\section{2}

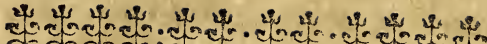

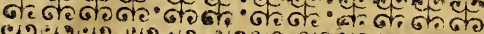

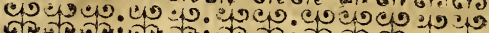
Gू.

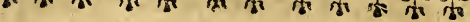

\section{TR OISIE'ME PARTIE}

Traitant de la Nature, des proprietés, cor bon ufage du Chocolat.

\section{CHAPITRE. I.}

Du Chocolat en général.

Eu aprés la découverte du nouveau monde, nous apprimes de nos Voyageurs, qu'entre les autres commoditez de la vie, on y trouvoit une forte d'aliment - compofé, qui fervoit tout enfemble à raffafier \& à defalte- 
du Caffé, \& du Chocolat. 193 rer les Americains, qui le mangeoient en pâté ou conferve feche, \& qui le beuvoient en liqueur. Nous apprîmes auffi que ces mêmes Peuples comprenoient cette conferve \& cette liqueur fous le feul nom de Chocolate ou Chocolat, par cette raifon que dans leur langue naturelle Choco fignifie fon, \& atte ou atle eau, car lors qu'on prepare cette liqueur, on l'agite avec un inftrument de bois d'une maniere à faire du bruit, voila l'étimologie du. nom de Chocolat.

Cet aliment étoit lors aufíf peu délicat que fes inventeurs étoient peu taffinez; mais aprés la conquête de la nouvelle Efpagne, les Efpa: 
I94 Lebonufage du Thé, gnols qui fe trouverent dans une efpéce de neceffité de s'accoûtumer â fon ufage, ne manquerent pas d'encherir fur ce qu'ils en avoient appris des Indiens, \& de le rendre beaucoup plus agreable par la foubftration de certaines drogues, qui fembloient n'y être mifes que pour en augmenter la quantité, \& par l'addition de divers aromatiques ou parfums qui pouvoient flatter le goût. Ce fut dans cét état quils commencerent à le negotier en Europe \& particulierement en Efpagne, où il fut bien-tôt dans une eftime prefque generale : cependant comme" il ne fe peut guere conferver au de-là de deux ans, \& que les Negotians con- 
du Caffé, of du Chocolat. igs fommoient fouvent une bonne partie de ce temps à leurs Voyages, ils furent obligez de changer la difpofition de ce commerce, \& de nous apporter en fubftance, les ingrediens qui font la bafe \& l'effentiel de cette compofition; ce fut alors que nous en apprimes le myftere, \& que nos Phy ficiens Scolaftiques fe firent fête d'examiner le formulaire de cette compofition, \& felon leurs mauvaifes coûtumes, de former des argumens pourle fophifme, fur un fujet qu'ils fembloient vouloir éclaircir, fi bien qu'ils pafferent bien tôt de la difpute, à ces diffentimens importuns, qui retiennent dans une cruelle incertitude ceux 
196 Le bon ufagedu The', qui cherchent à s'inftruire, ce qui a étably tant de faux pre.. jugez, qu'entre un fort grand nombre d'Autheurs qui ont écrit jufques icy du Chocolat, il n'y en a pas un feul même entre les plus modernes, de qui on puiffe tirer aucune infruction édifiante, car les premiers aprés s'être vainement efforcez d'accommoder à leurs opinions particulieres, les principes infuffifans de l'ancienne Philofophiế; \& les Commentateurs qui font venus enfuite, \& ceux mêmes dont les ovurages viennent d'occuper nos preffes, ayant fuivy la même ronte; les inutiles raifonnement des uns, fe reduifent à cette conclufion que le Chocolat eft froid; les 
du Caffé, \& du Chocolat. 197 argumens des autres à foûtenir qu'il eft chaud; en un mot les confequences de quelques-tins, à cette prétenduë preuve quil eft temperé, ny ayant d'ailleurs aticunes autres differences entre ceux qui tiennent pour une même qualité, fi ce n'eft que les uns la mette au premier, les autres au deuxiéme, \& quelques-uns au troifiéme \& a au. quatriéme degré.

Comme je ne pouvois faire aucune application utile de cette doctrine, \& que javois neanmoins pris une refolution d'approfondir mon fujet, je me fuis trouvé contraint de negliger la lecture de ces Auteurs, \& de me rendre certain par moy-même des bon- 


\section{Le bon ufage du The',}

nes \& des mauvaifes qualitez du Chocolat par un examen phyfique \& ferieux, des ingrediens qui entrent dans $f_{a}$ compofition, \& des qualitez, $\&$ proprietez qui en doivent refulter. Je ne fçay fi j’auray travaillé avec fuccés. Je m'en rapporte au jugement des bons Phyficiens \& des bons Medecins, qui font feuls capables d'en juger \& d'encherir fur mes oblervations, sils les croyent dignes de paffer à la pofterité, ou de les cenfurer fi elles font affés défectueufes pour devoir être fupprimées ; que fi je me trouve reduit dans le cas de cette cenfure, je la recevray avec d'autant plus de déference, que je n'expofe ce 
du Caffé, \& du chocolat 199 projet qu'à deffein d'être defabufé, fi tant eft que je fois dans l'erreur, ou d'être confirmé dans mes fentimens, fi les habiles gens y applaudiffent affés, pour me faire la gtace d'y ajoûter leurs obfervations.

Avant quede finir ce Chapitre ; Je dois faire obferver, que nous avons connu par le Formulaire des Indiens, auffi bien que par celuy des Efpagnols, que le Cacao a toûjours fait la bafe \& l'effentiel de la partie de Chocolat, \& que le fucre a toûjours été employé pour dóner du corps \& de l'agrément à cette pâte, c'eft pourquoy avant que de parler des ingrediens qui ont été fouftraits, \& de ceux qui 
200 Le bon ufage du Thé,

leurs ont été fubltituez par les reformateurs, je traiteray dans le Chapitre fuivant de ces deux principales drogues.

\section{CHAPITRE I I.}

Du Cacao, ó du sucre en particulier.

N reconnoît icy, \& ailleurs fous le nom de Cacao, le fruit d'un arbre qui croit en differens lieux des Indes Occidentales, \& principalement à Guatimala, Province de la nouvelle Efpagne. Il eft à peu prés de la grandeur \& de la forme du Châtaigner. Les Indiensle nomment le cacava- 
du Caffé, \& du Chocolat. 20 I quabuit, \& les Européens $\mathrm{Ca}$ caotal ou Cavavifere. Ce fruit eft renfermé au nombre de vingt ou trente amandes dans une forte d'écoffe, dont on peut comparer la forme exterieure à celle des melons.

Autrefois on croyoit que cét Arbre ne pouvoit fructifier fans être à l'ombre d'autres plus grands Arbres, mais les Efpagnols en ont planté avec fuccés dans des Vergers fort découverts \& même dans, l'inle de Cuba, qui n'a que trois pieds de terre folide. On croyoit auffi que fon fruit ne pouvoit acquerir une parfaite maturité que dans l'efpace de douze mois ou environ, \& neanmoins on eft 


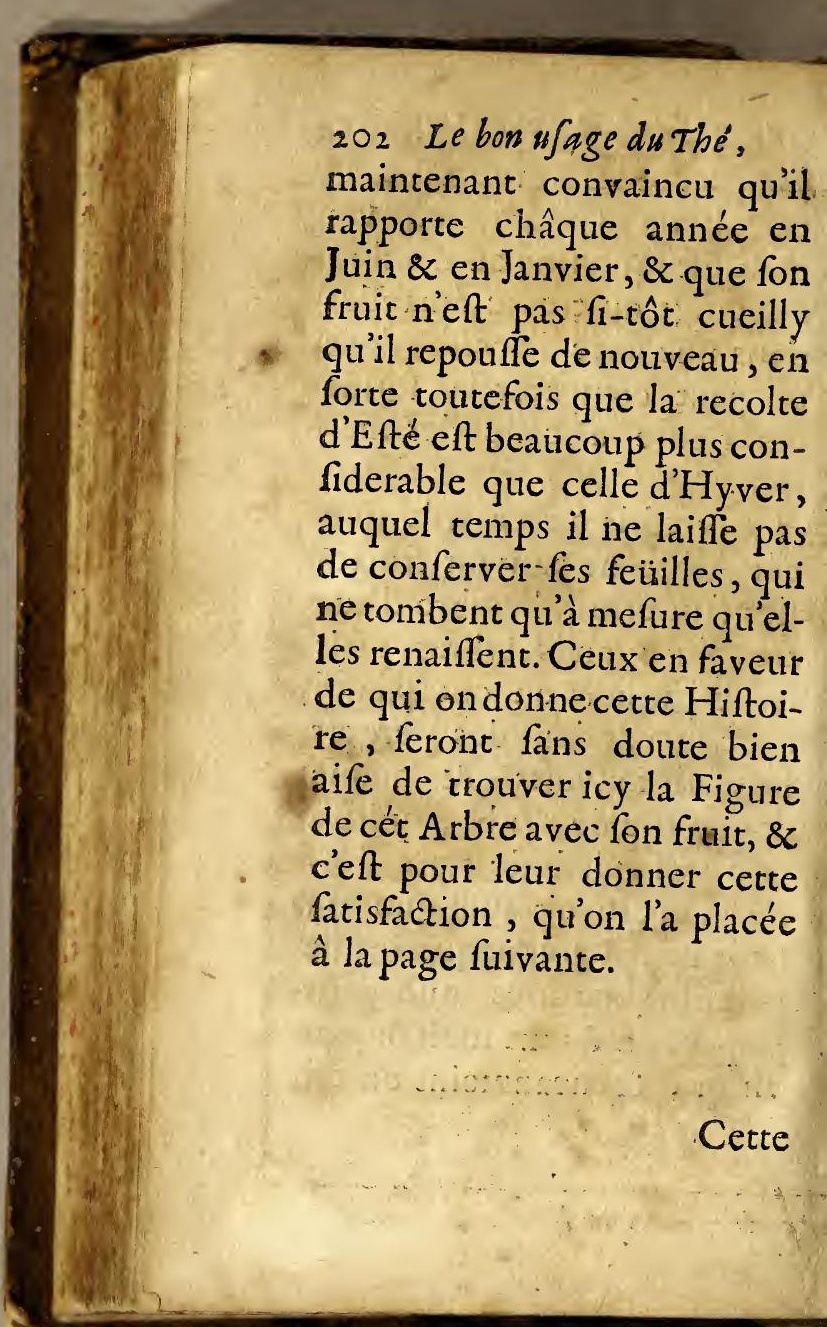




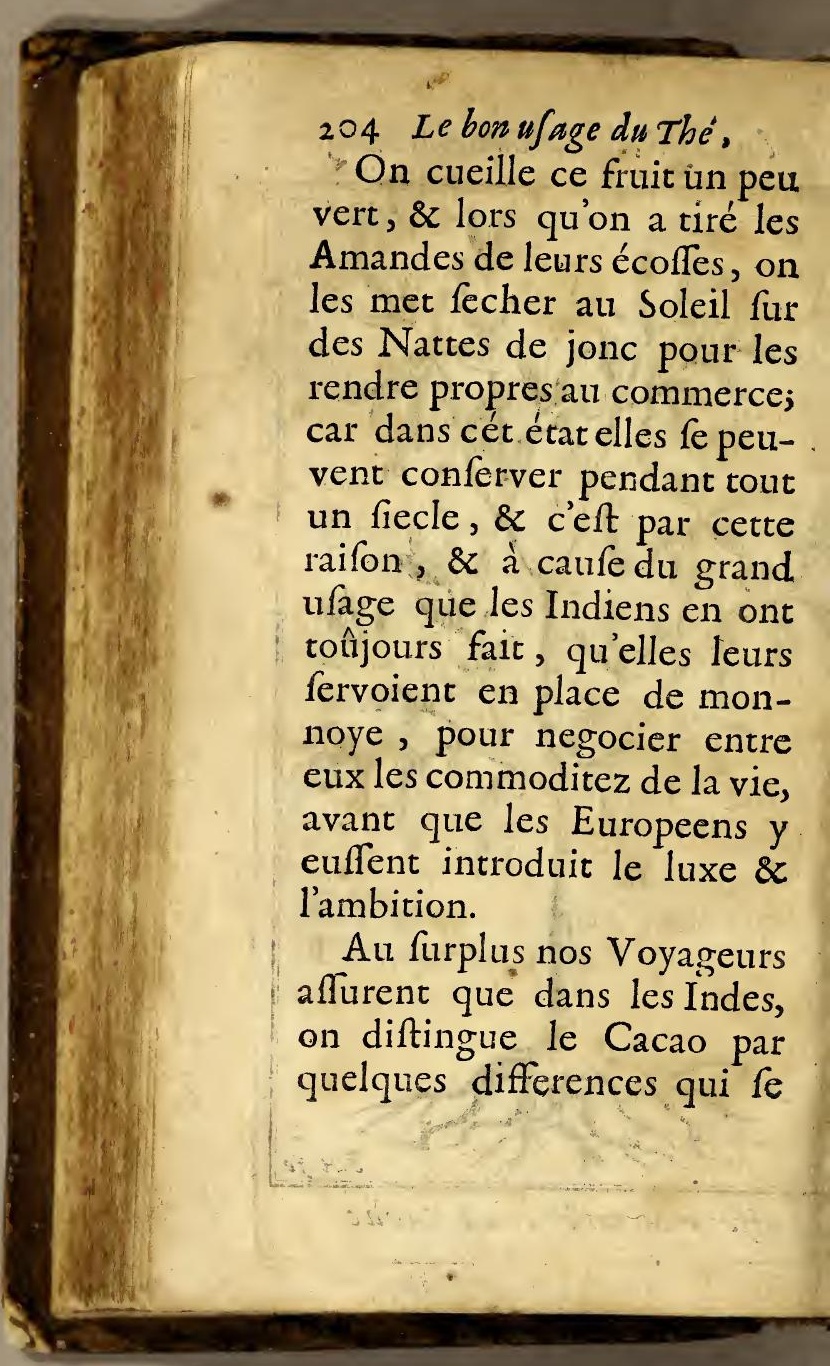


du Caffé, \& du Chocolat. 205 trouvent dans fa forme \& dans fa groffeur, \& en effet on nous en apporte icy de quatre fortes qui ne font pas à beaucolp prés de même qualité ; ce qui engage ceux qui veulent faire du bon Chocolat, d'entrer dans quelque forte de choix \& de difcernement fur le fait du Cacao, pour lequel on prendrá des idées utiles dans l'infpection de la Figure fuivante, \& principalement dans lexplication dont elle eft immediatement fuivie.

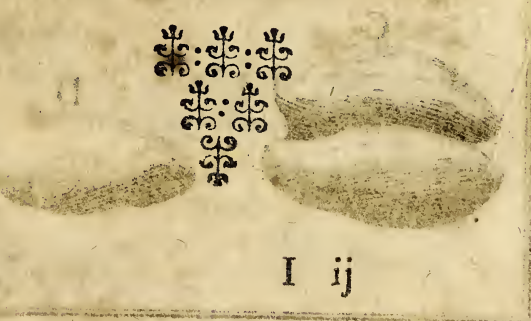


206 Le bon ufage du The,

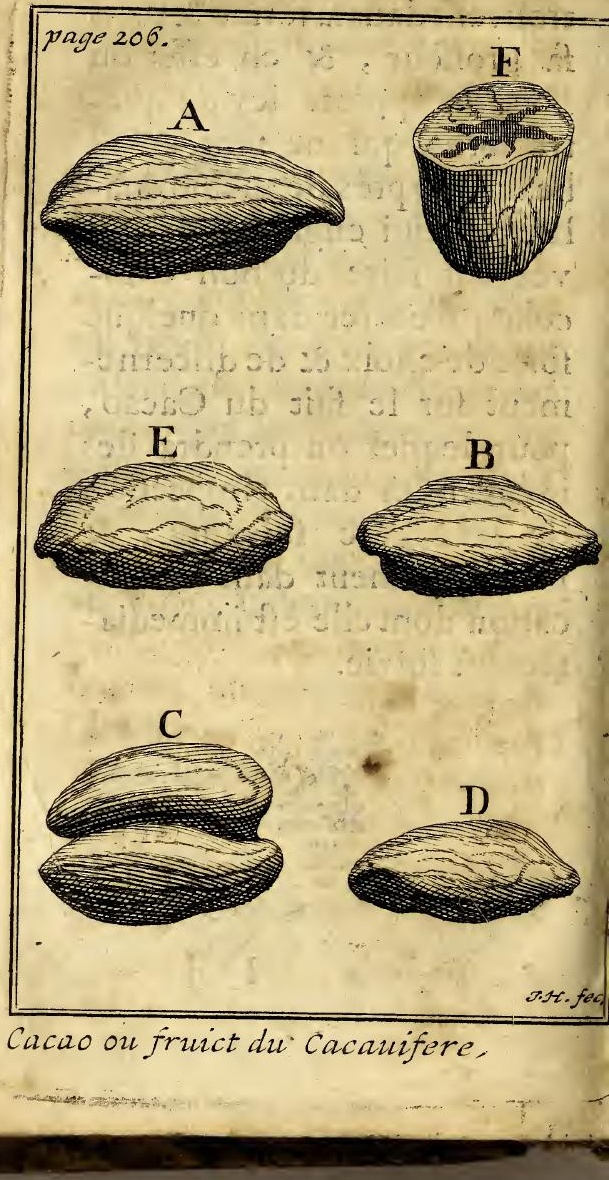


$d u$ Caffé, \& du Chocolat. 207 Pour l'intelligence de cette figure, il faut fçavoir que la plus groffe efpéce de Cacao eft prefque toûjours la meilleure. C'eft celle dont le $\mathrm{Ca}$ ractere eft marqué $A$. Les Amandes, de cette forte font oblongues inégales \& élevées en rondeur dans le milieu de leurs deux faces. Leur pelure eft d'un brun noirâtre, \& méme plus folide que celle des trois autres efpéces, dont celle-cy eft diftinguée par le nom de gros noir.

Le Cacao qui eft marqué B. \& qui pour avoir la même forme \& la même couleur peut être nommé petit noir, fe trouve quelquefois plus $\mathrm{fa}^{-}$ voureux, quoy que généralement parlant il ne doive

I iij 


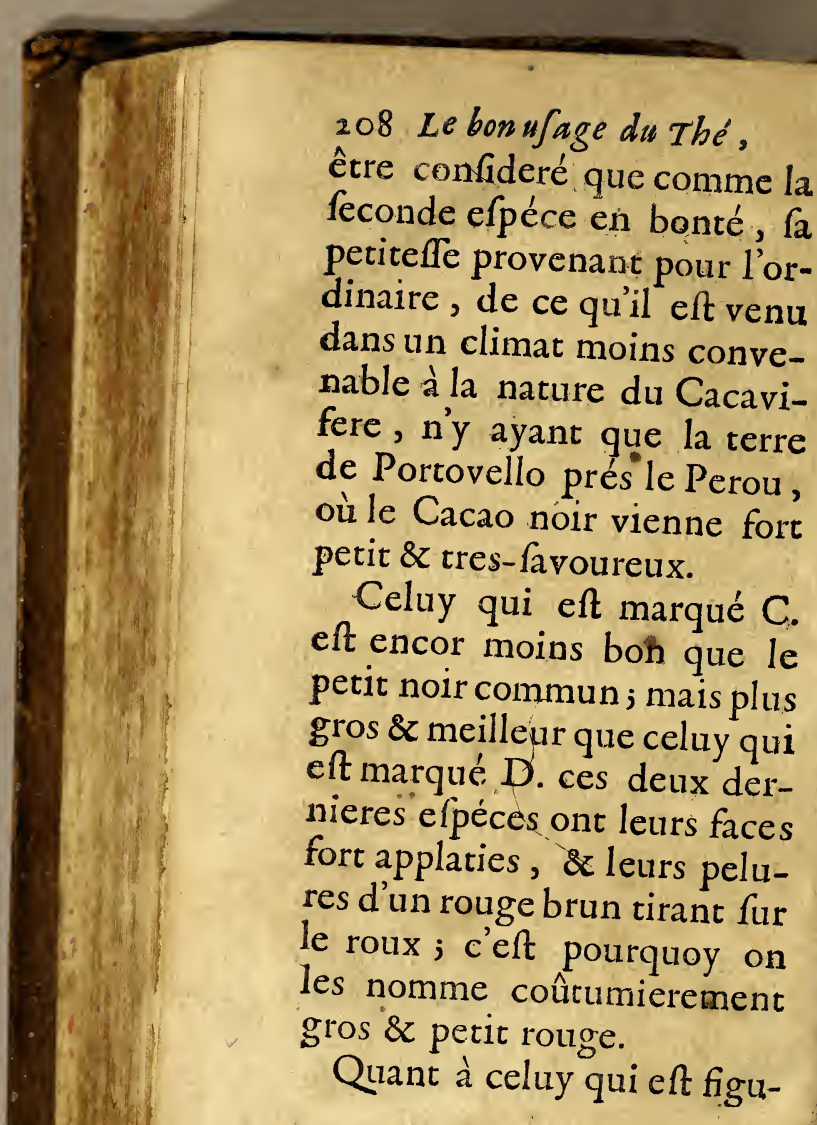


du Caffé, \&o du Chocolat. 209 ré fous la marque E. c'eft un amande du gros noir dépouiillée de fa pelure, pour montrer que fa fubitance eft divifée en plufieurs parcelles contiguës : ce qui eft encor plus clairement demontré par la figure $F$. où l'on affecte de la faire voir coupée tranfverfallement par le milieu.

Ce qu'on vient d'exprimer touchant les parcelles de chaque Amandes de Cacao, eft pour avoir lieu de dire que ces Amandes font fi grafles, qu'aprés les avoir tenuës fur le feu dans une poële de fer, affez long-temps pour rôtir \& pour brifer leurs pelures, ces parcelles fe divitent prefque d'elles-mêmes, en forte qu'en remuant alors le Cacao feuleI iiij 


\section{Le bon usage du The',}

ment avec la main, fon integrité eft détruite dans un moment.

Si avant cette preparation on mange de ces parcelles de Cacao, on trouve que leur goût eft en quelque forte moyen, entre celuy de nos Amandes douces \& celuy de nos Amandes ameres; car n'ayant ny la douceur des

- unes, ny l'amertume des autres, il ne laiffe pas d'avoir quelque chofe de cette faveur qu'on trouve genéralement dans toutes les efpéces d'A. mandes \& de Noifettes, \& qui les fait diftinguer de tous les autres fruits; mais tout de même que cette faveur genérale, eft couverte dans toutes les efpéces particulieres d'A- 
du Caffé, \& du Chocolat. 211 mandes \& des Noifettes, d'un goût qui eft fpécifique à chacune, \& qui dépend de la diverfe quantité $\&$ du differend mélange de fes principes; le Cacao a auffi une faveur âpre \& aftringente qui étably fon caractere particulier.

Il faut obferver maintenant, que les fimples qui ont de l'âpreté, ont de l'aftriction comme ceux qui ont de l'amertume, qui eft évident que les uns \& les autres ont beaucoup de parties terreftres \& acides, \& que fi les âpres font plus fupportables à la langue que les autres; c'eft parce qu'ils ont beaucoup de particules capables d'addoucir l'action des autres Elemés. Or comme entre les Elemens

$$
\text { I } \mathrm{v}
$$


212 Le bon ufage du The', des mixtes, il n'y a que les liquides \& les étherez qui puiffent faire cét adoucillement, que le Cacao n'a rien d'aqueux, \& qu'au contraire il eft fi gras qu'on en peut tirer par expreflion une confiderable quantité d'huile, il faut conclurre que les particules étherées font encor un de fes principes ptédominans, \& que fans ce principe il ne feroit pas diftingué des amers, d'où il faut inferer la poffibilité qu'il y a d'en tirerdes fels febrifuges, comme je l'ay érably en parlant du firop de Thé qui guerit les fiévres intermittantes, puifque d'ailleurs il eft fi aifé d'en feparer I'huile.

Il étoit facile aux Voya- 
du Caffé, \& du Chocolat. 213 geurs qui ont écrit les premiers du Chocolat, de reconnoître la grailfe furabondante du Cacao, quand ils n'auroient eu aucune connoillance phyfique, puifque lors qu'on prepare cette pâte, cét excés de graiffe paroît tres-fenfiblement dansla torrefaction, \& dans la diffolution de cette efpéce d'Amandes; outre que cette même pâte étant étendü̈ fur du papier en maffe ou en tablettes, non feulement elle prend au frais la folidité qui luy eft convenable; mais on remarque encore quion la détache enfuite tres-facilement du papier, \& quielle y laifle même des tâches fi graffes, quaux endroits de ces. 
- 2 I4 Le bon ufage du The', tâches, on ne le peut pas diftinguerde celuy qui eft huilé pour fervir à des Chaffis. A joutez que le Chocolat ainfi refroidi \& folide, fe peut tres - facilement liquefier de nouveau par le feu, \& même par la fimple chaleur de la main.

Mais il n'étoit pas à beaucoup prés fi facile, de découvrir que cette graifle du Cacao eft mufilagineufe, affoibliffante, relâchante, \& par confequent contraire à l'eftomach, dont la bonne difpofition dépend de la vertu élaftique de fes fibres \& de la force de fon levain. C'eft pourquoy ceux d'entre les premiers \& les nouveaux Auheurs qui ont reconnu l'a- 
$d u$ Caffe, \& du Chocolat. 215 bondance de la graiffe du Cacao, fe font efforcez d'établir une doctrine directement oppofée à cette propofition, en fouttenant que toutes efpéces d'huriles fulphureufes étant inflammables \& chaudes, il s'enfuivoit neceffairemét que le Cacao qui eft fort gras, devoit auffi être fort chaud.

Il eft vray que quelquesuns de ces Autheurs, \& entr'autres Monfieur Sylveftre du Four, qui vient de mettre la main à la plume pour la deuxiéme fois, à deffein de nous apprendre la nature \& les proprietez du Chocolat, femble vouloir infinuer que le Cacao eft d'une qualité temperée ; mais c'eft feulement parce quil fupofe que les parties terreftres \& froides 


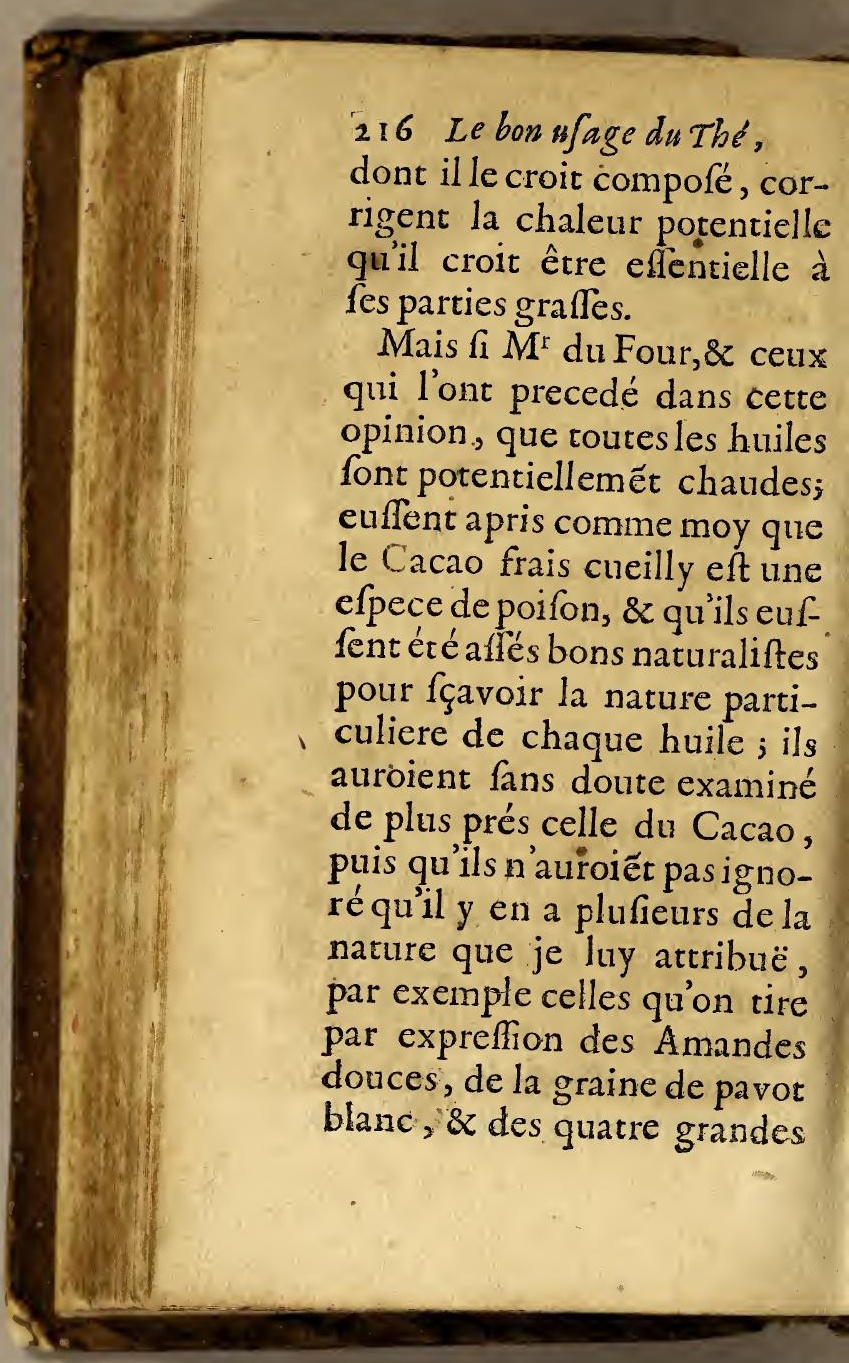




\section{du Caffe, \&o du Chocolat. 217}

femences froides, \& ils auroient pû. apprendre par quelques effais, qu'encore que ces huiles foient inflammables par la furabondance de leurs particules étherées, elles ne laiffent pas de contenir beaucoup de parties mufilagineufes, \& par confequent froides \& relâchantes, puis qu'en les expofant à l'humidité, ils autroient eu le plaifir de les voir en peu de temps reduites en fimples mufilages.

Ils auroient encore pû experimenter que fi toutes les hui- les potentiellement chaudes gâtent le teint des Dames, celles-cy an contraire, \& fur tout celles qui font les plus mufilagineufes $\&$ les plus froides, comme celle de la graine \&

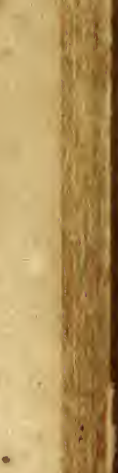


218 Le bon ufage du Thé, des femences que J'ay dites, luy donnent du frais, de la blancheur \& de l'éclat.

A prés cela reflêchiffant fur l'ufage qu'on fait à Mexique de l'huile de Cacao, où les Medecins l'ordonnent pour remedier aux inflamations \& aux brûlures, \& où les $\mathrm{Da-}$ mes s'en fervent familierement pour l'embelliffement de la peau, ils auroient du moins foupçonné qu'elle autroit bien pû́ être de la nature de ces huiles mufilagineufes, \& ils auroient incontinent paffé de ce foupçon àune entiere certitude, en obfervant les indifpofitions, qui furprennent prefque tous ceux d'entre nous qui font un grand ufage du Chocolat; 
du Caffé, \& du Chocolat. 219 mais du moins fingulierement \& certainement, tous ceux qui n'y font pas habituez dés l'enfance, \& encor tous ceux qui ont naturellement ou accidentellement l'eftomach foible.

Ce qui les auroit encore confirmé merveilleufement dans cette opinion, eft la facilité avec laquelle le Cacao s'unit \& fait corps avec le fucre fans aucun intermede, $\&$ fans qu'il foit befoin d'autre myftere que de les écrafer enfembles dans un mortier, ou fur une pierre à l'aide d'une mediocre chaleur, ce qui dépend de la nature analogique de ces ingrediens : car on ne peut -pas douter que le fucte ne foit 
220 Lebon usage du The,

fort abondant en cette efpece de graiffe gluante \& mufilagineufe, qui eft pareillement abondante dans le $\mathrm{Ca}-$ cao, \& qui produit tant de méchans effers, puifque les perfonnes qui ont l'eftomách tant foit peu foible, ne fçauroient manger une mediocre quantité de fucreries, fans reffentir bien-tôt une efpéce de dégoût, \& quelquefois même une indigeftion confrderable, ce qtion ne peut raifonnablement attribuer qu'aux parties mufilagineufes, relâchantes \& affoibliffantes du fucre; car les Phyficiens fcholaftiques fe mocquent des gens, lors quils rapportent tous ces méchans effets à la prétenduë chaleur 
du Caffé, \& du Chocolat. 22 I de ce mixte, puis qu'il ne fe pourroit qu'un aliment ou un medicament potentiellement chaud ne produifit des effets tout contraires; outre que le * Sucre n'eft que le fel effentiel d'une efpece de Canne, auquel on ne peut attribuer par confequent aucune chaleur prédominante, comme le fçavent ceux qui connoiffent la nature des Sels eflentiels.

Il eft vray que le blanchement du Sucre fe fait par le moyen de la Chaux, done il peut retenir quelques particules ignées ; mais ces particules font tellement embarraf. fées dans fes parties graffes $\& z$ mufilagineufes, \& elles y font proportionellement en fi pe- 


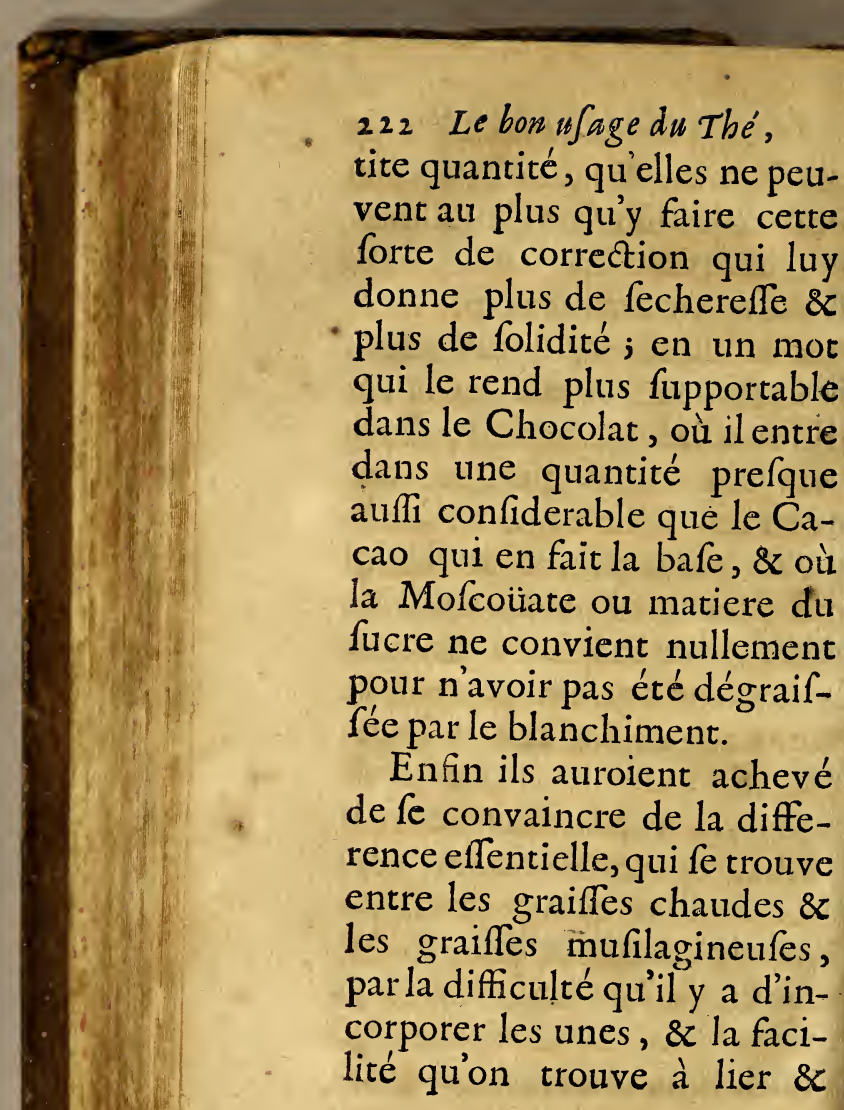


du Caffé, \& du Chocolat. 223 amalgamer les autres avec l'eau \& le lait; car de ce que la graiffe du Chocolat s'étend fi aifément dans ces deux fortes de liqueurs, ils auroient conclû abfolument qu'elles different en nature de la plufpart des autres graiffes, \&z que cette difference dépend de fes parties mulagineufes, qui font comme un moyen entre deux extrémes, \& qui la rendent également analogique aux huiles \&z aux fimples liqueurs.

Sur le fondement de ces puiffantes confiderations, j'ay dû conclurre qu'il étoit abfolument neceffaire pour faire un Chocolat auffi falubre qu'agréable, de fupprimer la graiffe furabondante du $\mathrm{Ca}$. 
224 Le bon ufage du The, cao, \& j’en ay recherché le moyen avec d'autant plus de fuccés, que par cette fouftraction, on ne luy ôte point la proprieté de s'amolir fuffifamment, pour être incorporé avec le fucre, \& avec les autres ingrediens qui entrent dans la compofition de cette pâte ; mais à l'égard du fucre j'ay penfé que fon blanchiment étoit une correction fuffifante, par cette raifon, que fon mufilage eft compofe de quelques parties refineufes \& balfamiques, qui le rendent moins froid \& moins relâchant que celuy du, $\mathrm{Ca}$ cao, ce qui fait qu'il n'a ny le fade ny l'infipide de celuycy, qui dans le Chocolat commun, émouffe \& envelo- 
du Caffe', \& du Chocolat. 225 pe les parties delicates des parfums \& des aromatiques qui pourroient chatouiiller plus agréablement le goût.

Au furplus cette preparation du Cacao dont je traiteray cy-aprés plus particulierement, eft ce qui a porté nos Artiftes à donner à leur Chocolat le furnom de dégraiffé, que les connoiffeurs ont trouvé preferable à toutes autres Cortes de Chocolat, par cetre raifon quavec un eftomach tres-foible, on en peut faire un grand ufage, fans craindre d'en rêffẹtir aucune incommodité, ce qui eft journellement experimenté, par les perfonnes mêmes qui font atcintes de toutes ces efpéces te maladies qu'on rapporte à indigeftion. 
226 Le boriujage du Thé,

Si on veut ajoûter à ces experiences uhe forte de raifonnement, on peut dire quaprés cette correction, on eft certain que le Chocolat ne peut être qu'un tres-bon aliment; car fi d'un côté il refte quelque chofe dans le Cacao de la qualité froide \& affoibliffante,elle eft rectifiée dans la compofition de la maffe, par l'addition des parfums \& des aromatiques qu'on y fait entrer \& dont il fera parlé cyaprés.

C'eft pourquoy bien que le fçavant Monfieur Bachot n'aye avancé que par forme de problême, dans la fameufe Théfe qui fut foutenuë fous fa préfidence le 25 . Mars I 684. que le Chocolat bien preparé 
dis Caffe, o du chocolat. 2 is prepare eft une fi noble confection, qu'elle eft plûtôt que le Nectar \& l'Ambrofie, la vraye nourriture des Dieux, \& qu'elle meritoit naieux d'être divinifée, que les champignons de l'Empereur Claudius. Jofe préfumer quilil foûtiendra deformais tres-affirmativement cette Théfe, lors qu'il jugera â propos de confeiller à ceux doñ il dirige la façon de vivre, l'ufage du Chocolat dégraiffé.

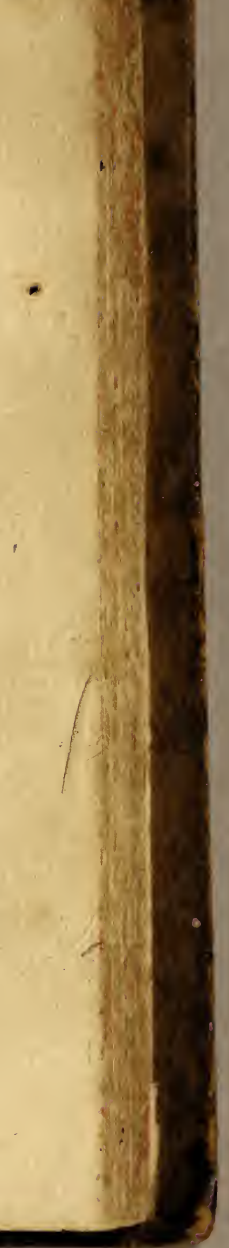

\section{K}




\section{Le bonufage du Thé,}

\section{CHAPITRE III.}

Des ingrediens que les Americains ajoûtoient au sucre of au Cacao, dans la compofition de leur Chocolat, avant la découverte de leur continent.

T Es ingrediens dont je 1 dois parler dans ce Chapitre ne fe trouvent point chez nos Droguiftes, \& quand on les pourroit trouver icy, je ne penfe pas que perfonne les voulutt faire entrer dans la compofition du Chocolat, celuy des Indiens où on les fait entrer, n'ayant rien qui puiffe flâtter nôtre goût ; c'ết dequoy je puis rendre un témoignage certain, ayant eu plu- 
du Caffé, \& du chocolat. 22 I fieurs fois occafion d'en goûter, \& l'ayant toûjours trouvé fade \& mal plaifant.

Cependant plufieurs confiderations mengagent à faire connoître quels font ces ingrediens, \& dans quelle dofe ils entrent dans cette forte de Chocolat. La premiere \& la plus forte de ces confiderations, eft que les curieux qui veulent tout fçavoir, feront bien aife d'en avoir au moins une defcription abregée ; mais je fçay d'ailleurs que ce traité pourra être porté aux Indes, \&c que les goûts font fi differends en fait de Chocolat, qu'il fe pourroit faire que cette defcription y feroit de quélque ufage, parmy quel- 


\section{Le bon usage du Thé,}

- ques-uns des François qui s'y font établis.

L'A chiote qui eft un de ces ingrediens, eft le fuc épaiffi qu'on tire du fruit de l'A chiore Arbre fruitier de l'Amerique. Ce fruit eft une graine rouge qui fe trouve en grande quantité dans de groffes gouffes rondes. Quand on a tiré cette graine de ces gouf fes, on la pile \& on l'exprime à la preffe, pour en tirerle fuc, qu'on expofe enfuite dans un lieu chaud pour en faire en évaporer l'humidité, \& quand il eft épaiffi à peu prés comme la pâte, on en forme des maffes de differentes formes, qui étant entierement deffechées font proprement ce quion appelle Achiore. 
du, Caffé, \& du Cbocolat. 223 - On dic que les Medecins de Mexiquie, l'ordonnent affez ordinairement dans la difficulté de refpirer, dans la fiévre, dans la diffenterie, dans la fuppreffion dirine, \&x generalement dans toutes les efpéces do maladies qui dépendent de l'obitruction des vifceres; ce jui me fait juger quil doit avoir une legere amertume \& une confiderable acidité, neanmoinsles Indiens le mettent en fi petite dofe dans leur Chocolat, qu'il femble que ce ne foit qua deffein de luy donner la couleur rouge.

-Les amandes du cocos ou palmier des Indes y entrent auffi en petite quantité. Elles font beaucoup plus groffes $\&$

$K$ iij 
224 Le bon usage du Thé, plus favoureufes que nos Amandes. On s'en fert à Mexique dans la confection des Maffepains, des Macarons, $\&$ des gateaux d'Amandes. On tes fait griller avec le $\mathrm{Ca}$ cao pour exalter leurs parties graffes, \& les déterminer à faire corps avec les autres ingrediens. Elles font fort abondantes en ce principe. On fait de leurs écoffes les taffes ou goubelers de Cocos, qui fervent affez coutumierement dans toute l'A merique à boire le Chocolat.

Les Noifettes Americaines font auffi du nombre de ces ingrediens, \& on les fait griller, comme il vient d'être dit des Amandes; quoy qu'elles ne foient pas fi graffes: C'eft 
$d u$ Caffé, \& du Chocolat. 225 pourquoy elles font reffentir un peu d'âpreté fur la langue comme nos Châtaignes encor yertes, dont elles ont à peu prés la groffeur, la figure \&z l'aftrictrion; ce qui fait qu' elles fortifient l'eftomach, \&z. qu'elles refiftent aux vapeurs hypocondriaques.

Il eft certain que le Mays entre dans le Chocolat Indien en affez forte dofe, mais comme c'eft une efpece de bled, dont la farine ne peut point rendre favoureufe une pâte qui ne fe fermente point, jeftime avec quelques $\mathrm{Au}$ teurs qu'il n'eft ajoûté à cette pâte que par oeconomie, ou par maniere de fophiftication.

Un Auteur François affuK iiij 
$d$ u Caffé, \& du Chocolat 227 efpéce de boifion temperante \& def-obftruante.

La fleur d'Orejevala entre pareillement dans la pâte Indienne du Chocolat. Elle eft ainfi nommée à caufe que fa forme a quelque rapport à celle de l'oreille. Elle eft pourprée au dedans \& verdâtre au dehors: Son odeur eft plaifante. Elle vient fur un arbriffeau que les Americains appellent Xuchimacutzli, ou Huchmacutzli. Pour être incorporée avec les autres ingrediens; elle doit être fechée à l'ombre \& enfuite pulverifée.

Voicy maintenant la defcription d'une efpece de Chocolat Indien, par où jacheveray de fatisfaire à la cu-

K y 


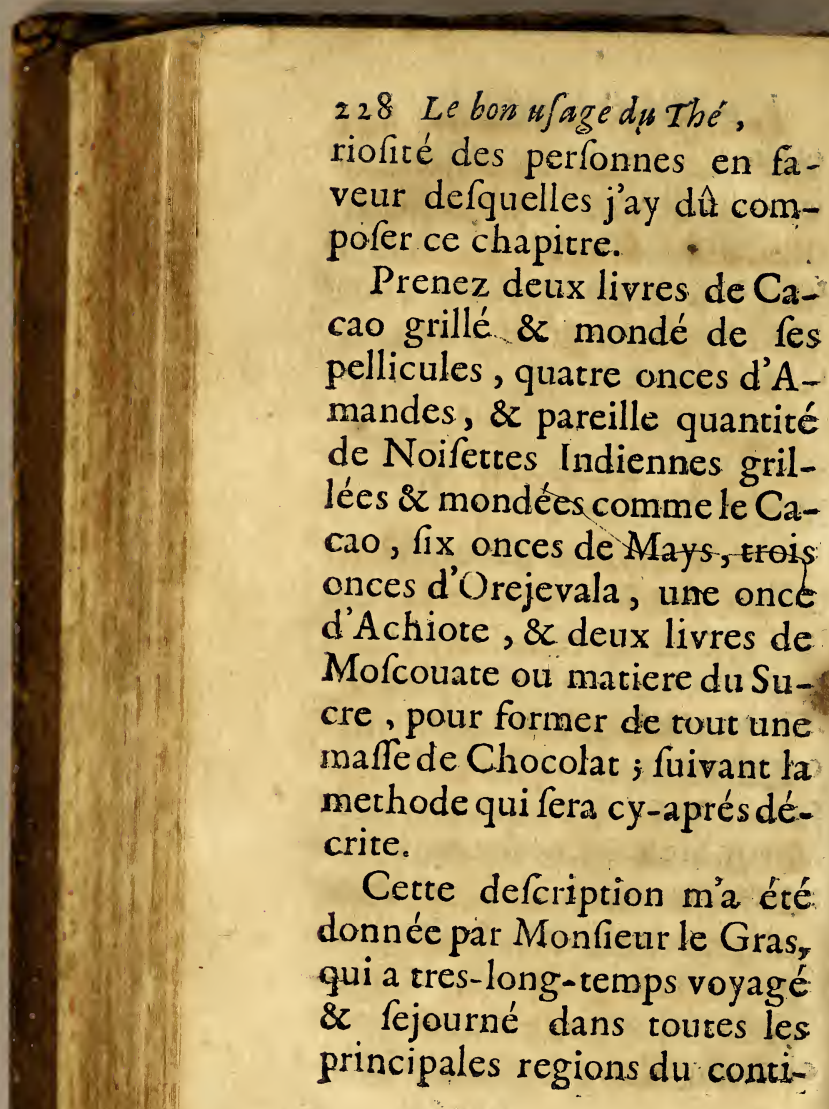


du Caffé, \& du Chocolat 229 nent de l'Amerique, où il a eu foin de s'inftruire fur l'Hiftoire du Chocolat, dont il m'a fait la grace de me communiquer les principales circonftances.

\section{CHAPITRE I V.}

De la reformation du Formulaire des Indiens touchant la compofetion du chocolat.

T Es Efpagnols ayant pris 1 racine dans les Indes, \& ayant pourvtu au neceffaire \& à l'utile,ils fe mirent en devoir de rechercher le voluptueux, ce qui leur fit découvrir qu'une certaine plante de la nouvelle Efpagne, produifoit une gouffe fort aromatique qu'ils. 
230 Le bonu uage du Thé, deftinerent a la confection du Chocolat, à laquelle elle ajốta en effet beaucoup d'agrément, ce qui leur donna lieu d'en fupprimer les ingrediens. dont il a été parlé dansle chapitre precedent, fi bien qu'ils: ne compoferent plus leur Chocolat quavec cette gouffe, le fucre \& le Cacao y ajoûtant feulement un peu de Poivred'Inde.

La Plante dont je veux. parler, étoit nommée parles Indiens Tlixochitl, \& fes goufles Mecafulhil. C'eft une herbe qui rampe le long des Arbres, \& qui a les feuilles femblables a celles du Plantain, mais plus longues \& plus. epaifles; du refte elle reffemble affez bien à celle qui pro- 
du Caffe" or du Chocolat. 23 II duit nos Aricots. Les Efpagnols la nommerent Campêche. Je ne fçay par quelle raifon, mais ils donnerent à fês. gouffes le nom de Vanilles, à caufe que Vanilla en leur langue fignifie petite gaine; $\&$ en effet fi elles font confiderablernent longues, elles font auffi fort étroites Elles renferment une forte de grains tresmenus, mêlez avec une efpéce de Pulpe noirâtre balfamique \& tres-odorante, ce qui fait quelles rendent le Chocolat tres-favoureux, \& qu'elles lay communiquent des proprietez admirables contré la plufpart des maladies de la poitrine, \& contre: les benefices \&x poifons; c'eft pourquoy on dit ordinaire- 
232 Le bon asage du Thé, mene que la poudre de $\mathrm{Va}$ nille eft l'ame du Chocolat, \& en effet celuy qui eft preparé par les trompeurs fans Vanilles, eft à mon fens une affez méchante boiffon.

Monfieur Ouel qui a beaucoup de terres \& d'effets dans les Inles, où l'on fait un grand ufage du hocolar, a fceu par le rapport de quelques Efpagnols Mexicains, que les Vanilles vertes ne fentent rien, \& qu'elles ne deviennent odorantes que par une preparation fecrette.

A l'égard du Poivre de Mexique, c'eft le Poivre de Tabafco, que les Efpagnols nomment Chilli, \& que nous appellons Poivre d'Inde, ou Poivre rouge, parce quien 
du Caffé, of du Chocolat. 233 effer fes goufles qui font rondes vers la queuë \& pointuës à l'autre extremité, font d'un aflez beau rouge. La pointe qu'elles donnêt au Chocolat, accommode mieux le gout des Efpagnols que le nôtre; c'eft pourquoy il eft affez rare qu'on en mette dans nôtre Chocolat : cependant it eft quelques François qui aiment cette faveur âcre \& picquante, \& qui par cette raifon preferent le Chocolat quion fait venir d'Efpagne, \&z dáns lequel le gout de ce Poivre fe fait toûjours remarquer.

Voicy maintenant quel étoie le Formulaire de cette pâte, avant que les Efpagnols y euffent ajoûté les parfums \& les aromatiques dont il fera parké cy-aprés. 
234 Le bon ufage du Thé,

Prenez quatre livres de Cacao preparé comme il a été dit, trois livres de fucre, dixhuit Vanilles, \& quinze grains. de poivre d'Inde, pour faire du tout une maffe de pâte fuivant la methode.

Lors que le commerce fut affez bien étably entre les deux continens, pour que les habitans de la nouvelle Efpagne, puffent tirer de celuy-cy toutes efpeces de commoditez, ils ne manquerent pas d'en tirer la canelle \& les Gerofles, qu'ils ajoûterent bien-tôt aprés à la confection du Chocolat. Il y a peu de gens qui ne fçachent que la canelle eft l'écorce d'un Arbre fauvage, qui vient fans: culture en divers endroits des 
du Caffé, o du Chorolat. 235 Indes Orientales, \& particulierement dans les infes de Java, de Malavar \& de Zeilan, $\&$ l'on. fçait encor quelle eft fort odorante, \& fort agreable au goût ; ceft pourqnoy elle eff comme tous les autres aromatiques cordiale, ftomachique \& diûretique.

Il en eft de même des Gerofles, qui font les fruits, ou felon quelques - uns les fleurs d'un Arbre qui croît aux Ifles des Moluques; mais ils ont cela de plus que la canelle, qu'ils abondent en une huile tres-odorante \& tres-fpiritueufe, qui fe détachent tres. facilement de leurs parties terreftres, \& qui donne une vertu cordiale \& balfamique aे toutes les compofitions où 
236 Le bon usage du Thé,

ils entrent. Au furplus, ils font trop connus dans le domeftique, pour quil foir neceffaire d'en parler icy plus particilierement, mais je ne dois pas obmettre, de raporter le Formulaire qu'on fuivit dans la nouvelle Efpagne, aprés que ces drogues y eurent été negociées.

- Prenez quatre livres de $\mathrm{C} a$ cao preparé, trois lives de Sucre, quatre Vanilles, deux dragmes de Canelle, huit Gerofles, \& dix grains de Poivre d'Inde.

Le Mufc \& l'Ambre gris ne furent pas long-tems fans être de la partie. Le Mufic eft la matiere d'une tumeur, qui fe forme tres-fouvent au nombril d'un animal du même nom, qui 
du Caffé, \& du Chocolat. 237 eft affez femblable à un Chevreiill. Cét animal qu'on voit au Royaume de Pegudans les Indes, ne fe repaift ordinairement que d'Herbes aromatiques, d'où vient que cette matiere excrementeufe étant hors de cette tumeur, \& expofée aux rayons du Soleil, devient un parfum tres -lfuave; qui eft tout enfembleice-2 phalique, cordial \& ftomachique. L'Ambre gris eft un Bitume qui découle de quelques fontaines dans la mer, où il fe condenfe, \& d'où if eft jetté à bord, principalement fur le rivage des Intes Maldives, où il eft digeré \& exalté par la chaleur du Soleil. C'eft le plus fuave \& le plus precieux de tous nos par- 


\section{Le bon ujage du Thé,}

fums, \& par confequent celuy qui a dans un plus éminent dégré les qualitez que je: viens de dire On verra par le Formulaire quil fuit, le changement que fit au déuxiéme, laddition do ces deux par-? funs. :

Prenez quatre livres de $\mathrm{Ca}$ cao preparé y trois livres de Sucre, douze Vanilles, anse dragme de Canelle, fix Gerofles, huit grains de Poivre d'Inde, fix grains d'Ambre, $\&$ trois grains de $M u f c$, pour former la maffe fuivant la methode.

Cette derniere defcription eft celle qui eft la plus ordinairement fuivie parmy nous, à cela prés que la plufpart des gensen fuppriment le Poivre 
du Caffe, o du Chocolat. $2+39$ d'linde, \& que les plus délicatsfubrfutent àla Canelle le Cafja lignea, qui eft tune autre écorce qui fe tire dés mêrne's lieux que la Canelle, \& qui nen eft prefque point diffe? rente quant à la forme; mais qui a plus de délicatefle pour l'odorát \& pour le goût, ayant même cette proprieté, qu' $\mathrm{e}$ ? tant tenuë bien long-temps dans la bouche, elle $s$ y reduit entierement en une efpece de mufilage.

2) Ilfe trouve encor beaucoup d'autres formulaires entre les mains de divers particuliers, mais qui ne different de celuy-cy, ny entreux mêmes, que dans la diverfié des dofes de la Vanille, de l'Ambre \& du Mufc, à cela prés nean- 
240. Le bon ufage du The', moins que quelques $\mathbf{u}$ un ajoûtent aux ingrediens dont je viens de parler, quelques grains de Cardamome, ou une tres-petite quantité de Gingenbre, deux autres efpeces de drogues Aromatiques, ayant les vertus tant de fois repetées, dont chacun peut faire tel ufage que bon luy femblera par - rapportà fon goût, qui feul doit être confulté, lors qu'il s'agit du choix \& des dofes des parfums \& des Aromatiques, qu'on veut faire entrer dans la compofitions du Chocolat, ayant tous à peu prés les mêmes proprietez.

Je ne fçaurois être neanmoins du fentiment d'un Comte Efpagnol, qui veut que pour faire du bon Chocolat, 
$d u$ Caffé, \& du Chocolat. 24 I on doive entierement fupprimer la Vanille, \& augmenter les dofes de l'Ambre \& du Mufc; car quand il feroit vray comme il nous l'affure, que la Vanille feroit méprifée dans la nouvelleEfpagne, pour être nommée le parfum des pauvres, ce mépris ne viendroit à mon fens, que de ce quelle y feroit trop commune, \& cela ne m’empêcheroit pas de la nommer icy le parfum des $\mathrm{Ri}$ ches, parce qu'elle y eft fort chere, \& quelle a d'ailleurs des qualitez qu'on ñe fçauroit tropeftimer.

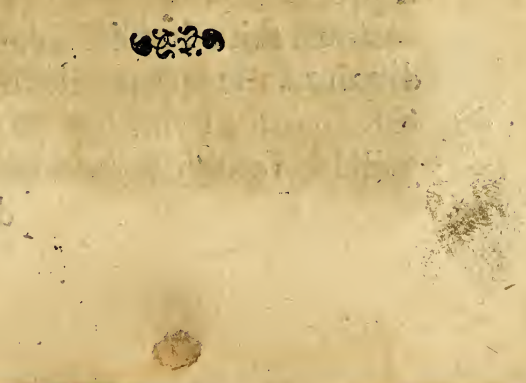


242 Le bon ufage du the

\section{CHAPITRE V.}

De la compofition dis Chocolat.

COmme on fait ordinaire. mént une confiderable quantité de Chocolat à la fóis, \& quil ent bon que cetre confection qui elt affez longue, sacheveneanmoins en un même jour, il eft à propos auffi que deux perfonnes y travaillent concurremment, car tandis que l'une s'occupeia preparer le Cacáo, lautre pulverife les parfums \& les aromatiques.

Pour faire le Chocolat ordinaire, la preparation du Cacao ne confifte quà le griller en la maniere que je

$$
\text { diray }
$$


du Caffé, \& du Chocolat. 243 diray bien-tôt : mais pour faire un Chocolat dont l'ufage ne puiffe avoir aucune mautvaife fuitte, il y a un peu plus de myftere, puifquil sagit d'extraire du Cacao, la quantité furabondante de fon huile froide \& mufilagineufe, fans neanmoins luy ôter ce quil en doit avoir pour être favoureux, \& pour faire corps avec le fucre. Je découvriray incontinent la façon d'y proceder, mais pour ne point fortir de l'ordre que je me fuis propofé, je dois dire auparavant en quoy confifte la pre-miere prepatation du Cacao.

Pour y proceder, il faut alIumer un bon feu de charbons. dans un fourneąu, \& placer enfuite fur le fourneau une 
244 Le bon usage du The', bafline de fer ou de cuivre eftamé, d'une capacité fuffifante pour contenter au large trois ou au plus quatre livres de Cacao, qu'on fera griller dans cette baffine jufquà ce que fa pelure le quitte aifement, obfervant de le remuer continuellement avec une efcumoire à confitures ou * autre pareil inftrument, afin que toutes les A mandes foient également grillées; puis ayant étendu une petite nappe ffur le plancher, vous jetterés deffus vôtre Cacao ainfi grillé ; \& l'ayant recouvert avec une partie de la même nappe, vous le remuerés avec les mains jufqu'à ce que toutes les pelures foient brifées, aprés quoy en le fecoüant dans une 
du Caffé, \& du Chocolat. 245 baffine, comme on fait le grain dans un Van, pour en feparer toutes les pelures qui voltigent \& qui tombent par ce moyen, vous le grillerés de nouveau, jufquà ce que fon huile foit fiffifamment exaltée, ce qu'on connoîtra lors qutil fera autant grillé qu'ille peut être fans tenir le moins du monde du brûlé, alors en achevant de détruire fon integrité avec un inftrument de fer, \& en liquifiant la graife avec une mediocre chaleur, on le reduira en forme de $\mathrm{pâ}^{2}$ e à l'effer de quoy plufieurs chauffent le fond d'un morier de bronze \& lun des otits de fon pilon, \& pilent e Cacao dans ce mortier;

L $\mathrm{ij}$ 
246 Le bon u age du Thé,

$\therefore$ duquel ils entretiennent la chaleur par le moyen d'un fourneau quiluy fert de pied; mais la plus ordinaire \& la meilleure façon d'y proceder, eft de l'écrafer corome font les Indiens avec un rouleau de fer, fur une pierre dure \& applatie quils nomment metate ou matatl \& que nous appellons pierre à Chocolat, échauffant pareillement cette pierre avec un brafier qu'on met deffous un peu auparavăt, \& qu'on y entretient autant quil eft neceflaire. La figure qui fuit reprefente la pofture dans laquelle on doit être pour cette operation, auffi bien que le brafier, le rout leau \& la pierre. 


\section{du caffé, or du chocolat. 247 :}

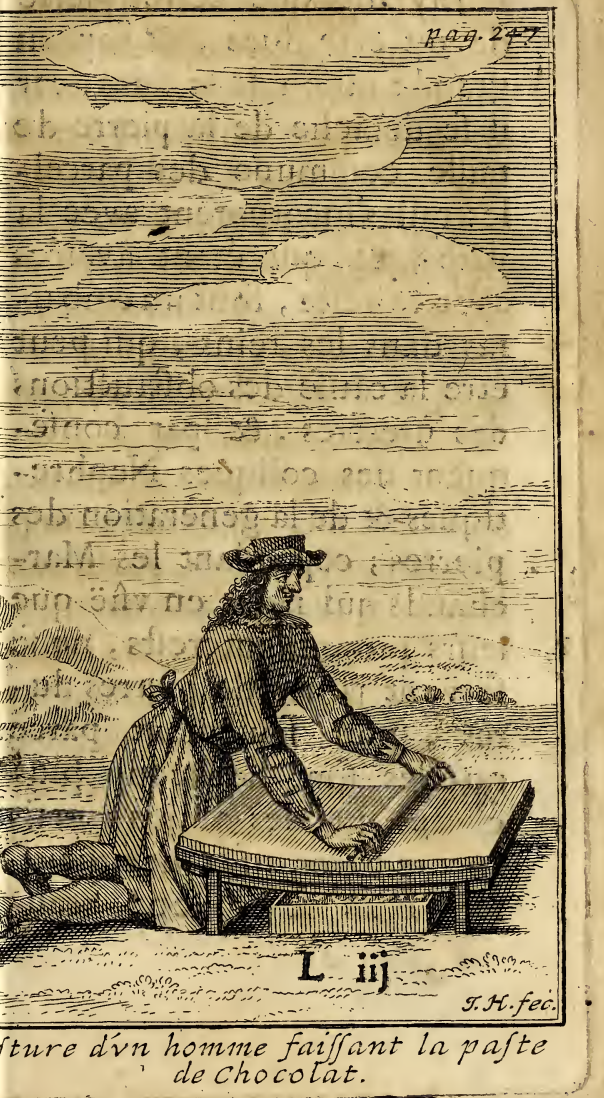


- 248 Le bon ufage du Thé:

Jay' dit que cette pierre devoit être dure, \& jay eu grande raifon de le faire, car il fe detache de la pierre de taille commune des parcelles qui s'incorporent avec la pâte, \& qui étant avalées avec le refte, font un embarras dans les reins, qui peut être la caufe des obftructions des ureteres, \& par confequent des coliques Nephretiques \& de la generation des pierres; cependant les Marchands qui n'ont en vâë que leurs propres interefts, ne fe fervent jamais de pierres dures, non feulement parce quelles font beaucoup plus cheres que les autres; mais encore parce qu'êtant échauffées elles fe caflent beaw- 
du Caffé, \& du Chocolat .249 coup plus facilement. Je diray comment on fe peut garantir des differentes furprifes de ces Marchands en parlant du choix du Chocolat.

Pour paffer maintenant à la maniere de dégraiffer le Cacao, il faut aprés qu'il a été ainfi liquefié, le mettre dans un fac de toile neuve \& pleine, dont l'embouchure fera en fuitte exactement coufuë, puis ayant mis une feuille de fer blanc un peu plus que mediocrement chauffée, fur le fond du preffoir qui eft reprefenté à la pagé 253 . \& par deffus cette feuiille un quarré de papier gris, on placera fur ce quarré le fac contenant le Cacao, qui aura été coupé à peu prés de la même 
250 Le bon ufage dw Thé; grandeur; puis l'ayant encos re recouvert d'un quarré de papier, \& enfuitte d'une feuille chaude de fer blanc, on impolera fur cetre feüille la table fuperieure du preffoir, que l'on contraindra à exprimer le Cacao, par quelques tours de viz, pendant quoy on aura prés du feu deux autres feuiilles de fer blanc, qui feront mifes en la place de ces premieres avec deux nouveaux quarrés de papier, dés quion jugera que les deux autres feront autant chargés qu'il eft poffible de la graiffe du Cacao, ce qu'on repetra jufqu'à dix ou douze fois, felon que le Cacao aura paru plusou moins gras.

On pourra s'affurer alors 
du Caffé, o du Chocolat. 2 I I quil fera autant dégraiffé qu'il le doit être pour n'avoir aucunes mauvaifes qualitez, \& quil aura neanmoins encore la jufte confintance qu'il doit avoir, pour s'unir intimement avec le fucre, \& avec les autres ingrediens de la pâte, qui fera beaucoup plus favoureufe que celle du Chocolat ordinaire.

On pourroit encore dégraiffer le Cacao de deux autres manieres, favoir en diftillantper decenfum fa graiffe furabondante, comme on fait quelquefois celle des gerofles, \& encore en le mettant dans une baffine aprés qu'il eft broyé, avec de l'efprit de vin auquel on mettroit le feu, \& qu'on agiteroit en remuant L v 


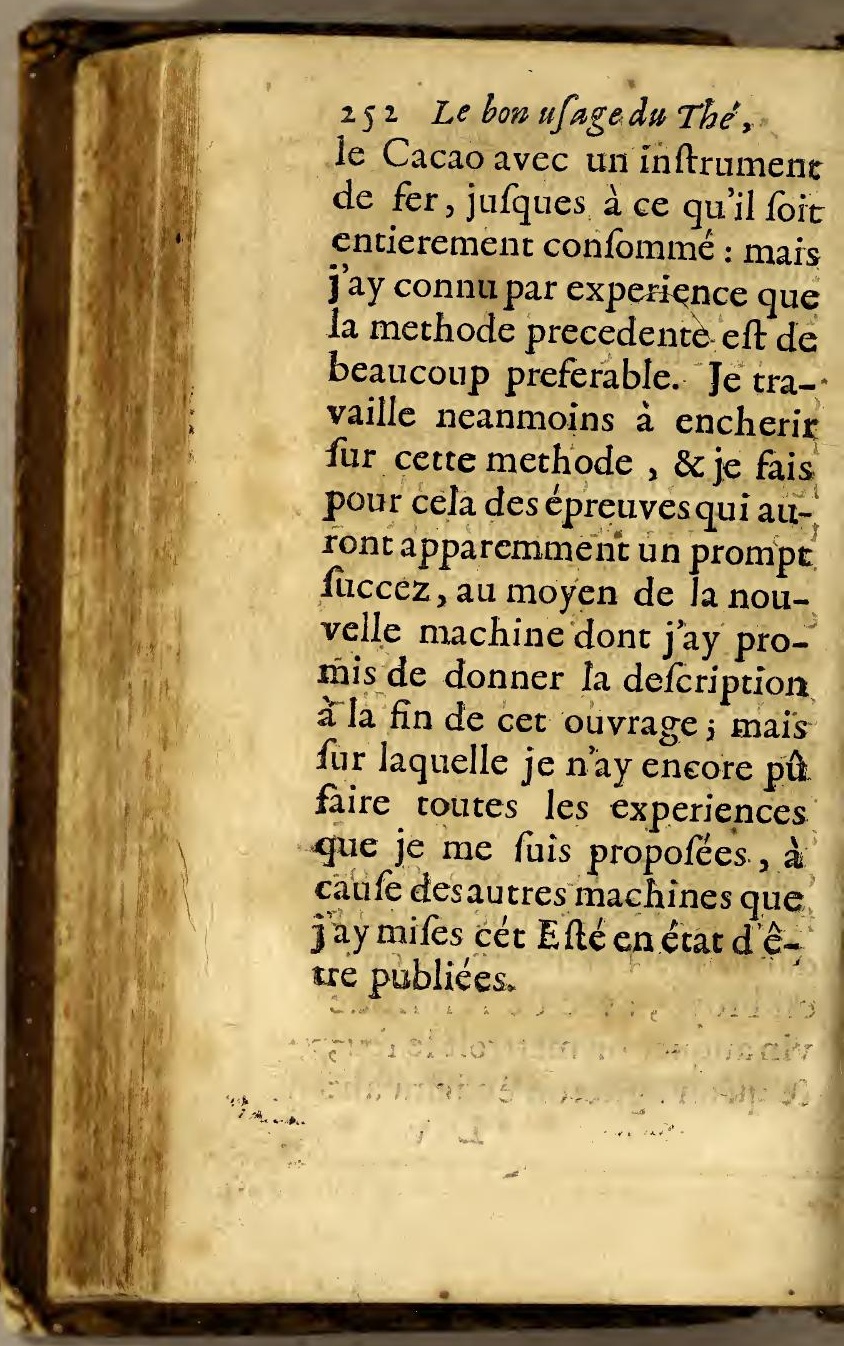




\section{du Caffé, \& du Chocolat. 253}

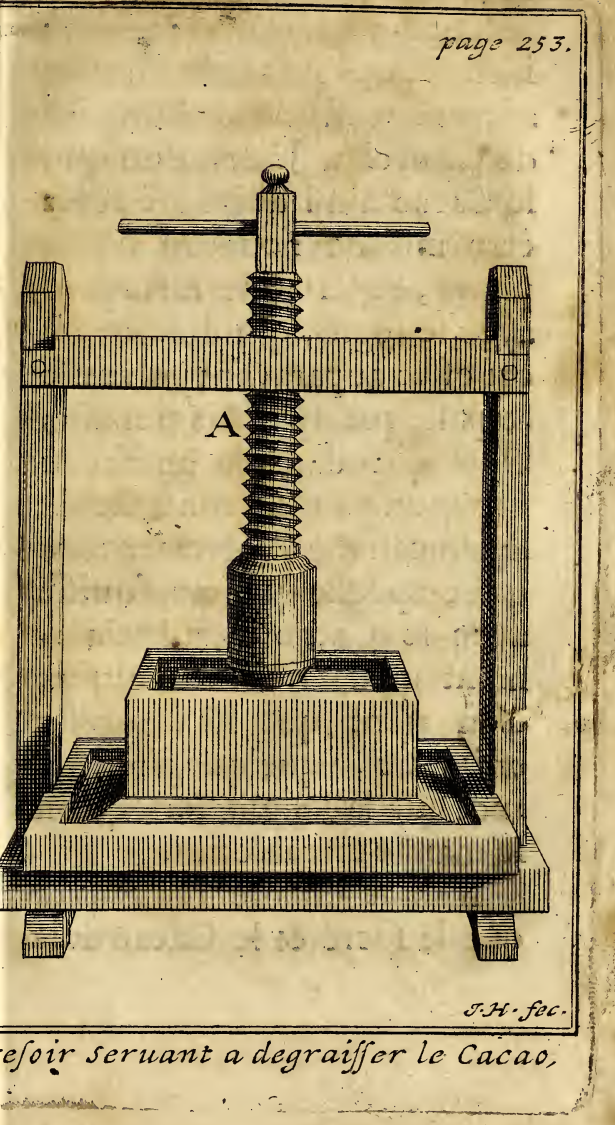


294 Le bon wage du The',

Pourdonner maintenant des inftructions fuffifantes Yur les autres circonftances de la pâte de Chocolar. Je dois dire que le Cacao ainfi dégraiffé, doiz être mis de nouveau fur la pierre, \& en fuite incorporé avec le fucre, qui doit être $a$ cét effet auparavant pulverifé \& paffé par un tamis tres-fin; bien que dans la methode commune on fe contente de le concaffer groffierement, ce qui empêche qu'il ne suniffe avec le Cacao auffi.intimement quil eft à fouhaitter, Paì vient que le Chocolat ardinaire, a quelque chofe de rude fur la langue lors quon le mange en tablettes.

It faut encore remarquer gue le fucre \& le Cacao doj- 
du caffé, \& du Chocolat. 255 vent être parfaitement incorporés enfembles, avant que d'y ajoutrer les parfums \& les Aromatiques, qui ne pourroient être long-temps agitez fur la pierre chaude, fans. perdre beaucoup de leurs parties odorantes \& favonreufes, ce qui fe fait plus ou moins: facilement, felon que ces parties font plus ou moins delicates \& fubtiles; c'eft pourquoy l'ambre \& le mufc doivent êrre pulverifés à part, afin de n'être ajoûtez à la maffe, quaprés y avoir fait entrer la Vanille, la Canelle, \& tous les autres aromatiques, qu' il eft bon de pulverifer enfembles ; par cette raifon que ceux qui font fort fees, \& facilitent la divifion de ceux qué 
256 Le bon usage du The, ont de l'humilité comme la Vanille, ou de l'huile, commeles Gerofles, ce qui ne fuffiroit pas neanmoins pour les difpofer à paffer par le tamis de foye (comme on le doit faire ) fi on n'adjoûtoit au tout quelques morceaux de fucre à diverfes reprifes,ce qu'on doit encore obferver en pulverifant le Mufc \& l'Ambre, quoyque ces parfums ne doivent pas être tamifés pour n'en pas perdre beaucoup de parties.

Il eft a remarquer que le Chocolat, où l'on fait entrer l'Ambre \& le Mufc, eft ordinairement infupportable aux perfonnes qui font fujettes aux vapeurs, mais quaufli fans ces parfums, on peut faire une 
du Caffé, \& du Chocolat. 257 forte de Chocolat fort agreable, feulement en augmentant le nombre des Vanilles, fur lefquelles on doit avoig d'autant moins de menagement, qu'elles contribuent beaucoup aux proprietez du Chocolat dégraiffé, c'eft ainfi que nos Artiftes ont nommé celuy dont je viens d'enfeigner la preparation, \& auquel on peut donner indifferemment la forme de tablettes, celle de rouleaux, ou celle de Maffes.

Pour faire les tablettes, on met à certaines diftances fur des feuilles de papier blanc, des morceaux de la pâte encore chaude, plus ou moins gros, felon quion veut que les. tablettes foient plus ou moins. grandes, \& pour les former ons 
$25^{8}$ Le bon uJage du Thé, agite feulement ces feuillles, en les contournane \& en. les fecoüant avec les deux mains, en forte que la pâte s'eftende fuffifamment. Pour donner la forme à un rouleau, il ne faut que prendre une demie livre de cette pâte, \& l'ayant mife au milieu d'une demie feuiille de papier, en prendre les deux marges, \& en l'agitant autant qu'il eft befoin, contraindre cette maffe à s'étendre en longueur; Enfin pour faire des maffes quarrées de differents poids, il ne faut qu'emplir de cette même pâte, des moules de ferblanc tenant juftemene une livre, une demie livre, ou tels autres poids que l'on veut. 


\section{du Caffé, \& du Chocolat. 259}

\section{CHAPITRE VI.}

De la Sopbiffication, du cboix, de la confervation, é du prix du Chocolat.

'il y a quelque chofedans Sle Chocolat ordinaire, qui puiffe corriger en quelque forte les mauvaifes qualitez du Cacao non dégraiffé, c'eft principalement le Sucre \& la Vanille; cependant jay déconvert que les trompeurs preparent leur Chocolat avec la Molcovate, c'eft-à-dire avec la fimple matiere du Sucre qui contient encore tout fon mufilage, pour n'avoir pas paffé par le blanchiment, où cette qualité vicieufe reçoit 
260 Le bon is age du Thé, quelque correction, \& cela parce que cette matiere leur coute la moitié moins que le Sucre. Ils font pis encore; car ils en fuppriment non feulement l'A mbre \& le mufc, mais même les Vanilles, par cette raifon qu' elles couftent au moins fix fols la piéce, \& même dans les temps où elles font un peu plus rares, jufques à dix ou douze fols, \& que neanmoins pour faire fans mufe ny Ambre un Chocolat d'une paffable forte, il en faut au moins deux ou trois pour chaque livre.

On peut bien juger que pour fubfifuer les Vanilles, ils augmentent confiderablement la dofe de la Canelle, dont la quantité excedente 


\section{du Caffé, \& du Chocolat. 261}

doit neceffairement produire de méchans effets; mais tout cela ne feroit rien, sils ne portoient leur fophiftication \& leurs tromperies jufquà cét excez, de preferer le plus petit Cacao, \& d'en augmenter la quantité par de vieilles amandes, ou même d'ajoûter à leur confection, une confiderable quantite de la pâte des Faifeurs de pains d'Efpices, ce qui fait un falmigondys dautant plus malfaifant, que la poitrine \& le ventre font tout enfemble irritez \& troublez par l'action de la $\mathrm{Ca}$ nelle, des épiceries \& du miel de cette pâte, ce qui eft tôtjours fuivy de diverfes indifpofitions, qui ne tirent que trop fouvent à de dangereufes confequences. 
262 Le bon ufage du The',

C'eft pourquoy lors qu'il s'agit de choifir du Chocolat, il faut bien s'appliquer à diftinguer parl'odorat \& par le goût, l'odeur \& la faveur des veritables $\&$ des faux ingrediens, connoiffance que je ne fçaurois communiquer, \& qu'on ne peut acquerir que par une efpéce d'habitude.

Mais il eft bien plus facile de connoître le Chocolat qui eft trop vieux fait, ou qui a été mal-confervé, puis qu’il a ordinairement une efpéce de moififfure à fa fuperficie; \& qu'en le flairant on découvre une odeur qui tient de l'aigre \& du rance.

Aprés tout, on ne peut bien être affuré de la bonté du 
du Caffé, \& du Chocolat. 263 Chocolat qu'en le faifant preparer chez foy, ou en n'établiffant fa confiance, que fur la fidelité de perfonnes finceres \& bien connuës. Je puis affurer neanmoins que fans avoir aucun commerce avec hos Artiftes, on peut en tirer d'eux fans craindre d'être ttompé, puis qu'ils le preparent toûjours dans les conferences publiques, que nous tenons tous les Vendredis depuis quinze années pour l'édification de la Medecine; mais de quelques perfonnes fidelles qu' on le puiffe prendre, on ne doit pas chercher le bon marché lors quion le veut a voir excellent, puifque fes differens degrez de bonté, dépendent principalement 
264 Le bon ufage dn Thé, des diverfes dofes de l'Ambre du Mufc \& de la Vanille, qui font des drogues affez cheres pourn'en pouvoir augmenter la quantité dans le Chocolat, fans en rehauffer le prix, c'eft pourquoy je n'eftime pas que le meilleur puiffe être donné à moins de fix francs la livre, celuy du fecond ordre à cent fols, celuy du troifiéme ordre à quatre francs, \& enfin celuy qui eft fimplement paffable à un écu.

Au refte foit quion le faffe preparer chez foy, foit qu'on le tire d'ailleurs, on ne doit s'en approvifioner au plus que pour une confommation de deux ans, puifque même avant l'efcheance de ce ter- 
du Caffé, \& du Chocolat. ${ }_{26}{ }_{5}$ me, il commence à degenerer, ce qui fe fait plûtốt ou plus tard, felon qu'il eft bien ou mal confervé, c'eft pourquoy pour prevenir cét inconvenient autant qu'il eft poffible, il faut l'envelopper dans du papier gris, le mettre ainfi enveloppé dans une boëte, \& placer cette boëte dans une armoire qui foit en lieu fec.

\section{CHAPITRE VII.}

De la Boiffon ou Breurage de Chocolat.

T A plus ordinaire \& la plus agreable façon de prendre le Chocolat eft en boiffon. Pour preparer cette boif- 
266 Le bon usage du The', fon on fe fert coutumierement de vaiffeaux femblables aux Caffetieres, avec cette feule difference que celles qui doivent fervir au Chocolat, \& qu'on nomme pour cette raifon Chocolatieres ont un trou dans le milieu de leurs couvercles, pour paffer le manche du moulinet dont-il fera bien-tôt parlé, ce qui eft neanmoins d'autant plus inutile, qu'il n'eft ny neceffaire ny commode, de tenir la Cho. colatiere couverte pendant qu'on fe fert de ce mouliner; au refte foit que la Chocolatiere foit troüée foit qu'elle ne le foit pas, il fuffit pour faire le breuvage dont il s'agit, d'y mettre une quantité d'eau proportionnelle au nombre 
du Caffé, of du Chocolat. 267 bre des prifes qu'on veut preparer, \& l'ayant mife devant le feu, d'y ajoûter pour chaque prife au moment qu'elle commence à boüillir, lés deux tiers d'une once de Chocolat rapé ou decoupé, \& pareille quantité de fucre, pour laiffer boüillir le tout environ durant un demi quart d'heure.

Il eft à remarquer qu'il ne faut point mettre de fucre avec le Chocolat, lors qu'on veut mettre en ufage le firop de Vanilles, parce qu'il donne feul à ce breuvage, toute la douceur, \& tout l'agreément qu'on peut fouhaitter, en le mettant dans chaque chique à la quantité d'une cuëillerée, aprés y avoir ver- 
268 Le bon ufage du Thé,

fé la liqueur de Chocolat, fur laquelle on peut fe difpenfer de faire agir le moulinet lors qu'on la veut preparer de cette forte, ce firop la rendant affez agreable, fans qu'il foit neceffaire de la faire mouffer.

Mais au contraire êtant preparée avec le fucre elle feroit mal plaifante, fi avant de la verfer dans lés chiques, elle n'avoit été affés longtemps agitée avec le moulinet, qui eft une petite forte de maffe de boüis dont la tête eft diverfement cizelée, $\&$ dont le manche ou batonnet eft affez long par rapport à la groffeur de la tête, qui doit remplir prefque toute l'embouchure de la Chocola- 
du Caffe, o du Cbocolat. 26 , tiere, afin d'être autant maffive quill le faut, pour donner beaucoup de mouvement à la liqueur, en contournant le batonnet dans la palme des mains, puifque c'eft par ces mouvemens, que les parties de l'air s'infinuient dans la liqueur, \& qu'elles le rarefient \& la mouffent, comme il arrive lors qu'on prepare la crême fouëttée.

Lors quavec le moulinet on veut bien faire mouffer le breuvage de Chocolat, il faut que par proportion à la quantité de la liqueur, fa maffe foit de telle hauteur, que fans toucher au fond de la Chocolatiere, dont elle doit être éloignée d'un demy travers de doigt, eliè ne laiffe pas d'être $M$ ij 
270 Le bon ufage du Thé, entierement noyée dans la liqueur, car fi la partie fuperieure en excede la hauteur, la mouffe ne fe fait qu'imparfaitement, mais les Marchands de liqueurs qui ont leurs Chocolatieres tantôt pleines tantôt prefque vuides, ne peuvent pas garder tant de mefures; c'eft pourquoy quelques-uns d'entre eux, y ajoûtent des jaunes d'œufs cruds pour le mieux faire mouffer, ce qui le rend indigefte $\& x$ dégoutant.

Au refte comme la mouffe ne fe fait qu'au deffus de la liqueur, on à coûtume de la verferdans la chique à diverfes reprifes, \& c'eft pour cela qu'il feroit incommode de palfer le bâton du moulinet 
du Caffé, \& du Chocolat. $27 \mathrm{I}$ dans le trou du couvercle, puifqu'il faudroit l'ôter \& le remettre à chaque reprife, outre que la Chocolatiere étant bouchée, l'air qui doit fervir à la géneration de la mouf$f e$, ne s infinuë dans la liqueur en quantité fuffifante que dans un trop long efpace de temps.

Jay dit que la precaution de boucher la Chocolatiere pendant qu'on mouffe le Chocolat, étoit auffi inutile qu'incommode, \& jay eu raifon de l'advancer; il n'en eft pas du Chocolat comme du Thé \& du Caffé, dont les parties volatiles fe diffipent tres-facilement, puifque celles du Chocolat font plus embaraffées dans fes parties graffes, $M$ iij 
272 Le bon ufage du The', \& qu'ileft affez probable d'ail leurs, que la plûpart des parties odorantes qui s'exhalent des parfums,retournent circulairement vers leur maffe cóme celles de l'Aymant; puis qu'il n'y a point des parfums qui ne fubfifte un tempstresconfiderable, malgré la prodigieufe \& continuelle diffpation de fes parties plus efficaces.

Il y a encore cette obfervation à faire, qu'on fe ferr de la maffe du moulinet pour entrainer la mouffe de la liqueur, à mefure qu'on la verfe dans la chique, ce qui doit engager encore à ne point embaraffer fon manche dans le trou du couvercle.

Par toutes ces confidera- 
du Caffé, \& du Chocolat. 27 tions, je tiens que le couve $\mathbf{r}$ cle des Chocolatieres ne doit point être percé, \& qu'elles ne doivent être par confequent aucunement differentes des Caffetieres, dont le Filtre fert utilement pour retenir le marc plus groffier du Chocolat. Il feroit inutile d'en donner encore une fois la figure; mais je ne me difpenferay pas de donner icy celle des moulinets, avec les differentes cizelures qu'on y peut faire.

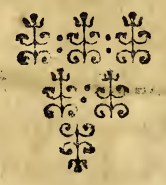

M iiij 


\section{Le bon wage du The,}

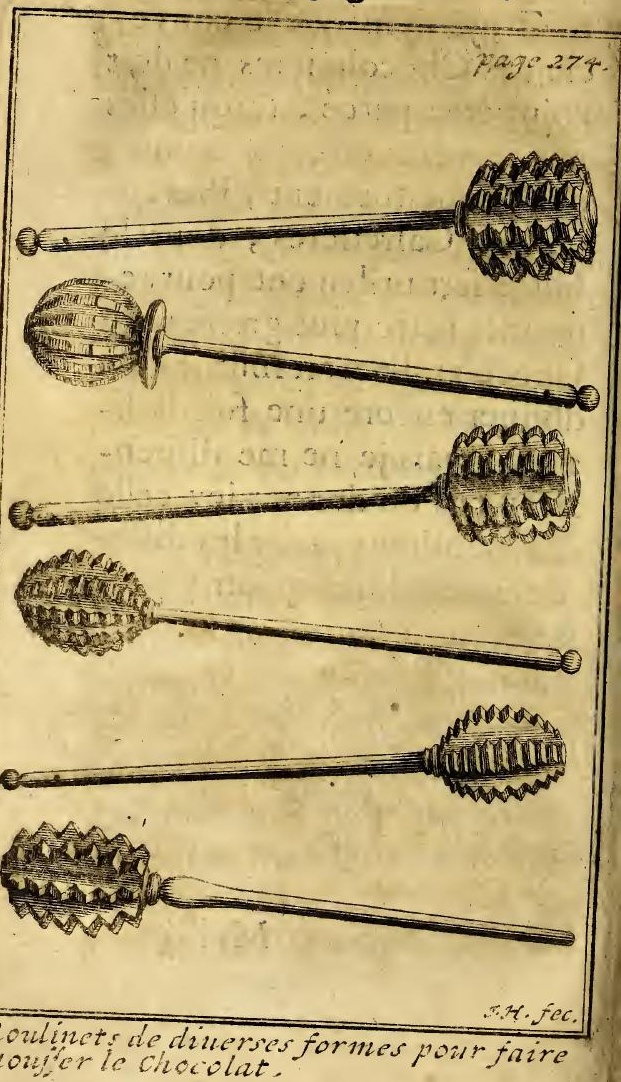


du Caffe, of du Chocolat. 275 Au furplus le Chocolat des Indiens fe mouffe beaucoup plus facilement que le nôtre, non feulement à caufe de la farine de Mays qui entre dans la compofition de la pâte;mais encore parce que dans la preparation de ce breuvage, ils preferent à l'eau commune, une forte de boiffon ufuelle qu'ils nomment Atolle, \& qui eft encore faite avec la même farine détrempée \& cuitte dans de l'eau; mais il leur eft affez ordinaire d'ôter une partie de cette mouffe, ce qui degraiffe en quelque forte leur Chocolat, en quoy il ne feroit peut-être pas inutile de les imiter, paique le breuvage de Chocolat fne fçauroit être trop maihre ny trop liquide; 


\section{Le bon u age du Thé,}

\& c'eft par cette raifon que jay ordonné pour chaque prife une dofe de pâte beaucoup moindre que celle qui a été prefcrite par tous les Auteurs qui m’ont precedé, \& que celle même qui eft de l'ufage le plus ordinaire.

Mais il feroit dangereux à l'exemple de quelques Indiens, de preparer à froid le breuvage du Chocolat, \& encore plus de le faire à la glace à l'imitation des Italiens, puifque de la forte, il eft capable de riviner en peu de temps l'eftomach le plus chaud, \& d'amortir le plus fort levain digentif.

Au contraire on peut s'affurer que le Chocolat clair, dégraifé, preparé avec le Sirop

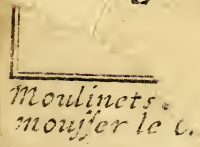


du Caffé, \& du Chocolat. 277 de Vanilles, \& bû par gorgées autant chaud quil eft poffible, ne peut jamais être nuifible; puis quavec un eftomach tres-foible on en peut faire un fort grand ufage, fans craindre d'en reffentir aucune incommodité, ce qui eft journellement experimenté, par les perfonnes mêmes qui font atteintes, de toutes ces efpeces de maladies qui dépendent de l'indigeftion.

Il y a encore cette notable difference, entre le Chocolat degraiffé \& le Chocolat commun, que le premier n'a aucunes parties qui puiffent boucher les pores ny obftruer les vaiffeaux, au lieu que la graiffe mufilagineufe du 


\section{Le bon usage du Thé,}

dernier, doir neceffairement faire des obftructions \& empêcher la tranfpiration, d'où vient qu'il caufe une repletion incommode, dans prefque tous ceux qui font naturellement gras ou qui font difpofés à le devenir.

C'eft peut-être par cette raifon, que certains Cafuiftes foûtiennent qu'il rompt le jeûne, mais fi le Cardinal Brancacio qui êtoit d'une opinion contraire, affure dans une differtation quil a faite exprés, qu'une taffe de Chocolat ne tire à cét égard à aucune confequence, pourveu quelle foit prife par une efpece de neceffité, $\&$ non pas à deffein de fe fouftraire à l'obeiffance qu'on doit à l'E. 
du Caffé, \& du Cbocolat. 279 glife, il auroit trouvé de bien plus fortes preuves de cette verité en faveur du Chocolat degraiffé, car outre qu'il ne tient pas plus de l'aliment que du remede, ta boiffon qu'on en fait n'ayant que tres - peu de parties graffes \& materielles, ne doit être confiderée au plus que commele vin, la bierre, \& les autres boiffons ufuelles, dont l'Eglife'permet un ufage refervé dans les heures d'abftinence.

Aprés tout, fi l'on pretend qu'on ne doit employer la pâte du Chocolat commun que deux mois aprés qu'elle eft faite, pour n'être pas trop graffe \&z trop relâchante, on doit conclure de ce qui a éte 
.

280 Lebon ufage du Thé,

cy-devant obfervé, qu'il eft inutil d'apporter la même precaution à l'égard du Chocolat dégraifé, puifque fi nouveau qu'il puifle être, il eft deftitué de fa graifle furabondante, \& par confequent depoïillé de fes qualitez nuifibles; c'eft pourquoy on peut le manger en tablettes fans en craindre aucun inconvenient, \& j’ay même obfervé qu'il fe conferve facileinent dans fa bonté beaucoup plus longtemps que le Chocolat commun, ce quile rend preferable pour ceux qui s'engagent à delongs voyages, ou quile negotient en des Pays éloignez.

On voit des gens qui boivent de l'eau peu avant que 
du Caffé, \& du Chocolat. 281 de boire du Chocolat commun, fondé fur cette faufie opinion, que le Chocolat elt de la nature des alimens chauds, dont-il eft bon de prevenir les méchans effets parleurs oppofez en quoy ils s'abufent d'autant plus, quau contraire il ne peut caufer que les effets ordinaires des choles les plus froides \& les plus indigeftes: mais au refte certe mauvaife precaution eft encore plus inurile dans l'ufage du Chocolat dégraiffé, qui eft un aliment medicamenteux des plus temperez \& des plus temperans.

ब大न्मक 


\section{Le bon usage du The',}

\section{CHA PITRE VIII.}

Des proprietez du Chocolat.

A Prés avoir expliqué afA fez clairement, la nature \& la bonne preparation du Chocolat, je dois prefumer que les perfonnes intelligentes, comprendront facilement d'où dépendent fes diverfes proprietez, aprés que je les auray fimplement déduites; c'eft pourquoy fans m'engager dans ce chapitre à faire d'inutiles raifonnemens, j'expoferay fimplement les obfervations que je dois à l'experience, \& je ne m'expliqueray au plus, que fur l'ufage qu'on doit. faire de cette 
du Caffé, \& du Chocolat. 283 boiffon dans chaque maladie.

Or étant pris avec le Sirop de Vanilles à differentes heures du jour, \& fur tout le foir en femettant au lict à la quantité de deux prifes, il eft d'un effet également prompt \& affuré, pour fufpendre le mouvement immoderé de la matiere du rheume \& des fluxionsde poitrrine, pour émouffer les parties falines \& irritantes de la feriofité qui excite la toux, pour éteindre les. inflâmations de la gonge \& de la pleure, pour calmer les differentes caufes des infomnies, \& pour reparer la fatigue des Predicateurs, $\&$ des autres perfonnes qui s'engagent frequemment à foûtenir 
284 Le bon uJage du Thé, des actions publiques.

Preparé de la méme manie, re, il eft auffi d'un grand fecours pour amortir la bile épanchée qui provoque les vomiffemens, \& qui fait les coliques bilieufes, le colera morbas, la diarrhée \& la diffenterie.

C'eft encore un remede tres - efficace dans la fiévre éthique, je veux dire dans cette fechereffe de poitrine qui conduit à la pulmonie, dans laquelle maladie on peut encore s'en fervir tres-utilement, pour en arrêter le progrez \& pour en addoucir les incommoditez, fur tout fi en place d'eau on le prepareavec le laick, qu'il faut écremer au commencement de fon ébullition. 
$d u$ Caffé, o du Chocolat 285 $\mathrm{Si}$ on le prepare avec le firop de coins, \& quion y adjoûte quelques goutes de teinture d'or ou d'eflence d'ambre, il remedia tres-efficacement aux indigeftions \& aux palpitations de coeur, fi bien que dansle befoin il pourroit fervir tout enfemble d'une nourriture fuffifante, $\&$ d'un remede aux plus familieres indifpofitions.

Refte à dire qu'en faifant cette boiflon un peu plus claire quà l'ordinaire, \& y mettant le firop de Caffé en place de celuy de vanilles, il aura prefque toutes les proprietez que jay attribuées au Caffé, ce qui ne peut être que fort agreable \& fort util, aux perfonnes qui haiffent le goût 
286 Lie bon ufage du Thé, du Caffé, \& qui fe trouvent neanmoins atteintes des indifpofitions aufquelles il convient.

\section{CHAPI TRE IX.} Du sirop de Vanilles.

T'Avois feulement commu$I$ niqué à nos Artiftes, le fecret du Sirop de Vanilles, que je ne voulois publier, quavec les autres découvertes que je referve pour le Journal de Medecine, mais il a trop de rapport avec ce traité, pour que je l'en puiffe raifonnablement detacher; en voicy la compofition.

Mettez dans une pinte d'eatu boüillante une poignée de fleurs de Borrache, autant 
du caffé, \& du chocolat. $28_{7}$ de celle de Bugloffe, \& une dragme des fels fixes \& effentiels de Cacao, mettez en même temps à part dans une auttre pinte d'eau boinillante, deux poignées de fleurs de Pavor rouge, \& une dragme de teinture d'or; laiffez infufer ces chofes à froid durant fix heures, puis ayant paffé ces deux teintures par la chauffe claire, mettez les dans une baffine avec fix livres de Sucre fin en poudre; faites boüillir ce mélange à pecit feu, \& quand il fera à mycuit adjoûtés-y, quinze belles Vanilles pulverifées; $o b-$ fervant de les érendre dans toute la liqueur, en l'agitant avec une fpatule de bois ou d'argent; puis ayant encore 
- 288 Le bon uJage du Thé, donné un quart de cuitte à vôtre Sirop, clarifiez-le en le paffant par la même chauffe, puis l'ayant remis dans la baffine adjoûtés-y trois onces de Sirop d'œuillets, \& le cuifez jufquen confiftance.

On donne ce Sirop avec beaucoup de fuccez pour adoucir \& pour digerer la matiere du rheume \& des fluxions de poitrine, pour arrêter la toux, pour remedier aux défaillances, pour calmer les efprits irritez, \& pourr rectifier les mouvemens depravez du fang.

Dans ces differentes occafions, on peut le prendre feul a la quantité de deux ou trois cuieillerées, mais dans les fiévres continuës \& malignes, il 


\section{du Caffé, ơ du Cbocolat. 289}

feroit mieux de mettre cette dofe, dans quatre onces d'eau de fleurs d'Orange ou de $\mathrm{Me}$ liffe, de même que dansle rheume, \& dans les fluxions de poitrine, on doit comme il a été dit, le mettre en place de Sucre dans le Chocolat dégraiffé.

Cette derniere façon de le prendre fera auffi tres-efficace dans les indigeftions, dans les vomiffemens, dans les coliques, dans la diarrhée \& dans la diffenterie, mais comme il eft des perfonnes qui ont une averfion infurmontable pour le Chocolat, il eft bon de dire quion peut aufi le prendre dans le Thé ou dans le Caffé fimple, ou dans le laict Cafferé, c’eft à dire dans 
290 Le bon asage du Thé, la teinture de Caffé tirée avec le laict.

Au furplus foit qu'on mette ce Sirop dans le Chocolat, dans le Caffé,ou dansle Thé, on peut s'affurer qu'il en augmente autant l'agréement que les vertus: \& par-deffus tout cela, on peut fans fcrupule en rendre lufage auffi familier, que celuy des meilleurs \& des plus communs alimens, ne pouvant caufer aucune alteration nuifible, en ceux-mêmes qui joüiffent d'une parfaite fanté, à la difference de toutes les autres chofes qui peuvent être confiderées comme remedes. 


\section{du Caffe', \& du Chocolat. 2 I9}

CHAPITRE X.

Du Chocolat Antiverien.

Uoyque jaye rangé le Chocolat fous le genre des Cordiaux, \& que la nature aye befoin d'être fortifiée par ces forres de remedes, pour refifter à la malignité des venins, dont la matiere venerienne eft une efpece, il ne faut pas croire neanmoins qu'il foit $d^{*} u n e$ confequence effentielle, pour l'acaion du fpecifique dont je vay parler, puifque fans rien perdre de fa vertu , il pourroit être donné en forme d'Opiate, ou en toute antre confiftance, \&: qu'il n'a été incor- 
292 Le bon usage du Thé,

poré dans cette pâte que pour en faciliter l'ufage:c'eft pourquoy ce n'eft pas icy le lieu d'en faire la defcription, mais ayant déja tant fait de bruit fousle nom de Chocolat antivenerien, je ne puis me difpenfer de donner au moins une idée de fa nature, \& quelques regles pour fon ufage,afin que ceux qui aiment le Chocolat, \& quiauront le malheur de fe trouver atteints de la plus univerfelle des maladies galantes, y puiffent trouver les éclairciffemés neceffaires pour leur confolation, \& pour fe tirer de la peine qu'ils auroient à comprendre, ce qu'on entend par ce nom 'de Chocolat antivenerien.

Or l'experience qui a montré quele mercure ou vif ar- 
du Caffé, or du Chocolat 293 gent eft un tres puiffant remede contre cette maladie, a fait connoître que fon ufage eft également dangereux \& difficile à fuporter.Les Artiltes experimentés attribuënt fes propriẹtez à fa crudité \& fes mauvaifes qualitez à fa propre nature. Comme celuy qu'on tire du plomb\& de l'étnitn,leur perfuade qu'il eft la femence au moins de la plûpart des metaux, la diverfe confiftance de ces metaux, leur fait conclure à bon droit, quêtant capable d'une parfaite digeftion, il doit être la propre matiere de l'Or, qui eft tres - maleable, qui eft fort pefant, \& qui eft fi analogique avec luy, qu'ils s'uniffent naturellement enfemble, toutes les fois quils

$N$ ij 
$294^{\circ}$ Le bon uJage du Thé,

font approchez par une mediocre diftance.

Ces confiderations me firent préjuger autrefois, que l'Or contenoit en luy un mercure fi parfait \& fi excellent, qu'il - pouvoit avoir toutes les vertus du mercure vulgaire fans en avoir les deffauts. Dans cette penfée je m’attachay à travailler fur la marcaffite ou mine d'or, \& je le fis avec de fuccez, que je trouvay la preparation du plus excellent anti-venerien qu'on puiffe jamais inventer, puifqu'il guerit radicalement la maladie que $j$ 'ay ditte en un mois ou environ, \& que fon ufage eft fi facile \& fi innocent qu'il agit pendant le fommeil, qu'il ne donne aucune émotion in- 
du Caffe, os du Chocolat. 295 commode, \& qu'on pourroit en ufer fans inconvenient beaucoup au delà de la cure.

Pour en tirer le bon effet que je viens de dire : je fais donner le premier jour au malade, une prife de l'extrait purgatif de nos Artiftes, \& trois heures apres un boüillon, ou un demy verre de vin blanc, fans obferver d'ailleurs pour ce jour, n'y même pour tous lestemps dela cure, aucun autre regime univerfel, que celuy de ne point trop charger fon eftomach ny en dînant ny en foupant, \& d'éviter l'ufage coûtumier ou exceffif, du veau, du porc, du poiffon, de la patifferie, des fruits, \& des legumes.

Je dis exprés l'ufage excef-

$N$ iij 
296 Le bon ufage du Thé, fif,ou coutumier; car en quelques rencontres, une petite quantité de ces choles ne peut tirer à nulle confequence, fur tout en ceux qui digerent bien:on peut même fans fcrupule boire du vin aux répas fuivant l'habitude ordinaire, mais aux autres heures du jour, on doit preferer les eaux mineralles de fainte Reine, ou une tizanne preparée avec le polipode, \& le bois de genévre; obfervant d'ufer feulement de l'une. ou de l'autre de ces boiffons, le deuxiéme jour de la cure fans faire aucun autre remede.

Le troifiéme jour je fais reiterer le même purgatif avec le même ordre: \& le quatriéme je fais donner au malade le 
du Caffé, \& du Cbocolat. 297 foir en fe couchant, \&2 au moins deux bonnes heures apres avoir foupé une tablette du Chocolat anti-venerien, \& je luy fais boire incontinent apres la quatriéme partie d'un demy feptier, ou de vin de Bourgogne, ou de vin d'Efpagne, ou de vin mufcat, ou d'hypocras ou d'eau clairette fuivant le gouft, ou felon que ces chofes fe trouvent plus commodement ou plus difficilement.

A pres cela l'ayant fait coucherdans un lit baffiné, ou luy ayant humecté toute la peau, avecl'efprit de vin compofé de nos Arriftes, je luy fais mettre une bouteille pleine d'eau chaude à la plante des pieds , \& quelquefois encor $N$ iiij 
298 Le bon ufatge du Thé, deux autres fous les aiffelles, \& l'ayant fait couvrir une fois plus que de coûtume,je le laiffe en cét état attendre la tranf. piration des hilimeurs, qui dans les premiers jours, ne va quelquefois guere plus loin que la moiteur, mais qui n'eft pas long-temps fans paffer à une fueur copieufe.

Le cinquiéme jour je repete la même chofe, le fixiéme je reviens aux purgatifs, les feptiéme \& huitiéme je repete encore ce que jay fait dans le quatriéme $\&$ dans le cinquié.. me, enfin le neuviéme je donne de nouveau le purgatif, \& je continuë ainfi jufques à la fin de la cure, à donner alternativement deux jours du fpecifique \& un jour du pur- 
du Caffé, \& du Chocolat. 299 gatif, cette methode n'étant variée que dans quelques occafions particulieres, dans lefquelles je dois m'accommoder aux difpofitions extraordinaires des perfonnes que je traite.

Refte à faire obferver, qu'encor que ces remedes puiffent guerir radicalement la maladie dont il s'agit; elle eft quelquefo's accompagnée d'autres efpecés de maladies galantes, par exemple des ulceres \& des carnofités de l'uretre, pour la guerifon defquelles on doit adjoûter à la cure univerfelle, les remedes particuliers qui leurs conviennent; de même que la carie des os doit être corrigée par le fer ou par le feu, fuivant les regles.

$$
N \vee
$$




\section{0 . Le bon ufage du Thé, de la Chirurgie, étant impof- fible d'y remedier par quelque autre moyen que ce foit, ny même parla falivation mercu- rielle, fi longue \& fi violente qu'elle puiffe être.}

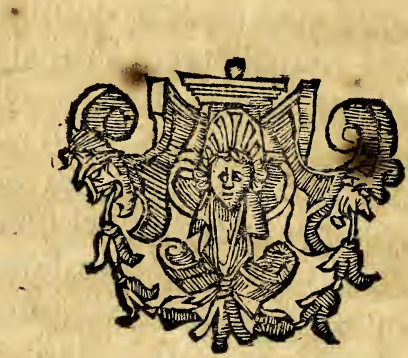




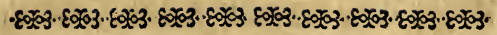

\section{LE BON USAGE}

\section{DU THE', DU CAFFE'} E T

\section{DU CHOCOLAT.}

\section{Quatrie'me Partie.}

Contenant l'explication des Eigures comprifes dains les parties precedentes, os quelques remarques fur des fingularitez de nouvelles inventions relatives au même fujet.

CHA P T RE I.

Des Figures de la premiere partie.

DOu traicter mon fujet auffi parfaitement quil éroit à fouhaitter, jay du fup- 
302 Le bon ufage du Thé,

pofer un Lecteur également curieux \& ignorant de tout ce qui en peut faire partie, \& m'impofer la necefficé de le fatisfaire fans aucune referve, 'mais n'ayant pû fuivre ma refolution, fans traitter de diverfes chofes, qui parồtront fort trivialles à un grand nombre de perfonnes, jay penfé que je devois m'en expliquer d'une maniere tres- abregée, dans les traitez particuliers que je viens de donner, \& en feparer même l'explication des Figures, pour ne pas fatiguer ceux qui ne cherchent que de nouvelles. 4 obfervations, ce qui a donné lieu à cetre quarriéme partie, qui aura fon ucilicé pour quelgues gens, \& quüi ne fera 
du Caffé, \& du chocolar. 30.3 point à charge aux autres.

Or dans la premiere planche dela premiere partie quii eft à la page $1 \mathrm{I}$. jay fait reprefenter la plante du Thé, feulement au nombre de deux. riges pour ne point confondre l'objet, étant d'ailleurs facile d'en imaginer tout un champ difpolé comme ceux de nos féves. On voir prés de ces tiges un Indien qui cueille ces fueilles de Thé l'une apres l'autre, \& quiles amaffe dans. un perir panier qui eft à fes. pieds, ce qui paroît dans un trop grand éloignement, pour avoir pî mieux reprefenter la denteleure de fes feuilles.

Au devant du champ où ces. tiges ont été placées, jay fait voir un Parquet fur lequel eft 


\section{Le bon usage du The',}

un carreau, où eft affis un Indien de confideration, tenant à la main une chique de Porceleine remplie de Thé, en forte que le Poulce foutient le deffous de la Chique, en appuiant fur le cercle qui luy fert de pied, \& les doigts indices \& du milieu, les bords de la Chique qui doivent être receus parles levres, \& qui ne font jamais trop chauds pour cela, ce qui fait qu'ils ne brûlent point les doigts, non plus

- que le cercle de deffous, au lieu qu'on ne pourroit prendre la Chique par tout autre endroit fans fe brûler,lors que le Thé y a été mis bouiillant, outre qu'il feroit difficile de la tenir d'une façon mieux 
du Caffé, \& du Chocolat. 305 feante \& plus commode.

Quand à la deuxiéme planche de la snême partie étant à la page 34 . elle reprefente à la premiere Figure la forme des pots à Thé, qu'on fair faire en Europe de la grandeur que l'on veut, de vermeil doré, d'argent ou d'étain. La deuxiéme fait voir un des pots de la Chine de terre fizelée fimple, enfin les 3. 4, $\&$ g.reprefentent trois differens pots de terre la même montez fur des lampes à confolles de Leron doré, ou feulement plané \& bruny, que jay inventées pour l'ornement \& pour la commodité, ny ayant rien de plus propre fur des cabinets \& fur des cheminées, \& le Thé 


\section{Le bon usage du Thé,}

pouvant être fait tres - agreablement fur la table même où l'on mange, ou en tout autre endroit que l'on veut, au moyen d'une méche imbibée d'efprit de vin,qu'on met dans. la fiole de la lampe.

CHAPITRE II.

Des figures de la feconde Pariie.

T A planche qui eft à la 1 page 86. reprefente la tige de la plante du Caffé, encore chargé de fon fruit entier, au bas de laquelle j’ay encore fait reprefenter la graine dépoüillée de fon écoffe, \& divifée par fêves diftinctes, à la difference de celles qui font encore dans leurs écof- 
du Caffé, \&o du Chocolat. 307 fes; car elles y font au nombre de deux, jointes du côté où eft une efpece de fente ; \& où elles ont une forte de face applattie, au moyen de laquelle êtant jointes, \& renfermées dans leurs écoffes, elles ont la forme qu'on voit en regardant la tige.

Je dois dire icy par occafion que pendant l'impreffion de ce livre, le prix du Caffé en graine s'eft tellement augmenté, qu'il s'eft vendu en gros jufquà trente cinq fols la livre, en forte quil fe vendra pendant le cours de l'Hiver prochain, au moins quarante fols, \& par confequent un écu en poudre, fur quoy même les Marchands fideles, ne pourront trouver 


\section{Le bon ufage du Thé,}

qu'un tres-mediocre profit.

La deuxiéme planche qui eft à la page I 49. fait voir à la premiere figure une Caffetiere montée fur un fourneau quil luy eft approprié, \& au moyen duquel on prepare le Caffé à la vapeur de l'efprit de vin, le fourneau ayant dans fon fond une lampe à trois méches quion voit à la deuxiéme figure, \& dans laquelle on met l'efprit de vin, pour fervir à l'entretien de la flamme des méches.

La troifiéme figure reprefente un éteignoir quon met fur la lampe, pour éteindre les méches lors que le Caffé eft preparé.

Ces fortes de Caffetieres à fourneaux peuvent être de 
du Caffe', \& du Chocolat. 309 quelque utilité, mais il s'y trouve neanmoins beaucoup de chofes à redire, car en premier lieu elles ne peuvent être portées fans quelque incommodité, par cette raifon qu'elles ont trop de volume, \& que la Caffetiere fe fepare trop facilement d'avec le fourneau. En deuxiéme lieu, parce que les trois mêches font un fi grand feu; que tres-fouvent il fond la foudeure \& l'éramure même du fer blanc. En un troifiéme lieu, parce que le reftant de l'efprit de vin ne peut être laiffé dans la lampe fans être répandu, \& que neanmoins il n'en peut être retiré pour être mis dans un autre vaiffeau fans peine $\&$ fans embarras. 
310 du Caffé, \& du Chocolat.

Ces confiderations m'ont porté à inventer la Caffetiere portraive qui eft figurée à la page I 5 I. \& qui eft d'autant plus commode, qu'étant fermée comme on la voit à la premiere figure de la planche, elle n'a au plus que quatre pouces de haut \& deux de diametre; quoy que dans cét ćtat elle comprenne le fourneau, la lampe, l'efprit de vin, le vafe à faire la boiffon, la poudre de Caffé, le fucre, la cuillere, un fufil, une bougie, deux taffes \& deux foucoupes, ce qui n'auroit pû être reprefenté par parcelles, mais j'ay crû que je devois du moins faire reprefenter cetze Caffetiere, telle qu'elle eft difpofée lors qu'on prepare le Caffé, \& 
du Caffé, \& du Chocolat. 3 II c'eft ce qu'on voit à la deuxiéme Figure, en laquelle j’ay fait paroître le manche ouvert c'eft à dire en état de fervir, au lieu que dans la premiere il eft ployé d'une maniere propre, à ne pas empécher que la machine ne foit mife commodement dans la poche.

Il eft à remarquer que la Lampe eft tellement difpofée qu'elle contient l'efprit de vin, fans qu'il s'en puiffe rependre une feule goute dans quelque agitation que ce foit.

Nos Artiftes ont de ces machines de differentes étoffes, entre lefquelles il y en a d'un prix modique, mais qui ne laiffent pas d'étre trespropres.

Au furplus jay dit que 
3 I 2 Le bon ufage du Thé,

cette Caffetiére n'étoit qu'une legere idée d'une nouvelle machine beaucoup plus complette, \& en effet on n'aura pas de peine à en demeurer d'accord, lors qu'on aura leu ce que nos Artiftes en ont dit dansla lifte de leurs Marchandifes, qu'ils m'ont prié de placer à la fin de ce Livre.

Quand à la Planche qui eft à la page I55. outre qu'elle * exprime fuffifamment ce dont il s'agit, elle eft precedée en quelque forte de fon explication, à caufe de ce quion a dû dire en cét endroit, touchant la Caffetiére reprefentée par la premiere figure.

Il en eft prefque de même de la figure qui eft à la page $\mathrm{I}_{2}$. car tout ce que jen 
du Caffé, \& du Chocolat 3 I 3 puis dire icy, eft que le corps de ce fourneau eft de terre cuitte, \& que le deffus peut être de la matiere même des Caffetieres, c'eft-à-dire de cuivre ou d'argent; car quand à la Lampe fa forme eft affez indifferente pourvî qu'elle ait trois mêches, qui répondent chacune vers le milieu du fond de chaque Caffetiere.

Pour ce qui eft de la Planche qui eft à la page 168. je dois dire que la premiere Figure reprefente un cabaret à Caffé, qui ne fçauroit être bien feant fans être d'argent, \& que celuy de la deuxiéme figure, eft ordinairement de veritable lachinage; mais que néanmoins nos Ebeniftes en 
314 Le bon ufage du Thé,

font de façon de la Chine, qui ne laiflent pas d'être tres-propres \& tres-honneftes, \& qui font comme les veritables. Chinois, ou carrez, comme celuy dont je parle, ou Octogones, ou ronds, ou de diverfes autres formes.

\section{CHAPITRE III.}

Desfigures de la troifiéme Partie.

$\mathrm{F} N$ parcourant le traité du Chocolat, qui fait le fujet de la troifiéme partie de cét Ouvrage; on trouve à la page 203 . une Figure qui reprefente le Cacavifere avec fon fruit entier; mais qui ne demande pour explication, que ce qui en a êté dit dans le Chapitre 
du Caffé, o du Chocolat. 3 Is Chapitre deuxiéme de cette même partie; où il eft particulierement traité du Cacao, c'eft-à-dire des amandes renfermées dans ce fruit, \& qui font la matiere principale du Chocolat.

Il en eft ainfi de la figure qui eft à la page $20 \mathrm{~g}$. \& qui reprefente les diverfes efpeces de Cacao, car elle eft immediatement fuivie d'une fuffifante explication.

Quand à la figure qui eft à la page 247. \& qui reprefente un homme faifant la pâte du Chocolat, il faut obferver que les pieds qui foûtiennent la pierre, doivent être de fer , \& qu'ils doivent faire corps avec le chaffis de même matiere qui eft marqué A \& qui tient 
3 I 6 Le bon usage du Thé, tout le carré de la pierre dans le milieu de fon épaiffeur, ce qui fert beaucoup à la conferver, empéchant même qu'elle ne foit fi facilement fenduë par la chaleur, au refte la chaufrette marquée $B$, peut être de terre ou de fer, mais quand on fait le Chocolat fur un plancher de bois, il eft mieuxx qu'elle foit de terre, quoy qu'étant de fer on pourroit mettre une tuile au deffous. Il eft à remarquer qu'elle doit être mife fous la pierre, une heure au moins avant que de commencer le travail, afin qu'elle foit chaude quand on y mettra le Cacao, mais avec cette obfervation, qu'il ne faut d'abord qu'un brafier peu ardent pour mieux conferver la 


\section{du Caffé, \& du Chocolat. 317}

pierre, qu'une chaleur trop forte \& trop fubite ne manqueroit pas de caffer.

Refte à dire que les deux extremitez du rouleau font beaucoup plus menuës que fon milieu, qui doit avoir au moins la groffeur d'une forte torche, \& qui doit être limé \&x poly, \& enfin que ces mémes extremitez reçoivent en forme d'Effieux deux poignées de bois, qui facilitent bealicoup le mouvement qui doit étre donné au rouleau pour écrafer le Cacao \& le Sucre, \& pour incorporer tous les ingrediens de la pâte.

Je viens maintenant au preffoir qui eft reprefenté à la page $253 . \&$ dans la forme duquel on doit remarquer fon

$\mathrm{O}$ ij 


\section{Le bon ufage du Thé,}

écroiie marqué $A$, à l'extremité fuperieure duquel eft le travers qui fert à le tourner; pour ce qui eft de fon extremité inferieure, elle eft jointe au carré ou table de bois qui fert à preffer également la feuiille de deffus, celle de deffous étant appuyée fur le fond du preffoir, ainfi qu'on peut l'imaginer.

Il eft à remarquer que par l'ufage de ce preffoir, non feulement on tire la graiffe furabondante du Cacao, à l'ayde du papier gris qui s'en imbibe, mais on confume même parla chaleur, les parties mufilagineufes qui le rendent relachant \& affoibliffant.

Aprés tout n'ayant rien à dire fur les Moulinets qui font 
du Caffé, \& du Chocolat. 319 figurez à la page 274. \& où leurs differentes formes. font affez clairement exprimées, je finirois cette troifiéme partie, fi pour fatisfaire à la curiofité de quelques perfonnes, je ne me trouvois obligé à déduire dans le Chapitre fuivant, les Marchandifes à la difpenfation defquelles nos Arriftes font particulierement occupez.

\section{CHA PITRE IV.}

Des Marchüdifesquifont aztuellement dippenfées par les Artif. tes du Laboratoire Royal des quatre Nations.

A L'occafion des exercices Aque j'ay l'honneur de di$\mathrm{O}$ ij 
3.20 Le bon ufage du Thé,

riger fous les ordres de Monfieur le premier Medecin du Roy, concernant la recherche \& verification des nouvelles découvertes de Medecine, les Artiftes que jemploye à cét effer s'occupent encore autant urilement pour le public que pour eux-mêmes, à la difpenfation des Remedes, Inftumens \& Machines, dont on va voirle dénombrement. .

La Teinture cordiale ou $\mathrm{Or}$ potable, \& la poudre Diapharetique d'or.

La Pierre infernale, la Teinture \& le Vitriol de Lune, ou Argent.

Le Sel, les fleurs \& le Magiftere de Zink, d'Etain \& de Bifmuth, ou Eftain de glace. 
$d u$ Caffé, \& du Chocolat. 32 I Le Sel, le Magiftere, le Baume \& l'Efprit ardent de Saturne ou plomb.

Les Criftaux de l'Efprit de Venus, ou Cuivre.

Le Crocus aftringent, le Crocus apetitif, la Teinture, l'Extrait \& le Sel de Mars, Fer ou Acier.

Le Sublimé doux, le Precipité blanc, le Precipité rouge, le Precipité jaune ou Turbit mineral, \& l'Huile de Mercure ou argent vif, \& generalement toutes les preparations. Chimiques des Metaux \& Marcafites.

Le Regule, le Soulfre doré, le Crocus, le Verre, le Diaphoretique, les Fleurs, le Cinabre, l'Algaroth, le Bezoard, \& l'Huile ou Benrre d'Antimoine.

$\mathrm{O}$ iijj 
322 Le bon usage du The',

Le Magiftere, le Sel \& la

Teinture de Corail.

Le Criftal mineral, le Sel

Policrefte, l'Eau forte, l'Erprit \& le Sel Alkali du Nitre ou Salpeftre.

L'eau Regale, les fleurs, IEfprit volatile \& l'Efprit fixe de Sel armoniac.

L'Eau Stiptique, la Pierre Medicamenteufe, le Gilla le Sel \& 1"Efprit de Vitriol.

L'Eau \& l'Efprit d'alun.

Les Fleurs, le Baume, le Sel, le Magiftere \& l'Efprit de Souphre.

L'Huile \& le Sel volatile de fuccinum, Karabé ou Ambre jaune.

L'Effence d'ambre-gris, l'Huile de Briques ou des Philofophes, l'E f prit de Sel, \& ge- 
du Caffé, \& du Chocolat. 323 neralement toutes les preparations Philofophiques, concernant les Sels Mineraux \& les Bitumes.

La Refine de Jalap, la Refine de Scammonée, l'Extrait d'aloës \& l'extrair de Rhubarbe.

L'Hiile \& le Sel de Gayac. L'Effence \& l'Eau diftillée de Canelle.

La Teinture, l'Extrait-\& le Sel de Quinquina.

L'Effence de Gerofles, l'Huile de Mufcades, les Fleurs de Storax, l'Huile de Mirrhe, l'Huile \& les fleurs de Benjoin. L'eau de Vie rectifiée, l'Ea de Vie Thericale, l'Efprit de Vin rectifié, l'Efprit de Viix' Tartarifé, \& lESprit de Vin Camphoré.

$$
\text { o y dr }
$$


324, Le bon ufage du Thé,

L'Efprit de Sucre, \& Vinaigre diftilé, \& l'Eau rouge de la Reine d'Hongrie ou Efprit de Vin compofé.

L'Excellente Eau de la Reine d'Hongrie de Montpellier, \& celle qui eft preparée publiquement avec l'Efprit de Vin rectifié \& les pures fleurs de Rofmarin.

L'Eau de Cordouë, l'Eau de fleurs d'Oranges, l'Eau de millefleurs, l'Eau d'Anges, \&c le Lait virginal.

La Crefme, la Teinture, le Magiftere, le Sel Volatile \& le Sel Emetique de Tartre.

Les Pierres à Canteres.

Le Laudanum ou extrait dOpium.

L'Huile \& le Sel de Tabac. L'Huile \& l'Efprit de Therebentine. 
du Caffé, \& du Chocolat: 325

L'Huile de Camphre.

L'Huile \& l'Efprit de gomme Ammoniac.

Le Sel \& l'Eau diftilée d'Ozeille,d'A bfinche, de Cochlearia, de Creffon, de Meliffe, de Mirthe, de Rofes, de Lavande, de Courges, de Melons, de Citrons, de Fraifes, de Noix, de Pyffenly, d'Aigremoine, de Menthe, de Serpolet,de Scordium, d'Alkequange, de $\mathrm{Ve}$ ronique, de Chelidoine, de Laituës, de Fenouil, de Pavots, de Primevere,d'A rgentine, de Nenuphar, de Chicorée, de Reyne des Prez,de Tilleüil,de Cerfeüil, de Pourpier, de Melilot, de Bourache, de Rhuë,de Quintefeüille, de Muguet, de Centaurée, de Scabieufe, de Scorçonnere,d Houblon, d'Ar- 


\section{Le bon wjage du Thé,}

moife, de Sabine, de Rofmarin, de Genévre, de Perficaire, de Lis, de Sureau, de Thim, de Sauge, de Confolides, de Parietaire, de Soucy, de Fumeterre, de Bugloffe,de Planain de Chardon beny, de Millepertuis, \&c.

L'Effence, de Rofmarin, de Sabine, de Rhuë, de Sauge: de Sariette, d'Anis, de Fenoïil, de Fleurs d'Oranges, de Jafmin, de Tubereufes, de Genévre, \&c. Et generalement toutes les preparations Spagiriques qui fe font furles diverfes parties des plantes.

La Poudre, I'Axunge, l'Efprit Sudorifique \& le Sel vôlatile de Viperes.

L'Efprit \& le Sel volatile de Crapaux, de Corne de Cerf \& d'urine. 
du Caffe', \& du Chocolat. 327 Les Eaux diftillées de Tefte de Cerf, \&z de Sperme de Grenoüilles.

L'E fprit de Miel, l'Huile de Cire, \& generalement les Remedes qui fe tirét des animaux entiers ou de leurs parties.

L'eau de pluye, l'eau de neige, l'Eau de rofée de May, \&z generalement les Eaux qui fe tirent des Méteores.

Le Sirop d'oeillets, le Sirop de Grenades, le Sirop de Corail, le Sirop de Canelle, le Sirop Magiftral, le Sirop de Kermes, le Sirop de Fleurs d'Oranges.

Le Sirop de Capillaires de Paris, de Montpellier \& de Canada.

Les Tablettes de Guymauves, \& les Tablettes d'Acier. 
328 Le bon ufage du Thé,

La conferve de Rofes,la conferve de Aleurs d Oranges, la conferve de Violettes, la Conferve d'Ache, \& la conferve de Kinorhodon ou Grattecul.

$\mathrm{La}$ Confection d'Hyacinthe \& la Confection d'Alkermes, fimples ou ambrées.

Les Pillules perpetuelles, les Pilules d'aloës, Ante cibum ou de Franfort, les Pilules de Mercure \&z les Pilules Catholiques.

Le Sucred'Orge \& les Sucs de Regliffe, de Blois \& d'Alençon.

L'Orvietan Original d'Italie, \& la Theriaque de Paris, de Venife \& de Montpelier.

Les Trochifques, les.Huiles, les Baumes, les Emplâtres, les Ceroüennes, les'Onguents 
du Caffé, \& du Chocolat. 329 les Cerats, \& generalemene tous les Remedes de la Pharmacie ordinaire.

Le Sirop de Vanilles qui fe met dans le Chocolat en place de Sucre pour en augmenter l'agrément, \& qui eft d'un effet merveilleux dans les rhumes \& dans les fluxions de poitrine.

Le Sirop de Caffé qui fe met pareillement dans le Caffé, pour en augmenter l'agrément $\&$ les vertus.

Le Sirop de Thé fimple dont on fait le même ufage à l'égard de la boiffon de Thé, \& le Sirop de Thé Febrifuge, qui guerit en tres - peu de jours \& de prifes, toutes les. efpeces de Fiévres d'accez. Les Remedes du Roy com- 


\section{Le bon uJage du Thé,}

muniquez par feu Monfieur le Prieur de Cabriere, \& divers autres remedes experimentez pour la guerifon des Hernies ou Defcentes.

L'Eau, les grains \& les parfums Hyfteriques, \& divers autres Specifiques contre les Vapeurs, les Suffocations, les Retentions, les pertes blanches, \& les autres maladies de la Matrice.

- Le Chocolat degraiffé, le Caffé Volatile, \& le Thé en conferve,

Le Baume blanc de Judée. LeVerjus \& le Fiel de Bœuf preparez.

La Pâted'A mande, la Crême de Perles, il'Eaude Secondine, l'Eau de Fraifes, l'Eau \& la Pomade Cofmetique, \& diver- 
dis Caffé, \& du Chocolat. 33 I fes autres preparations pour corriger le vice de la peau du vilage \& des mains.

Le Baume A poplectique ou Parfum d'Angletcre.

L'Effence Vegetale, $\&$ divers autres remedes pour arrêter la douleur \& la carie des dents. L'Opiatte de Corail, la Pomade rouge, \& divers autres remedes pour les vices des dents \& des lévres.

Le Baume vert de Monfieur. de Blegny, l'Eau Phagedenique, le Baume du Perou, l'Eau. d'Arquebufades, le Colire de Lanfrant, \& plufieurs autres Topiques tres-efficaces, pour Cicatrifer les playes \& les Ulceres.

L'Eau Ophtalmique, l'Onguenc, oculaire, la Tutie pre- 
332. Le bon ufage du Thé, parée, \& divers autres remedes contre les maladies des yeux.

L'Opiate Antivenerien, les Bougies, l'Injection amortiffante, l'Onguent Cicatrifatif, $\&$ generalemét les plus promts les plus faciles \& les plus affurez fpecifiques contre les maladies Veneriennes.

L'Huile de Palmes, \& l'Emplâtre contre les douleurs des Rhumatifmes \& de la goutte.

I a Pomade contre les Hemorrhoïdes.

L'Onguent infaillible contre la teigne.

Les grains purificatifs du fang.

La poudre Cephalique, l'Opiate vomitive, $\&$ divers autres remedes contrele'Migraine, \& toutes autres douleurs de tête. 
- du Caffé, \& du Chocolat. 333 Les Caffolettes Royales à Lampe \& Girandolles, fervant à parfumer \& à des-infecter les Chambres pour le plaifir \& pour la fanté, trescommodement \& à tres-pet. de frais, fans aucune apparence de fumée, la vapeur qui s'en exhale étant imperceptible.

Le Lait Virginal d'Amarante,qui fortifie le cour \& le cerveau, \& qui refifte à l'air infecté qui caufe la pefte, la perite verolle, la diffenterie \& les autres maladies populaires \& contagieufes, en la recevant en vapeur par la refpiration,aus moyen desCaffolettes r oyales. Les Sels de Thé, de Caffé \& de Cacao.

Le Cachou Ambré, \& les Paftilles d'Efpagne pour la 
334 Le bon uJage du Thé, bouche \& pour les parfums.

Toutes les efpeces de pots á Thé, de Caffetiéres \& dechocolatieres, nouvellement inventées par Monfieur de Blegny, pour preparer tres-utile. ment le Thé, le Caffé \& le Chocolat avec le Livre nouvellement Imprimé par Privilege du Roy, qui enfeigne le bon ufage qu'on doit faire de ces boiffons, \& des utenciles qui fervent à les preparer.

Le Thé de la Chine, la Fleur de Thé du Japon, \& les Vanilles de Guatimala.

L'Ambre, le Mufc \& la Civette de la meilleure qualité. Toutes fortes de Vafes de Porcelaines, de Criftal, de racines \& de bois veinez, pour prendre les Sirops \& les autres 
du Caffé, \& du Chocolat. 335 boiffons cy-devant fpecifiées.

Diverfes pierres Medicamenteules pour preparer en tous lieux \& à peu de frais toutes fortes d'Eaux minerales artificielles.

L'Eau digeftive qui fortifie le cœur \& l'eftomach , \& qui rectifie les vices de la digeftió.

Les Eaux diftillées de Thé \& de Caffe.

La Machine admirable notrvellement inventée par Monfieur de Blegny, qui n'eft qu'auffi grande \& prefque auffi pefante qu'une mediocre marmite, \& dãs laquelle neanmoins on peut preparer toutes fortes d'alimés \& de ragoufts, rôty, bouilly, friture, grillades, patifferie, \&c. auffi bien que toutes fortes de remedes, mé- 
336 Le bon usage du Thé, meles plus difficiles \& les plus laborieux de la Chimie, fans bois ny charbon, fans fujertion ny embarras quelcóques, à feu toûjours égal, en moins detemps \& à moins de dépens que toutes les operations \& preparations qui fe font à l'ordinaire, fervant en outre à rôtir la graine \& à preparer la boiffon du Caffé, fans permettre la diffipation d'aucune de fes parties volatilles, \& rôtir \& degraiffer le Cacao pour la preparation du Chocolat : en un mot à tout ce qui peut demander du feu.

Le Trefor d'Efculape qui n'occupe que la quatriéme partie d'une poche ordinaire, \& qui contient diverfes boëtes $\&$ fioles, oì font renfermez 


\section{du Caffe, \& du Chocolat. 337}

tous les remedes qui peuvent fervir aux occafions preffantes $\&$ fubites; ce qui eft d'une trés-grande urilité aux perfonnes fujettes aux vapeurs, à celles qui font menacées d'Apoplexie ou d'autres maladies promptes \& mortelles, à celles qui ont quelque lieu de craindre les venins ou poifons, \& particulieremêt à celles qu'une ardente charité conduit dans les prifons \& dans les maifons des pauvres infirmes. L'Orvietan Catholique, ou antidote univerfel qui ne coute prefque rien, \& qui furvient à toutes les maladies des pauvres gens $\&$ de leurs beftiaux.

L'huile de Nicotianne \& divers autres Specifiques contre la fourdité \& le tintement d'oreilles. 


\section{$33^{8}$ Le bon ufage du Thé,}

La Pomade Hemorrhö̈adale \& divers autres topiques pour refoudre \& pour adoucir les hemorrhoüdes.

Les Bandages de la Manufacture Royale, à reffort brifez $\&$ à vis, montez fuivant les - obfervations de Monfieur de Blegny qui en eft l'Invenceur, pour affurer la guerifon des Hernies ou Defcentes curables, \& pour retenir les plus gliffantes \& les plus fortes dans tous les differens mouvemens du corps.

Les Bandages \& les Peffaires qui arrêtent toutes efpeces de Defcentes de Matrice.

La Poudre Cornachine, la Poudre Hydragogue, \& plufieurs autres Specifiques finguliers contre les Hidropifies curables.

Les 
du Caffe, \& du Chocolat. 339 Les Dragées purgatives \& les Maffepains purgatifs.

Le Corail \& les Yeux d'Ecreviffes preparez.

L'Eau d'Ognon, l'Eau de Bellegarde, l'Eau Imperiale, \& les autres compofitions plus efficaces contre le gravies les pierres, les glaires, \& generalement ce qui caufe les coliques Nephretiques.

Le Diabotanum, ' \& divers autres Emplâtres pour réfoudre \& diffiper les Loupes.

Les Beficles à reffort pour redrefferles yeux bigles, \& les autres Inftrumens, Machines $\&$ remedes Specifiques, pour la prefervation \& pour la guerifon de toutes les efpeces de maladies curables, qui ont été examinez \& approuvez par 
34.0 Le bon usage du Thé, les premiers \& plus fameux Medecins \& Chirurgiens de la Cour \& de Paris ; ainfi qu'il eft juftifié par les approbations authentiques qu'ils ont accordées à Monfieur de Blegny, \& qui font incerées à l'entrée de fes Livres, dont le Catalogue enfuit.

L'Art de guerir les Maladies Veneriennes, expliqué par les principes de la Nature $8 x$ des Mechaniques. 3. Volumes in 12 . qui fe vendent 4.1. 10.1 .

Les Recueils des Journaux de Medecine, contenant toutes les nouvelles découvertes des Medecins \& Artiftes de ce fiécle. 3. Vol. in 12 . 6.1.

Le Remede Anglois, pu- 
du caffe', \& du Chocolat. $34 \mathrm{I}$ blié par: ordre du Roy, avec les obfervations de Monfieur le premier Medecin de fa $\mathrm{Ma-}$ jefté, 1 . Vol. in I 2 . 1.1 .

La Doctrine des Rapports de Chirurgie, fondée fur les Maximes d'ufage, \& fur la difpofition des Nouvelles Ordonnances. $\quad$ I. Vol.in 12 . I.1. I O.f.

Les Obfervations qui ont été faites fur les Aftres depuis l'Invention des Lunettes d'approche, avec les utilitez qu'on en peut tirer pour la pratique de la Medecine. I. I. IO. f.

Differtation fur un remede qui guerit la maladie Venerienne promptement, furement \& facilement. I s.f. L'Hiftoire Anatomique d'un enfant qui a été 25 . ans dans

P $\mathrm{ij}$ 
42 Le bon ufage du The', le ventre de fa mere, avec des Refléxions qui en expliquent tous les Phœnomenes. I o.fols,

L'Art de'guerir les Hernies ou Defcentes, avec la conftruction l'ufage \& les utilitez des Bandages à reffort inventez par l'Autheur, un Volume in 12. I. 1. 1 o.f.

Et quelques autres auffi curieux.

Au refte prefumant que les Curieux feront bien aife de trouver icy une plus ample defcription des Caffolettes Royales, que ce qui vient d'en être dit, j'ay crû qu'on trouveroit icy avec plaifir, les regles que j’ay données pour le bon ufage quon en doit faire. 
du Caffe, \& du Chocolat. 343

CHAPITRE V.

Des Caffoletres Royales, nouvellement inventées par l'Autheur.

DEndant tout le cours de 1 la vie humaine, les actions naturelles caufent également la diffipation des fubitances fpirituelles \& corporeltes, dót la reparation doit être continuelle dans chaque perfonne pour fa confervation. Les fubftances fpirituelles font reparées par l'air que nous refpirons, \& les corporelles par toutes les fortes d'alimens liquides \& folides que nous recevons par la bouche, \& que nous comprenós fous le terme

$P$ iij 
344 Le bon ufage du Thé, general de nourriture; mais tout de même que l'ufage des mauvais alimens nous determine à toutes efpeces de maladies, de même auffi un air impregné de particules impures \& contraires à nôtre confitution, ne tend que trop efficacement à la deftruction de nôtre fanté : c'eft pourquoy lors que nous fommes libres fur le choix des alimens, nous preferons naturellement les plus fains \& les plus conformes à nôtre temperament, \& lors que nous fommes abftraints à la neceffité d'ufer fans diftinction de ceux qui nous font le plus contraires, nous nous efforçons par differens moïens d'en corriger les plus méchanres qualitez. La même chofe 
dis Caffé, \& du Chocolat 345 fe pratique à l'égard de l'air. On choifit le meilleur quand on peut. On corrige le mauvais autant qu'il eft poffible, \& il eft tres-raifonnable d'en ufer ainfi ; mais les moyens qui ont été pratiqués jufques icy pour cette rectification, fembloient demander quelque rafinemét pour une jufte œconomie \& pour une plus grande utilité.

C'eft pourquoy ayant été penetré par les remontrances de nos Artiftes. Je me fuis attaché à ce rafinemét avec tant de fuccez, que j'ay inventé un tres-agreable moyen pour parfumer les chambres dans tous les differends befoins qu'on en peut avoir, \& cela fi commodement \& à peu de frais, qu'il feroit difficile de donner

$P$ iiij 
346 du Caffé, \& du chocolat. au public une invention plus avantageufe.

Ce moyen eft une petite lam. pe tres propre, ayant deux petites confoles qui foutiennent un globule de criftal, dont l'embouchure forme un tuyau tres-delicat, un pelı courbe dans fon milieu en forme d'an.gle mouffe. La periteffe de ce globule n'empéche pas qu'il ne contienne une quantité confiderable de liqueur à caufede fa forme ronde. C'eft dãs fa capacité que doit être con-: tenuë la liqueur qu'on veut reduire en vapeur pour parfu-s merles chambres, \& il fuffit pour qu'elle y entre, qu'on chauffe un peu le globule, \&z qu'on mette enfuite le bec dãs la liqueur quion y veut infi- 
du Caffé, \& du Chocolat. 347 nuer, car elle y eft attirée naturellement par la chaleur \& par le vuide; alors ayant placé le globule fur le cercle qui eft foûtenu parles deux confoles, $\&$ mis dans la lampe qui eftau deffous, un peu defprit de vin $\&$ une petite mêche de coton, on allume cette mêche, qui fans fe confommer fait une petice flamme tres-agreable, au moyen de laquelle le globule étant échauffé, la liqueur boüillonne \& s'exhale par le petit tuyau, d'où refulte une vapeur continuelie, qui eft prefque imperceptible, \& qui ne laiffe pas de parfumer toute la Chambre.

On peut placer cette lampe en tel endroir de la Chambre quion veut, du moins fi on en excepte le deffous de la che- 


\section{$34^{8}$ Le bon u Jage du Thé,}

minée, parle tuyau de laquelle la vapeurs'exhaleroit. On peut même le cacher dãs un recoin ouderriere un pilaftre d'alcove, obfervant feulement que plus il eft bas placé, plus l'air de la Chambre fe trouve également parfumé, le proprede la vapeur étant de monter. On peut auffi dans un même lieu en mettre deux ou tel autre nombre que l'on veut, felon qu'il doit être plus ou moins parfumé, quoy qu'un feul foit fuffifant, pour ôter toute la mauvaife odeur d'une grande chambre, \& pour la remplir du parfum dont on a fait choix.

Il eft à remarquer, qu'en empliffant feulement les deux tiers du globule de quelque liqueur odoriferante que ce foit, elle ne fe trouve qu'à pei- 
du Caffé, o du Chocolat. 349 ne diffipée en l'efpace d'une heure, pendant lequel il ne s'ufe qu'à peine pour trois deniers d'efprit de vin, fi bien que la liqueur odoriferante ne pouvant valoir qu’à peu prés autant, il arrive que pendant tout le temps qu'tune Dame peut être à fa toilette, fa charnbre eft tres-agreablement parfumée, feulement en faifant au plus un fol de dépenfe.

Ce quil y a en cela de commode, eft quion n'a pas la fujettion d'obferver la confommation de la liqueur, pour fe mettre en peine d'éteindre la Lampe lors que la globule raroit vuide; car bien qu'il fic tres-mince, jay trouvé le moyen de le rendre propre à refifter au feu fans contenir aucune liqueur, pendant tout 


\section{Le bon ufage du The',}

le teinps que l'on veut.

Ces parfums ont encore cela de plaifant, qu'on en peut faire placer autant qu'on veut fur les branches des luftres de chryftal, ou de toutes autres efpeces de Girandolles \& de chandeliers à plaques, pour parfumer les fales \& les chambres, lors des bals, des balets, ou des autres Fêtes galantes, car les lampes de ces Caffolettes font du moins un aufi agreable effet que les bougies; outre qu'on peut y en mettre un tres-grand nombre, fans craindre quil faffe à beaucoup prés tant de fumce, que la moindre paftille mife dans une Cafolette commune, ou que la moindre quatité d'eau odoriferante mife fur une pelle chaude, qui font les deux fa- 
du Caffé, ou du Chocolat. 39I çons ordinaires de parfumerles chambres, \& qui font l'une \& l'autre défectueufes en cela, qu'elles confommét beaucoup de matiere en peu de temps, \& qu'il en exhale une vapeur fi épaiffe, qu'il ne fe peut qu'elle n'apporte un grand dommage aux lits, aux tapifferies \& autres meubles.

Au furplus lorfqu'il ne s'agit que du plaifir, on peut faire choix du patfum qu'on aime le mieux, la paftille même, \& les autres parfums folides pouvant à cét effer être diffous dans de l'efprit de vin, ou dans telle au. tre liqueur que l'on veut; mais fans cela on a affez d'autres liqueurs odoriferantes, par exemple l'eau - rofe commune, l'eau de rofes mufcades, l'eau de mille Aleurs, l'eau de 
352 Le bon usage du Thé, fleurs d'oranges, l'eau de Cordouë, l'eau d'A nge, \&c.qui donnent un parfum tres-agreable auffi bien que le lait virginal de Benjoin, \& la liqueur qui fe trouve dans ces efpeces de pots pourris, qui font compofés avec les fleurs les plus odoriferantes.

Outre ces liqueurs, le lait virginal d'Amarante que je fais preparer en nôtre Laboratoire, eft d'une odeur tres-fuave $\&$ tres-falubre, ayant la proprieté de fortifier le cerveau \& le coeur, $\&$ de refifter puiffammét à toutes efpéces de mauvaișair; c'eft pourquoy il doit être preferé à toute autre liqueur odoriferante, lors qu'en temps de pefte, de pourpre, de petite verole, de diffenterie $\&$ de toute autre efpéce de maladies contagieufes, il s'agit de rectifier 
du Caffe, \& du Clocolat. 353 un air malin \& veneneux, \& de s'oppofer à fon infinuation dans la maffe du fang.

Il y a encore beaucoup d'autresindifpofitions dans lefquelles on peut tirer un tres-grand fecours de ces Caffolettes, en metrant dans les globules certaines liqueurs convenables, car ces liqueurs étant receuës en fumée par la refpiration, elles s'infinuent directement dans les poulmons, d'où elles font incontinent portées aut cour, \&zenfuite dans les vaiffeaux fanguinaires fans rien perdre de leur vertu, ce qui les rend plus efficaces que fi elles avoient été prifes par la bouche, puifqu'elles ne f̧̧auroient foûtenir les digeftions \& lès filtrations qui fe font dãs 
354 Le bon ufage du Thé, les voyes de la nourriture, fans être confiderablemét alterées: c'eft pourquoy lors qu'on voudra refifter à un affoupiffemét incommode fans ufer de Thé ny de Caffé, on pourra mettre dans le globule l'eau diftillée de l'une ou de l'autre de ces boiffons, de même que pour corriger une infomnie on $y$ pourra mettre l'eau de pavot.

L'eau de ferpolet fervira pour arrêter \& pourdigerer les rhûmes \& catharres. L'oxicrat fait avec l'eau-rofe \& le vinaigre de faturne, fera employé pour temperer les fiévres ardentes \& continuës. L'eau rouge de la Reine d'Hongrie arrêtera tres-fouvent les fiévres intermittantes. L'eau ftyptique fera d'un grand effet con- 
du Caffé, \& du Chocolat. 355 tre les hemorragies du nez, contre les expectorations fanglantes, \& contreles pertes de fang de la matrice. L'eau de muguet fervira beaucoup dans la migraine. Leau hylterique de nôtre Laboratoire abaiffera prefque toutes les efpéces de vapeurs dans les deux fexes: Nôtre eau de vie Theriacale fera un grand remede contre les défaillances \& contre les palpitations de cour. L'eau de limaçons aidera aux fonctions du foye. Les efprits de cochlearia \& de creffon refifteront puiffamment à la malignité du fcorbut, \& détruiront efficacement, toutes efpéces de difpofitions mélancoliques \& hypocondriaques. L'eaud'oignons mêlée avec un peu d'efprit de 
${ }_{35} 6$ Le bon aragedu Thé,

Therebentine, appaifera prefque toutjours la colique nephretique, \& pouffera par les urines le gravier des reins; des ureterres \& de la veffie.Les regles retenuës pourront être provoquées parla feule vapeur de certaines eaux aux femmes. $\&$ filles dont on fera affùré.Les pertes blanches feront fouvent abforbées par les efprits de fuccinum \& de Therebentine mêlés en portion égale. L'eau alumineufe abregera de beaucoup l'accés de la goutte ; enfin les Medecins pourront aifément pourvoir par ce moyen, à une infinité d'autres maladies fimples \& compliquées, par la vapeur d'une infinité d'autres efpeces de liqueurs, qu'ils pourront prefcrire au befoin, fui- 
du Caffe, of du Chocolat. 357 vant les regles de l'Art, au moyen dequoy ils auront le plaifir de les guerir pour la plûpart, fans exciter les dégoûts, les horreurs \& les troubles, quion ne fait que trop fouvent reffentir à la nature, en donnant par la bouche les remedes qui font de l'ufage ordinaire, ce qui ninterrompt que trop fouvent les mouvemens falubres qui tendent à la guerifon. A u refte on doit dire que ces Caffolettes ont été fi agreablement receuës du Roy \& de toute la Cour, qu'elles ontmerité à jufte titre le furnom de Royales, que jay crû leur devoir donner.

\section{F I N.}




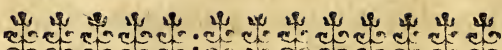

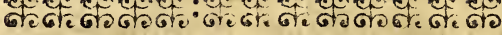

\section{T A B L E}

DES CHAPITRES. contenus dans ce traité du Thé, du Caffé, \& du Chocolat.

PREMIERE PARTIE:

Traitant de la nature, des proprietés, \& de l'ufage du Thé.

Chapitre I. E la forme exterieure $d u$ Thé, des lieux ò̀ l'on les cultive, \& de fes differentes de. nominations.

Chap page I Chap.II. Du choix, of des differens prix du Thé. page 16 


\section{T A B L E.}

Chap.I I I. De la natureparticuculiere du Thé.

page 24

Chap.IV. Des differentes manieres de prendre le Thé. page 30

Chap.V. Des vertus particulieres du T. hé.

Chap.V I. Du sirop du Thé febrifuge.

page 54

SECON.DE PARTIE.

Traitant dela nature, des proprietés, $\&$ du bon ufage du Caffé.

Chap.I. Es lieux oir on cultive le Caffé, de la forme. o de jes differentes denominations. page 87

Chap.I I. De la natsure du Caffé. page 93

Chap.1 I I. Du choix, de la torrefaction, \&u duprix de la graine de Caffé. page III 


\section{T A B L E}

Chap.IV. Du choix, de la preparation, \& du prix de la poudre ou farine de Caffé. page 137 Chap.V. De la preparation de la teinture ou boiffon de caffé, $G$ de fon ufage en general. p. I 45

Chap. V I. Despreparations medecinales du Caffé.

p. 370

Chap.VII. Des proprietés parti-

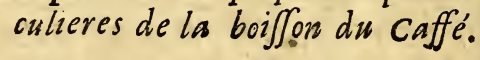
page 179

\section{TROISIE'ME PARTIE.}

Traitant de la nature, des proprietés, \& du bon ufage du Chocolat.

Chap.I. D Chocolat en geDeral. page 192 Chap.II. Du Cacao, \& du Sucre en particulier.

Chap.III. Des ingrediens que les 


\section{T A B L E.}

Americains ajoûtoient au sucre, of aul Cacao, dans la compofition de leur Chocolat, avant la découverte de leur continent. page 220

Chap.I V. De la reformation dus formulaire des Indiens touchant la cöpofition du Chocolat. p.229 Chap. V. De la compofition du Chocolat.

Chap.V I. De la Sophiftication, du choix, de la confervation, $\sigma$ du prix du Chocolat. p.259

Chap.VII. De la boiffon ou breuvage du Chocolat.

Chap.V III. Des proprietés dus chocolat.

Chap IX. Du sirop de Vanilles. page 286

Chap.X. Du Chocolat Anti-venerien.

p.291 


\section{T A B L E.}

\section{VATRIE'ME PARTIE.}

Contenant l'explicarion des Figures comprifes dans les parties precedentes, \& quelques remarques fur des fingularitez de nouvelle invention, relatives au même Sujer.

Chap.I.

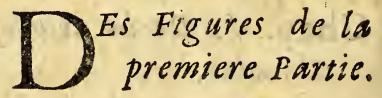
page 301

Chap.I I. Des Figures de la Seconde Partie,

Chap.III. Des Figures de la troi-

Giéme Partie,
Chap.I V. Des marchandijes qui font act uellement difpen jées par. les Artifies du Laboratoire Royal des quatre nations, p. 319 Chap.V. Des Caffolettes Royalles nouvellement inventées par l'Antbeur.

Fin de la Table.

p. 343 




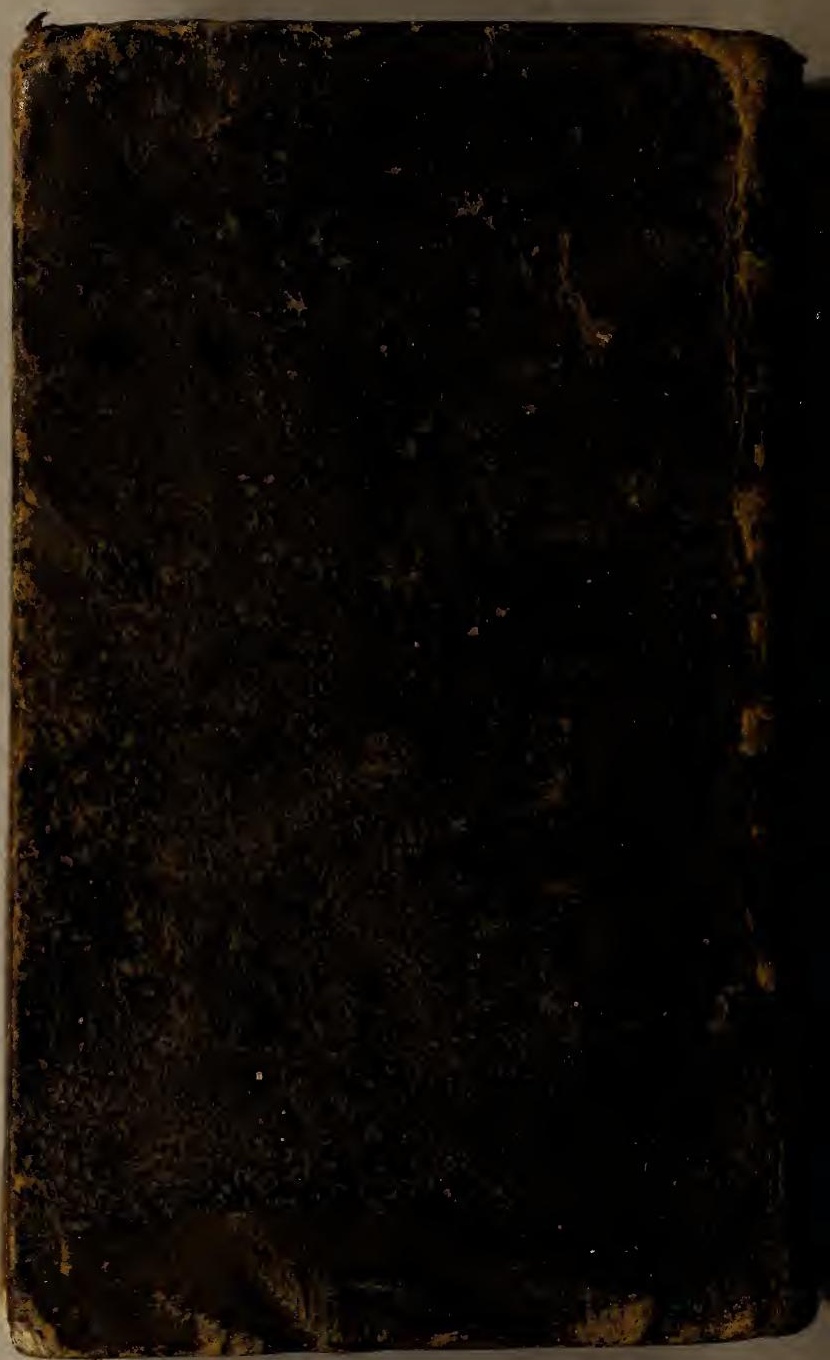

